
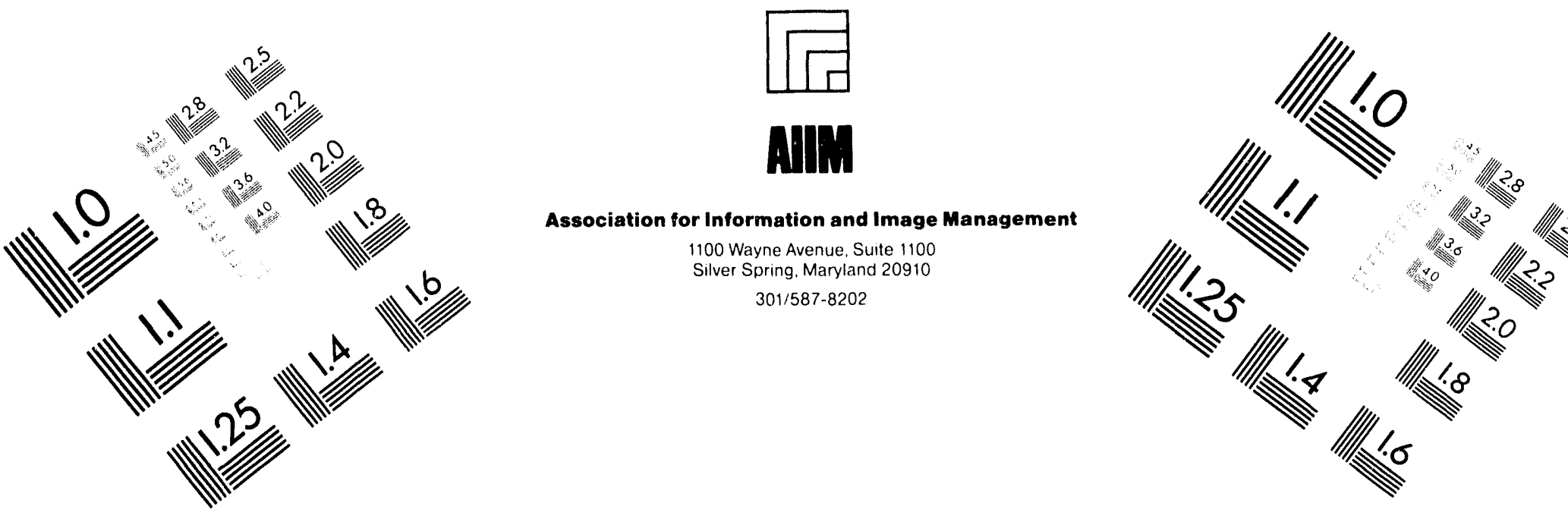

\title{
Centimeter
}

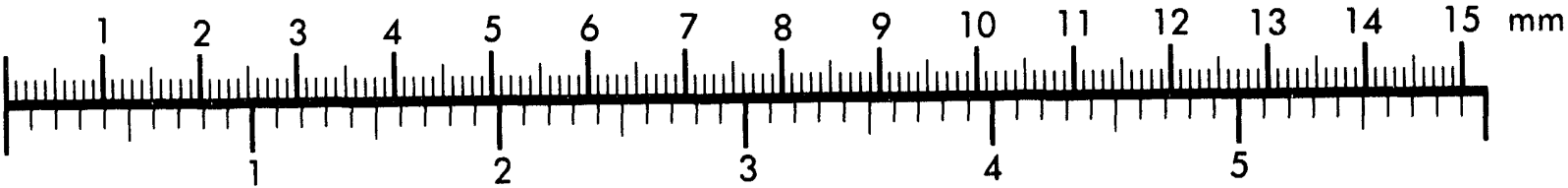
Inches
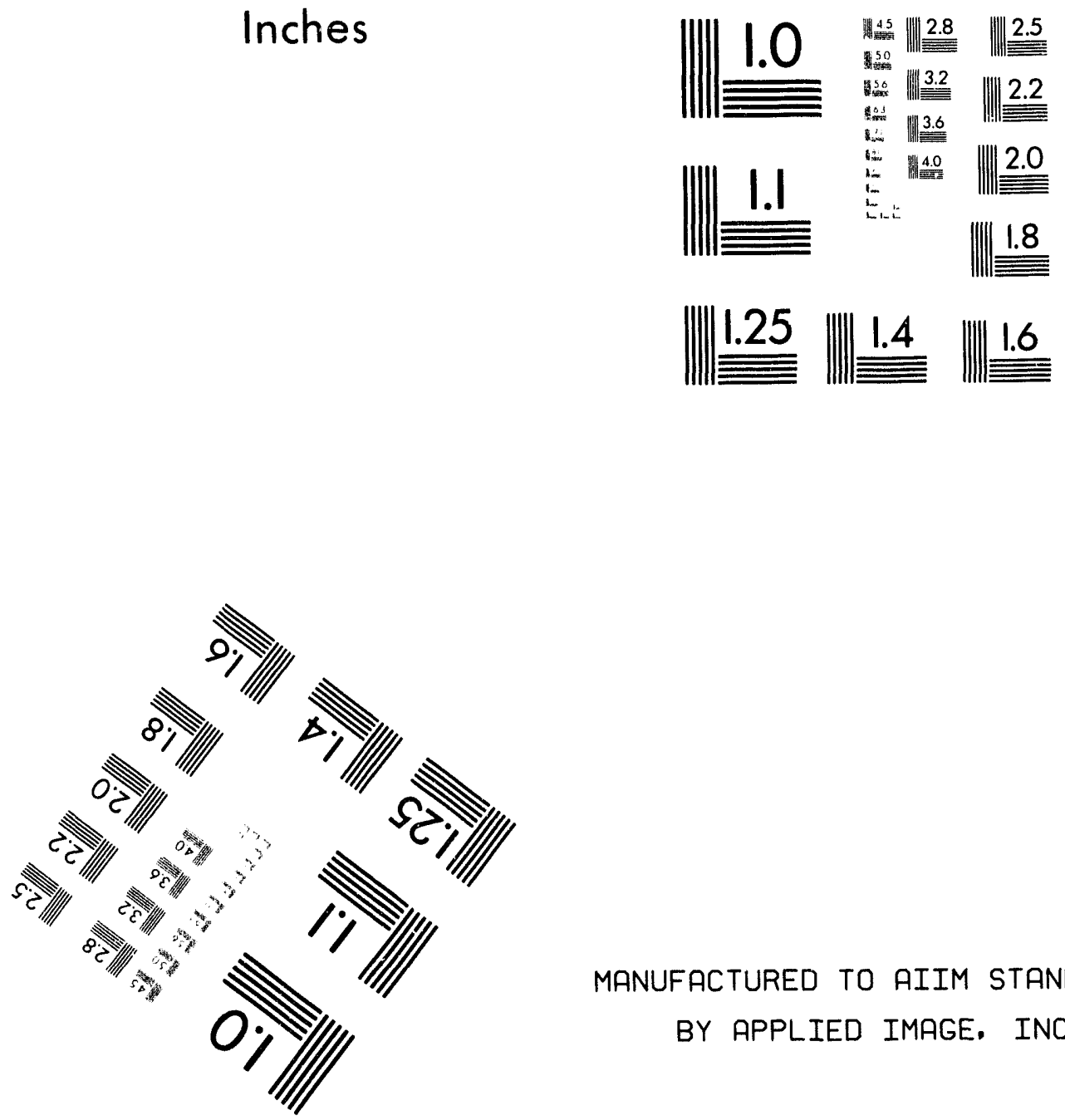

MANUFACTURED TO AIIM STANDARDS

BY APPLIED IMAGE. INC.

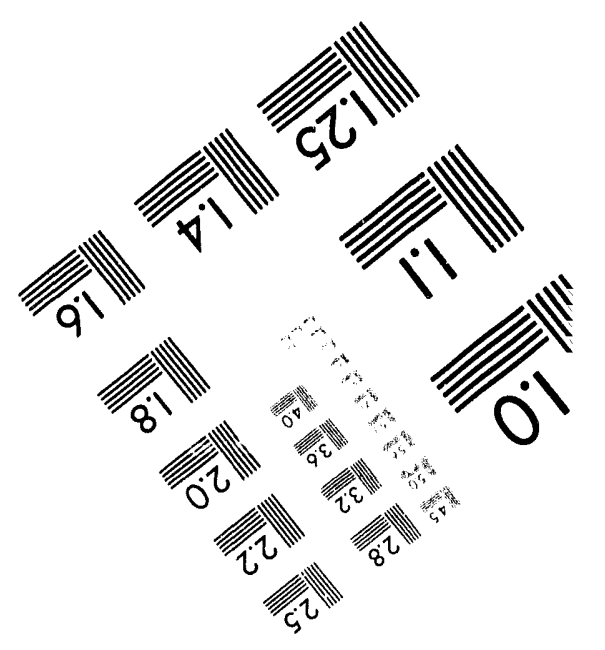



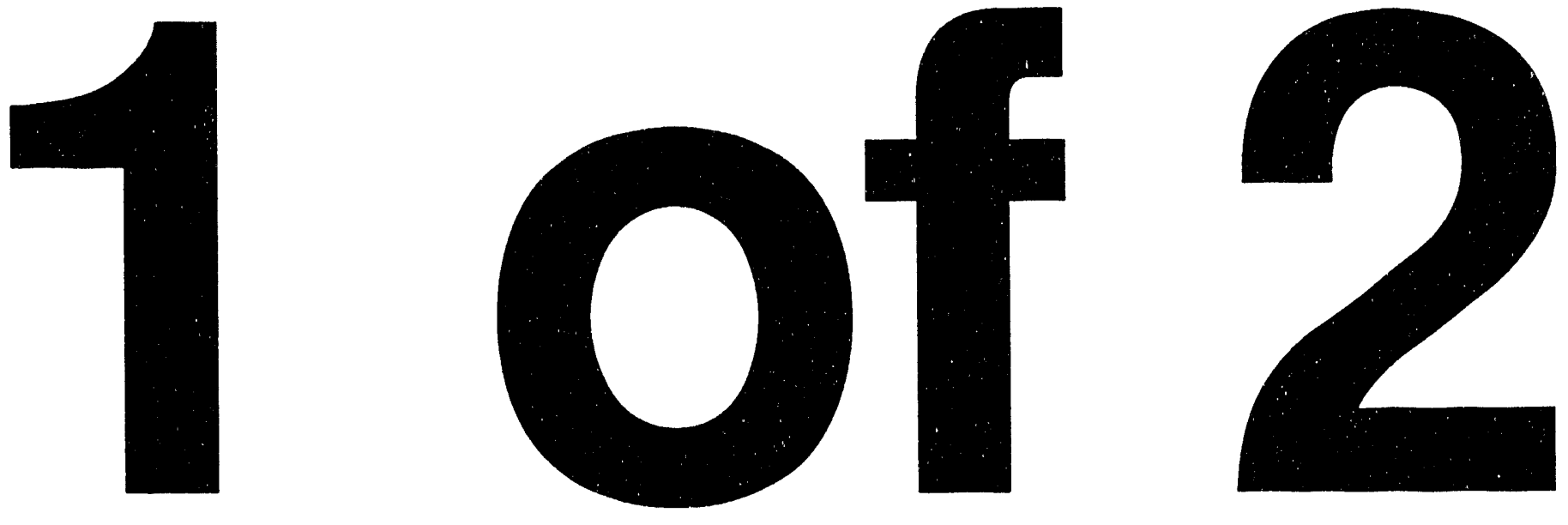


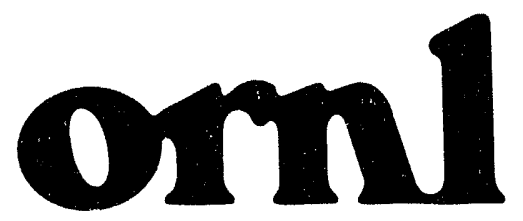

OAK RIDGE

NATIONAL

LABORATORY

MAGTIN MARUETRA

\section{PROCESS EVALUATION OF THE REGIONAL BIOMASS ENERGY PROGRAM}

C. Robert Wilson

Marilyn A. Brown

Robert D. Perlack

MANAGED BY

MARTIN MARIETTA ENERGY SYSTEMS, INC.

FOR THE UNITED STATES

DISTRIBUTION OF THIS DOCUMENT IS UNLIMITED

DEPARTMENT OF ENERGY 
This report has been reproduced directly from the best available copy.

Available to DOE and DOE contractors from the Office of Scientific and Technical Information, P.O. Box 62, Oak Ridge, TN 37831; prices available from (615) 576-8401, FTS 626-8401.

Available to the public from the National Technical Information Service, U.S. Department of Commerce, 5285 Port Royal Rd., Springfield, VA 22161.

This report was prepared as an sccount of work sponsored by an agency of the United States Government. Neither the United States Government nor any agency thereot, nur any of their employees, makes any warranty, express or implied, or assumes any legal liability or responsibility for the accuracy, completeness, or usefulness of any information, apparatus, product, or process disclosed, or represents that its use would not infringe privately owned rights. Reference herein to any specific commercial product, process, or service by trade name, trademark, manufacturer, or otherwise, does not necessarily constitute or imply its endorsement, recommendation, or favoring by the United States Government or any agency thereof. The views and opinions of authors expressed herein do not necessarily state or reflect those of the United States Government or any agency thereof. 


\title{
PROCESS EVALUATION OF THE REGIONAL BIOMASS ENERGY PROGRAM
}

\author{
C. Robert Wilson \\ Marilyn A. Brown \\ Robert D. Perlack \\ March 1994 \\ Prepared for the \\ Office of Technical and Financial Assistance \\ Office of Energy Efficiency and Renewable Energy \\ U.S. Department of Energy \\ Prepared by the \\ Oak Ridge National Laboratory \\ Oak Ridge, Tennessee 37831 \\ Managed by \\ Martin Marietta Energy Systems, Inc. \\ for the \\ U. S. Department of Energy \\ under Contract DE-AC05-84OR21400
}




\section{TABLE OF CONTENTS}

LIST OF FIGURES AND TABLES $\ldots \ldots \ldots \ldots \ldots \ldots \ldots \ldots$ ACKNOWLEDGEMENTS $\ldots \ldots \ldots \ldots \ldots \ldots \ldots \ldots \ldots \ldots$

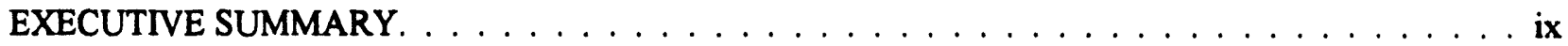

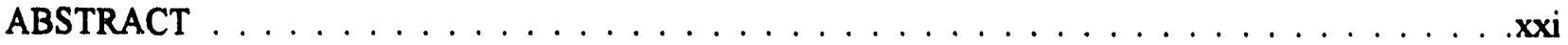

1. OVERVIEW OF THE PROGRAM AND THE EVALUATION $\ldots \ldots \ldots \ldots \ldots$

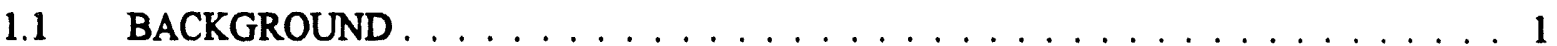

1.2 PROGRAM STRUCTURE $\ldots \ldots \ldots \ldots \ldots \ldots \ldots \ldots$

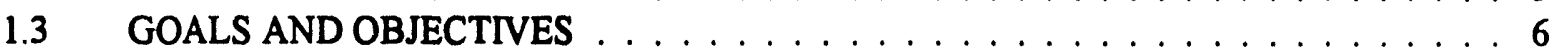

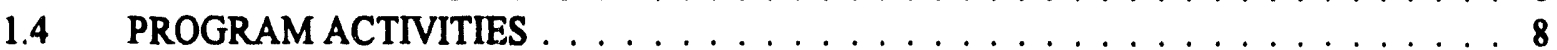

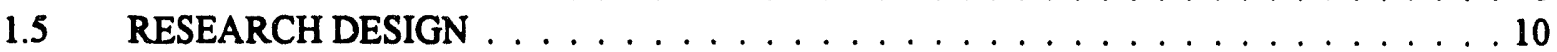

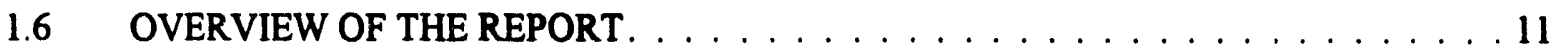

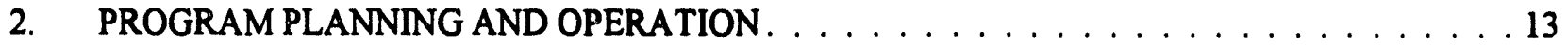

2.1 PARTICIPATION IN PLANNING AND OPERATION $\ldots \ldots \ldots \ldots \ldots$

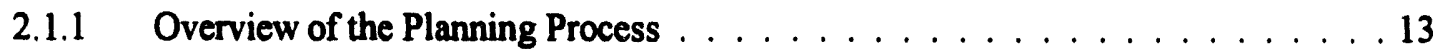

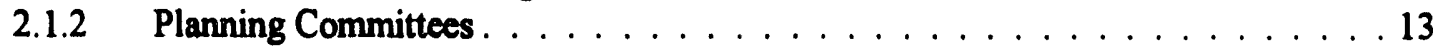

2.1.3 Technical Advisory Groups . . . . . . . . . . . . . . . 16

2.1.4 Role of the Planning Committee and Technical Advisory

Groups in Project Selection. . . . . . . . . . . . . . . . . . . . . . . 16

2.2 RELATIONSHIPS WITH HOST ORGANIZATIONS . . . . . . . . . . . . . . . 19

2.2.1 Nature of Host Organization . . . . . . . . . . . . . . . . . . . . . . 19

2.2.2 Host Involvement with and Impact on the Regional Program . . . . . . . . . . . 19

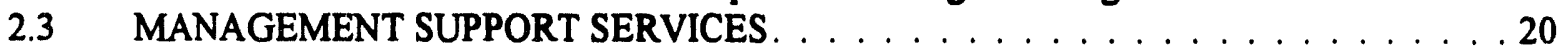

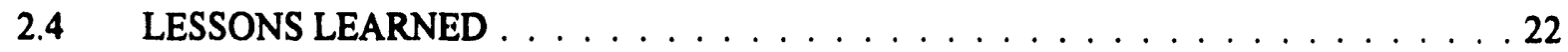

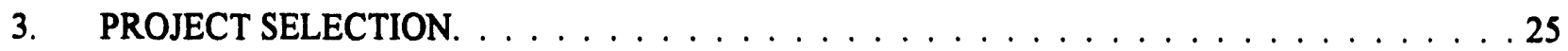

3.1 OVERVIEW OF THE PROJECT SELECTION PROCESS . . . . . . . . . . . . 25

3.2 COMPARISON OF SELECTION PROCESSES ACROSS REGIONS . . . . . . . . . 27

3.2 .1 Overview of Regional Programs . . . . . . . . . . . . . . . . . . . 27

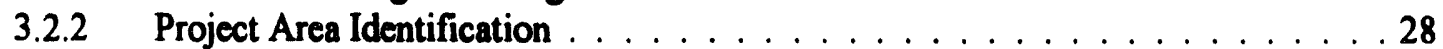

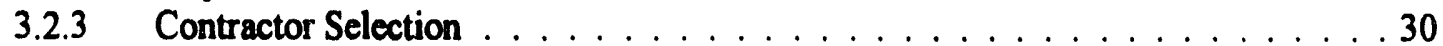

3.2 .4 Management Support Services . . . . . . . . . . . . . . . . . . . . 30

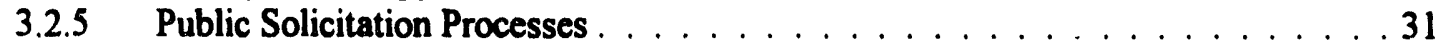

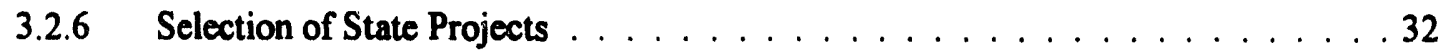

3.3 PROJECT SELECTION CRITERIA $\ldots \ldots \ldots \ldots \ldots \ldots \ldots$

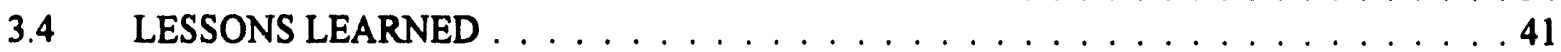




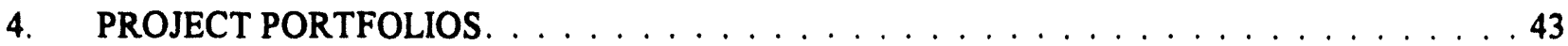

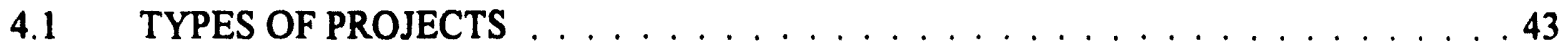

4.1.1 Technology Feasibility, Development, and Demonstration. . . . . . . . . . . 44

4.1 .2 Technology Assessments . . . . . . . . . . . . . . . . . . 47

4.1.3 Information Development and Diffusion. . . . . . . . . . . . . 48

4.1.4 Resource Assessments . . . . . . . . . . . . . . . . . . . . . . . 50

4.1.5 Economic, Market, and Infrastructure Analyses . . . . . . . . . . . . . 50

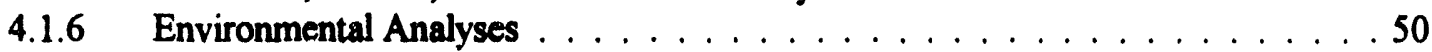

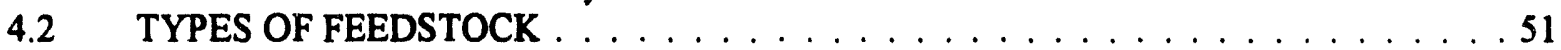

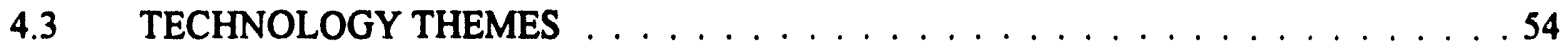

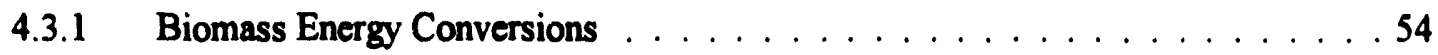

4.3.2 MSW Disposal and Alternatives . . . . . . . . . . . . . . . . 56

4.3.3 Residential Wood and Pellet Stove Development . . . . . . . . . . . . . . 58

4.3.4 Biomass Derived Liquid Fuels . . . . . . . . . . . . . . . . . . . . . . . 60

4.3.5 Anaerobic Digestion Technology Development . . . . . . . . . . . . 61

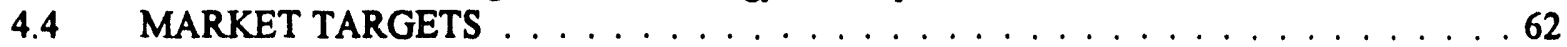

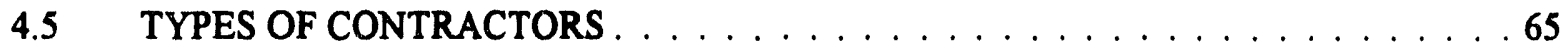

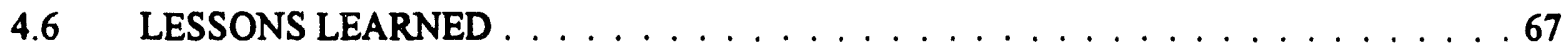

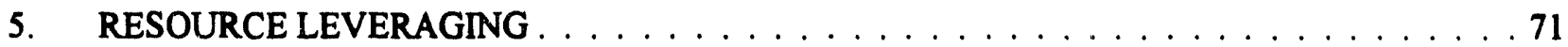

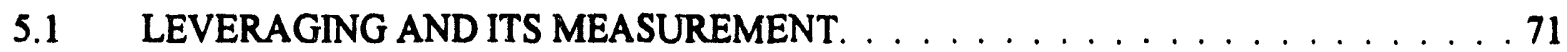

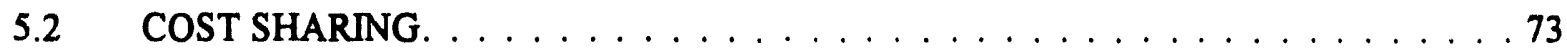

5.2.1 Cost Sharing and Project Type . . . . . . . . . . . . . . . . 74

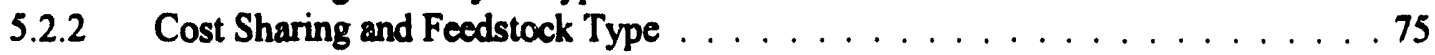

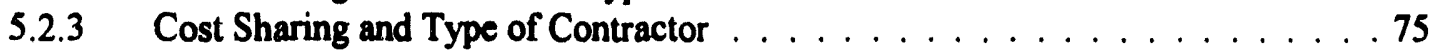

5.3 STRATEGIES FOR ACHIEVING COST SHARING $\ldots \ldots \ldots \ldots \ldots$

5.4 FACTORS INFLUENCING MULTI-PARTY PARTICIPATION . . . . . . . . . . . 78

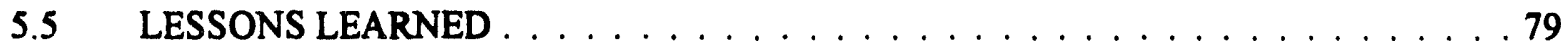

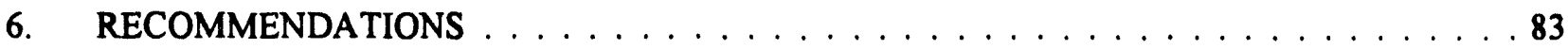


APPENDICES

A CURRENT BIOENERGY USE, FUTURE POTENTIAL, AND BARRIERS TO PRODUCTION AND USE

B REP GOALS AND OBJECTIVES

C PROGRAM PLANNING, BY REGION

D PROJECT PORTFOLIOS, BY REGION

E INFORMATION DEVELOPMENT AND DISSEMINATION ACTIVITIES, BY REGION

F COST SHARING, BY PROJECT TYPE, FEEDSTOCK, AND CONTRACTOR

G COMMERCIALIZATION POSSIBILITIES AND OUTCOMES

$\mathbf{v}$ 


\section{LIST OF FIGURES AND TABLES}

Figure 1.1 Regions of the Regional Biomass Energy Program . . . . . . . . . . . . . . . . . . . . . 2

Figure 1.2 Organizational Structure of the Regional Biomass Energy Program . . . . . . . . . . . . . . . 4

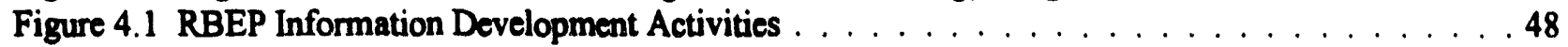

Figure 4.2 RBEP Information Dissemination Activities . . . . . . . . . . . . . . . . . . . . 49

Figure 4.3 Size of Target Market and Stage in the Technology Adoption Decision . . . . . . . . . . . 63

Figure 5.1 Leveraging Ratios for RBEP's Regional Projects . . . . . . . . . . . . . . . . . . . 74

Table 1.1 Regional Biomass Energy Program Funding Profile $(\ldots \ldots \ldots \ldots \ldots$

Table 1.2 Regional Biomass Energy Program Projects, by Type and Region . . . . . . . . . . . . . . . . 5

Table 1.3 Objectives of the Regional Biomass Energy Program . . . . . . . . . . . . . . . . . . . . . 7

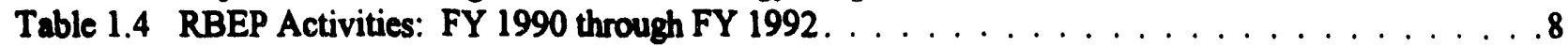

Table 2.1 Planning Structures: Role of the Policy Group . . . . . . . . . . . . . . . . . . . . . . 15

Table 2.2 Planning Structures: Technical Advisory Groups . . . . . . . . . . . . . . . . . . . . . . . 17

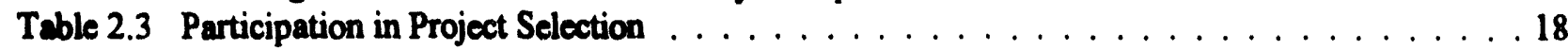

Table 2.4 Relationships with Host Organizations . . . . . . . . . . . . . . . . . . . . . . 20

Table 2.5 Use of Management Support Services . . . . . . . . . . . . . . . . . . . . . . . 21

Table 3.1 Comparison of Approsches to Project Selection. . . . . . . . . . . . . . . . . . . . . 26

Table 3.2 Project Area Identification and Project Selection . . . . . . . . . . . . . . . . . . . . . 30

Table 3.3 Contractor Selection Processes for Regional Projects . . . . . . . . . . . . . . . . . . . . . 31

Table 3.4 Use of Public Solicitation Processes . . . . . . . . . . . . . . . . . . . . . . . . . . 32

Table 3.5 Selection of State Projects . . . . . . . . . . . . . . . . . . . . . . . . . . . . . 33

Table 4.1 Percent of Expenditures by Project Type: Regional Projects from 1987 to $1991 \ldots$. . . . . . 45

Table 4.2 Percent of Expenditures by Project Type: State Projects from 1987 to 1991 . . . . . . . . . . 45

Table 4.3 Percent of Expenditures on Technology Development and Demonstration, by Developmental Stage: Regional Projects from 1987 to 1991 . . . . . . . . . . . . . . 47

Table 4.4 Percent of Expenditures on Technology Development and Demonstration: State Projects from 1987 to $1991 \ldots \ldots$. . . . . . . . . . . . . . . . . . . . . . 47

Table 4.5 Percent of Expenditures on Woody vs Non-Woody Biomass: Regional Projects

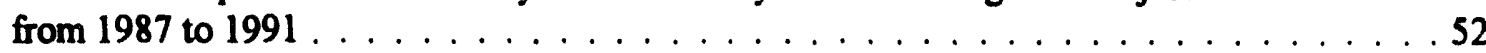

Table 4.6 Percent of Expenditures by Type of Feedstock: Regional Projects from 1987 to 1991 . . . . . 53

Table 4.7 Summary of RBEP Technology Themes. . . . . . . . . . . . . . . . . . . . . . . . 54

Table 4.8 Percent of Expenditures by Type of Contractor: Regional Projects from 1987 to 1991 . . . 65

Table 4.9 Percent of Expenditures by Type of Contractor: State Projects from 1987 to $1991 \ldots$. . . . 67

Table 5.1 The Evaluation of Resource Leveraging . . . . . . . . . . . . . . . . . . . . . . . . . 72

Table 6.1 Lessons Leamed and the Recommendations Derived from Them. . . . . . . . . . . . . . . . 85 


\section{ACKNOWLEDGEMENTS}

We would like to thank those who provided information for the construction of this report. Special thanks goes to Fred J. Kuzel, program manager of Great Lakes Regional Biomass Energy Program, Phil Lusk, formerly Regional Manager of the Northeast Regional Biomass Energy Program, Anne Stubbs and Russ O'Connell of the Coalition of Northeastern Governors, Steve Morgan of Citizen's Conservation Corporation (support services contractor for the Northeast region), Pat Fox, program manager and Craig Chase, support services contractor, of the Pacific Northwest and Alaska Bioenergy Program; Phil Badger and Dave Stevenson, program manager and assistant manager, respectively, of the Southeastern Regional Biomass Energy Program; Dave Swanson and Steve Sargent, program manager and assistant manager of the Western Regional Biomass Energy Program, and NEOS Corporation, support services contractor for the Western Region. In addition, we would like to thank the state bioenergy representatives across the nation who contributed data and insights.

Finally, we are grateful for the guidance and input of Mike Voorhies, DOE program manager of the Regional Biomass Energy Program, and Harry Lane, Director of DOE's Office of National Programs, Office of Energy Efficiency and Renewable Energy. Their comments on an earlier draft of this report were very useful. 


\section{EXECUTIVE SUMMARY}

\section{BACKGROUND AND PURPOSE}

The U.S. Department of Energy (DOE) established the Regional Biomass Energy Program (RBEP) in 1983 to increase the production and use of biomass energy resources. Through the creation of five regional programs (the Great Lakes, Northeast, Pacific Northwest, Southeast, and West), the RBEP focuses on regionally specific needs and opportunities. Recognizing that biomass needs and opportunities are best identified at the regional level, the RBEP allows regional managers the latitude to develop program goals, objectives, and activities appropriate to their regions.

In 1992, the DOE asked Oak Ridge National Laboratory (ORNL) to conduct a process evaluation of the RBEP Program. The resulting evaluation, the subject of this report, had the following objectives:

- document the goals and strategies of the five regional programs;

- explain how these goals and strategies were developed;

- describe the economic and market context surrounding the commercialization of bioenergy systems within which these goals and strategies were developed and implemented;

- assess the criteria used to select projects;

- describe experiences with cost-sharing;

- identify program accomplishments in the transfer of information and technology; and

- offer recommendations for program improvement.

The process evaluation also sought to prepare the groundwork for conducting an impact evaluation of the RBEP, which would focus on quantitative indicators of program achievements.

\section{RESEARCH DESIGN}

The process evaluation consisted of four stages: (1) a review of program documentation and other available literature; (2) structured interviews with DOE and regional program managers; (3) a mail survey of regional program managers to verify the survey information; and (4) development of a project level database.

A 、 ety of program documentation was reviewed, including annual operating plans, project reports, conference proceedings, and minutes of key planning meetings. Individual interviews were conducted with the DOE program manager and all five regional managers, as well as managers of host organizations and support 
contractors. In addition to collecting a broad range of information spanning the lifetime of the program, a mail survey of regional program managers collected detailed information about activities initiated with FY 1991 funds.

In order to address questions raised by DOE management concerning longitudinal trends in the RBEPs, a project level database was developed. Information was collected on projects that were conducted between FY 1987 and FY 1991 and were funded and supervised directly by the regional offices. In addition, similar information was developed on state-supervised projects that received RBEP funds in the Southeast and Pacific Northwest.

These data produce a portrait of program operation over a unique period in the life of the program (1987. 1991). A $50 \%$ decline in appropriations for the year of 1989 caused suspension or cancellation of numerous projects. In addition to adapting to reduced resources, the program has also adjusted to ongoing economic and technological developments. Evolution of the program subsequent to this time frame is not reflected in this report.

\section{FINDINGS}

The findings from this evaluation are organized into the following topics ${ }^{1}$ :

- Goals and Objectives

- Program Planning and Operation

- Project Selection

- Project Portfolios

- Internal and External Resource Leveraging

A selection of lessons learned are highlighted in boldface and described below. Recommendations then follow in a subsequent section.

\section{RBEP Goals and Objectives}

The goal of the RBEP is to increase the production and use of biomass energy resources. The specific goal statements cited by each of the five regional programs are consistent with this program-wide goal.

1 A brief review of the economic and market context is included as an appendix to this report. Biomass energy faces market, regulatory, and technical barriers to implementation. Market barriers include competition from inexpensive conventional fuels and conversion systems, undeveloped feedstock markets, weak stakeholder coalitions, and insufficient financing mechanisms. Regulatory barriers include plant siting requirements and environmental regulations. Technical barriers include a lack of industry standardization, absence of a supply infrastructure for feedstocks and equipment, and a low level of awareness of bioenergy by potential users. 
DOE has established four objectives to support its program goal (Figure A.1). Furthermore, each of the five regional programs has established its own set of objectives. While the regional programs do not cite all the DOE objectives as their own, the activities of each of the five regions are consistent with the DOE statement of objectives. Three additional objectives are cited by at least two of the regional programs (Figure A.1). These objectives are consistent with DOE's goal for the Regional Biomass Energy Program.

\begin{tabular}{|c|c|}
\hline 1. & $\begin{array}{l}\text { Improve state, local government, and industry capabilities and effectiveness in the production } \\
\text { and use of biomass jesources }\end{array}$ \\
\hline 2. & Support planning activities, including resource availability, utilization, and research needs \\
\hline 3. & $\begin{array}{l}\text { Encourage economic development through public and private inves tment in biomass } \\
\text { technologies }\end{array}$ \\
\hline 4. & $\begin{array}{l}\text { Perform research and engage in cost-shared projects to demonstrate applications of biomass } \\
\text { technologies; reduce or eliminate market barriers; understand economic and environmental costs, } \\
\text { benefits, and risks; and accelerate market acceptance of biomass technologies }\end{array}$ \\
\hline 1) & 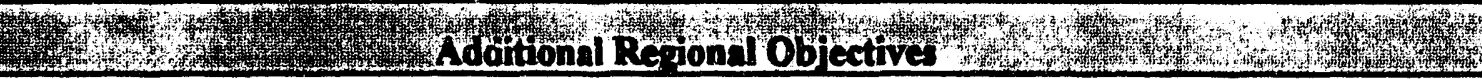 \\
\hline 5. & $\begin{array}{l}\text { Transfer results of government-sponsored biomass research and development to the private } \\
\text { sector }\end{array}$ \\
\hline 6. & Mitigate adverse environmental impacts of biomass use \\
\hline 7. & Match local biomass resources with conversion technologies and/or energy requirements \\
\hline
\end{tabular}

Figure A.1 Objectives of the Regional Biomass Energy Program

\section{Program Planning and Operation}

The five regional programs have similar program planning struc.ures. Each of the five regional programs has a planning committee $t$ t helps determine programmatic goals, objectives, and activities. Each also has subject-specific technical ad . sury groups.

RBEP program planning is highly participatory and has particularly strong involvement of state bioenergy representatives. Interagency participation and industry involvement is characteristic of all five regional programs. Four of the five regions place state bicenergy representatives on the planning council. Industry representatives have access to the planning process in all five regions, and in one region they are 
members of the planning council. The regional programs have also made an effort to involve the managers of the other regional programs in their planning and project selection processes.

Technical advisory groups in each region have strong industry input and have helped insure a portfolio of projects that is adapted to regional needs. In all regions, participation in the technical advisory group is balanced and broadly based, so that governmental, academic, and industrial viewpoints are incorporated.

Industry involvement in RBEP program planning, while strong at the technical advisory level in all regions, could be improved in the highest level planning committees. Industry input is substantial in all five regions, but planning committees have direct industry representation only in the Southeast. In the other four regions, industry input into the planning committee occurs as a result of the supporting activities of the technical advisory committees, informal industry discussions with planning committee members, and through briefings by industry personnel during planning committee meetings.

All five regional programs receive funding from DOE through a host organization that has responsibility for operational management. Host organizations have had a significant impact on the structure and activities of the regional programs. The host for the Northeast region has been especially active and has helped the region develop linkages with state government, federal agencies, and non-profit groups. Host organizations in the West and Southeast provided vision in the early years of the program. By contrast, host organizations of the Great Lakes and Pacific Northwest regions have been significantly less visible in their promotion of their regional bioenergy program.

Investment in support services in two regions (West and Pacific Northwest) is considerable. This may create problems of coordination and control, which could be prevented by reducing this reliance on outside contractors and expanding in-house staff capabilities. The Northeast region, by contrast, employs support services in more specific tasks and invests a smaller portion of the regional budget in support services. The remaining two regions (Southeast and Great Lakes) do not employ support services contractors.

Support for a network of state bioenergy representatives is one of the distinguishing characteristics of the RBEP. Relationships with state agencies have been strong. All five regions conduct activities to maintain a network of state bioenergy representatives, although they do so in different ways: providing technical assistance grants for general program support (Northeast and Great Lakes), funding specific projects (Southeast), providing both (Pacific Northwest), and conducting resource assessments (West). As a result of this RBEP funding, state bioenergy representatives provide the RBEP with a nationwide network of agents who are responsible for communicating technical information and assisting bioenergy conversion. 


\section{Project Selection}

A variety of project selection methods have been employed, each with strengths and weaknesses. The RBEPs use three different project selection methods. A top-down approach has been employed by the Northeast, Pacific Northwest, and Great Lakes, the Southeast and West use a market mechanisms approach. and entrepreneurial methods are employed by most state bioenergy programs. Each of these methods can be effective, and each faces its own threats and opportunities. The top-down approach gives the planning committee the opportunity to control the content and quality of project proposals, as well as the opportunity to build multi-party participation and leveraging into the design of projects. This approach is enhanced if the planning committee is actively involved with industry, and the program maintains openness and participation. The market mechanism approach can bring in broad input from industry, and enhance industry acceptance and participation. Because it is critically dependent on the quality of proposals received in response to requests for proposals (RFPs), several years might be required to get such a system established. Time limits for response to RFPs can constrain leveraging and multi-party participation.

Project selection takes place in stages that differ between regions using market-mechanism vs topdown approaches. General project areas are identified in all regions by regional managers and planning council members, and by industry spokespersons in some cases. These project areas are subjected to strategic review by the planning council. In those regions employing a top-down process, concepts for specific projects are developed within the planning council, the technical advisory committee, or by interested parties. Projects are selected by the planning committee and a formal RFP solicitation process is used to select contractors. In those regions employing a market mechanism approach, general areas are established by the planning committee, but the specific projects are selected competitively as part of the RFP process. Contractors are selected along with projects in this approach.

Public solicitations promote industry participation in all regions. The market mechanism approach used by Southeast and West draws in more participation than the top-down approach used by the other three regions. Public solicitation is used differently in different regions. In two regions it is used for project identification and selection, while it is used for contractor selection in the other three regions. Two approaches toward the use of RFPs for regional projects are seen within the RBEPs. Two regions (the Southeast and West) have searched widely and publicly for project ideas reflecting their market mechanism approach. The other two regions (the Great Lakes and Northeast) have narrowly defined the project areas of their RFPs, reflecting their top-down approach. Both the Pacific Northwest and the Great Lakes have now adopted a market mechanisms RFP. 
Support for State programs varies dramatically between regions. RBEP support for state projects ranges from providing technical assistance grants for general program support (Northeast and Great Lakes), funding specific projects (Southeast), providing both (Pacific Northwest), or conducting resource assessments (West).

Strong similarities exist in project selection criteria as well as systems for ranking and selecting proposals. The systems used to rank and select projects are similar across the five regions. Each region evaluates the strengths and weaknesses of proposals according to a set of criteria and a scoring system. In addition, each region conducts a post-scoring discussion that functions as a "reality check" on the outcome of the scoring process. Although the five regional programs describe their project selection criteria in different terms, they use essentially the same criteria. These include: market potential, market readiness, financial justification, capabilities of project participants, cost sharing, multi-agency participation, use of low or negative value feedstocks, and environmental implications.

The Northeast's approach toward the establishment of leadership positions and multiparty participation is unique. The Northeast region has attempted to identify project areas in which there is breadth of interest but in which no other agency has taken a coordinating role.

\section{Project Portfolios}

The portfolios of projects and activities supported by each of the regional programs are both diverse and unique in terms of the balance of technologies, project types, feedstocks, market targets, and contractors.

Each region concentrates on a different set of biomass technologies. The most common technology themes of the program nationwide are biomass energy conversion, municipal solid waste disposal and alternatives, residential wood and pellet stove development, biomass derived liquid fuels, and anaerobic digestion technology development (Table A.2). The diversity across regions is great. Ouly the first two technology themes are common to all five regions, and each region concentrates on a different set of technologies. Nationwide, RBEP has focused approximately $38 \%$ of regional project resources on technology development and demonstration projects; $14 \%$ on technology assessments; $14 \%$ on information development and dissemination; and the residual on environmental, economic, market, infrastructure, and resource assessments. The West, Southeast, and Great Lakes programs dedicate more than one-third of their regional project dollars to technology development and demonstration, while the Pacific Northwest focuses on technology assessments (primarily entailing fuel characterization and standards development). The Northeast spends a large proportion of its resources on environmental analyses. 
Across its history, RBEP has emphasized technology development over technology demonstration. Within the technology development and demonstration category, over $85 \%$ of the regional project resources have been spent on engineering designs, modeling, and laboratory and field testing. Less than $15 \%$ of these funds have supported demonstrations of market-ready technologies; these projects have been conducted in the Southeast and Great Lakes. In contrast, the state projects funded by RBEP have had a stronger focus on demonstrating technologies that could be commercialized immediately.

Table A.2 Summary of RBEP Technology Themes

\begin{tabular}{|c|c|c|c|c|c|}
\hline \multirow[t]{2}{*}{$4 \% 4 \% 3 \%$} & \multicolumn{5}{|c|}{2088181} \\
\hline & 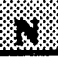 & 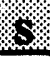 & a & an: & 2 \\
\hline Residential Wood and Pellet Stove Development & $\mathbf{x}$ & $\mathbf{x}$ & & $\mathbf{x}$ & $x$ \\
\hline MSW Disposal and Alternatives & $\mathrm{x}$ & $\mathbf{x}$ & $x$ & $\mathbf{x}$ & $x$ \\
\hline Biomass Energy Conversions & $\mathbf{x}$ & $\mathbf{x}$ & $\mathbf{x}$ & $\mathbf{x}$ & $x$ \\
\hline Biomass Derived Liquid Fuels & & & $x$ & $\mathbf{x}$ & $x$ \\
\hline Anaerobic Digestion Technology Development & & $\mathbf{x}$ & & $\mathbf{x}$ & $\mathbf{x}$ \\
\hline
\end{tabular}

Consulting firms and university researchers have been involved as contractors in the great majority of the regional projects conducted with the five RBEPs. Over the five-year period, from 1987 to 1991, consulting firms and university researchers have received about three-quarters of regional project funds nationwide. Only a small fraction of RBEP's regional project expenditures have involved industry as contractors (6\%); most of this investment has taken place in the Southeast, which has directed $20 \%$ of its project funds to industry participants. Contracting with industry is a more common feature of RBEP-supported state projects. In the Southeast and Pacific Northwest, the funding of state projects with industry participants represents $15 \%$ and $24 \%$, respectively.

RBEP has a strong track record of addressing the environmental implications of biomass energy. The RBEP was an early leader in exploring the environmental implications of bioenergy. These issues are especially important for the Northeast region, where environmental tradeoffs determine the constraints and opportunities faced by the program.

Market targeting is taking place in all regions, but most information dissemination efforts are targeted at broad audiences. 
Resource assessments have been conducted by all five regional programs, but divergent approaches have been employed. Over the past decade, resource assessments and facilities directories have been developed by all five of the regional programs, and provide basic data for almost every state in the nation. These assessments vary in terms of the means by which they were derived, their level of resolution, and the degree to which they identify point sources of available residue. A consistent format for the development of these resource assessments across regions has not been developed.

\section{Internal and External Resource Leveraging}

The RBEP is unusual among government programs in the degree to which it has been able to attract outside resources. It has shown a variety of approaches to be successful. Although levels and types of leveraging vary from region to region, all five of the regional programs are highly leveraged (Fig. A.1). The leveraging ratio for bioenergy projects across the program as a whole is conservatively estimated to be 1.9. RBEP's decade-long track record in orchestrating multi-party participation and the leveraging of resources provides a wealth of experience that should prove useful to DOE as it seeks to maximize the impact of federal investments.

Across the five RBEPs, a range of different approaches is used to attract leveraging. The Pacific Northwest and Alaska Bioenergy Program requires cost sharing on both its regional projects and its state-based demonstrations. The Southeast and Western programs require specific amounts of cost sharing on all the technology development and demonstration projects arising from their project solicitations, but they do not make explicit efforts to recruit cost sharing for these projects. The Northeast actively recruits cost sharing for its multiyear activities and major programmatic thrusts. While the Southeast does not require cost sharing on generic market analyses or economic assessments, these projects often have some level of cost sharing.

RBEP has an opportunity to become a leader within DOE in establishing standards for the acquisition and reporting of leveraging. The regional program's extensive experience in project cost-sharing, interagency involvement, and multi-party participation provides it with the background to assess a range of different approaches towards the acquisition and accounting of resource leveraging. This experience base could be useful for a broad range of DOE programs. 


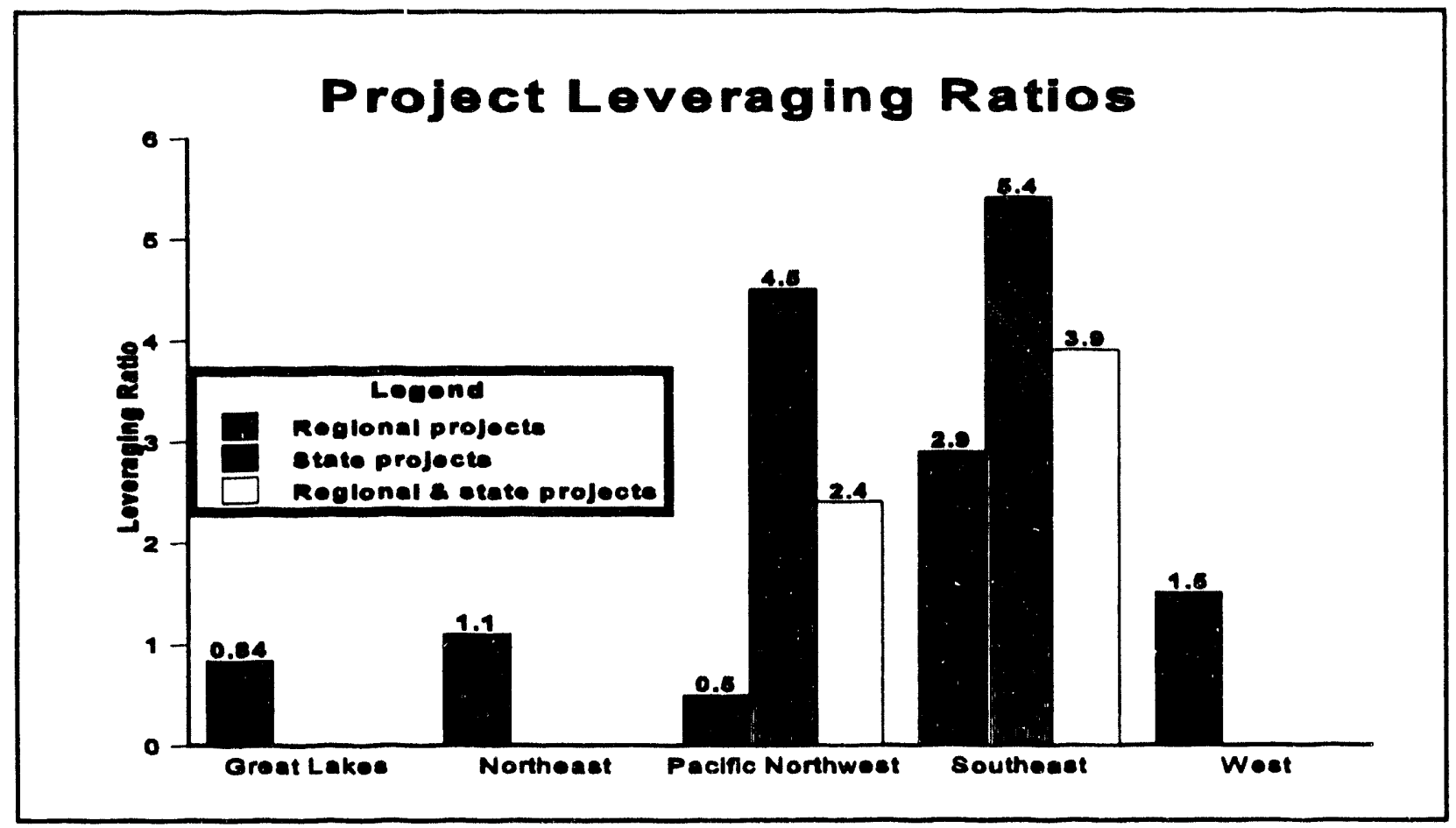

Fig. A.1 Project Leveraging Ratios within RBEP

The RBEP's diverse experience highlights the need for guidelines for the regional programs. Working with a wide range of state and federal entities as well as private sector parties, the regional programs have developed diverse patterns in the ways they acquire, compute, and report leveraging. The regions vary, for instance, in the way they account for financial versus non-financial leveraging, as well as the way they treat the acquisition of funds from state agencies and oil overcharge funds. Application of similar conventions across the five regional programs would make it easier for RBEP to interpret its cost sharing experiences.

More industry involvement means more cost sharing. Most of the Program's leveraged resources have been attracted by technology demonstration and deployment projects conducted with private sector industrial firms. Projects conducted by consulting firms, state agencies, and university faculty, on the other hand, tend to attract relatively small amounts of cost sharing. 


\section{RECOMMENDATIONS}

Several recommendations emerge from this process evaluation that pertain to the planning, operation, and management of the Regional Biomass Energy Program. Table A.3 summarizes the lessons learned from which these recommendations were derived. A fuller description of the lessons learned appears at the end of each chapter. The concluding chapter contains a fuller description of each recommendation. 
Table A.3 Lessons Learned and the Recommendations Derived from Them

\begin{tabular}{|c|c|}
\hline $\begin{array}{l}\text { Continued support for state } \\
\text { bioenerixy programs. }\end{array}$ & $\begin{array}{l}\text { Historically, the RBEPs have invested about half of their funds in a network of state } \\
\text { bioenergy programs. This network represents a unique and valuable asset for the } \\
\text { program. }\end{array}$ \\
\hline Stronger DOE networking support. & $\begin{array}{l}\text { - RBEPs need more funding for demonstration. } \\
\text { - Have had a more hands-on, market oriented approach than other programs. } \\
\text { Have a state level network for contract administration and information dissemination. }\end{array}$ \\
\hline $\begin{array}{l}\text { More active support of the } \\
\text { technology demonstration } \\
\text { component of DOE bloenery } \\
\text { development efrorts. DOE should } \\
\text { broker these relationshlps. }\end{array}$ & $\begin{array}{l}\text { - Strong state network to support demonstration activities. } \\
\text { - Active information dissemination network. } \\
\text { - Strong interaction with industry. } \\
\text { - Inadequate funding at present for demonstration activities within RBEP. }\end{array}$ \\
\hline Greater focus. & $\begin{array}{l}\text { The breadth of the RBEP programs means that while many areas are addressed, some } \\
\text { are not addressed in depth. } \\
\text { Technology demonstration has been limited because of the breadth of the program and } \\
\text { the low level of funding. }\end{array}$ \\
\hline $\begin{array}{l}\text { Stronger emphasis on market-ready } \\
\text { short-term projects. }\end{array}$ & $\begin{array}{l}\text { RBEP's distinctiveness among DOE sponsored programs is the degree to which it is } \\
\text { linked with industry and immediate or near-term commercial potential. RBEP should } \\
\text { strengthen this focus. } \\
\text { This could be made more workable if RBEP repositions itself as the bioenergy } \\
\text { demonstration arm of DOE, and can obtain funds for the support of demonstration } \\
\text { projects from other components of DOE. }\end{array}$ \\
\hline $\begin{array}{l}\text { Recognition for the program's } \\
\text { success in the acquisition of outside } \\
\text { resources. }\end{array}$ & $\begin{array}{l}\text { - RBEP is unique in its track record of resource leveraging. The diversity of the five } \\
\text { programs and their related state programs provides it a breadth of experience that } \\
\text { could prove useful to other programs within DOE. }\end{array}$ \\
\hline $\begin{array}{l}\text { Development of guldelines for } \\
\text { reporting resource leveraring. }\end{array}$ & $\begin{array}{l}\text { - Tremendous diversity in programs and nature of the resource leveraging they report. } \\
\text { - Reporting conventions within regions but not across the regions. }\end{array}$ \\
\hline $\begin{array}{l}\text { Minimal emphasis on leveraging } \\
\text { ratios to allocate funding until } \\
\text { reporting standards are developed } \\
\text { and the regions bave had time to } \\
\text { adapt to them. }\end{array}$ & $\begin{array}{l}\text { There are many types of leveraging, and no simple relationship between leveraging } \\
\text { and the value of projects. Many inherently valuable projects cannot be easily } \\
\text { leveraged. Projects with especially high leveraging ratios may not have the greatest } \\
\text { impact. } \\
\text { - The five regional programs differ in the way they record and report leveraging. }\end{array}$ \\
\hline $\begin{array}{l}\text { Expanded industry participation in } \\
\text { regional contracting. }\end{array}$ & $\begin{array}{l}\text { - Across RBEP as a whole, only } 6 \% \text { of all contracting for regionally based projects has } \\
\text { been conducted by industry participants. The remainder of regional projects have } \\
\text { been conducted primarily by consulting firms and university researchers. }\end{array}$ \\
\hline $\begin{array}{l}\text { Stronger involvement of industry in } \\
\text { planning. }\end{array}$ & - Industry membership on planning council in only one of five regions. \\
\hline Enhancement of host relationships. & $\begin{array}{l}\text { The support the Northeast region has received illustrates the potential benefits the } \\
\text { RBEPs can receive from strons relationships with hosts. }\end{array}$ \\
\hline $\begin{array}{l}\text { Reduced reliance on support } \\
\text { services contracting. }\end{array}$ & $\begin{array}{l}\text { - The magnitude of support services contracts in two regions may create problems of } \\
\text { coordination and control. }\end{array}$ \\
\hline $\begin{array}{l}\text { Quantifiable goals for the regional } \\
\text { programs. }\end{array}$ & $\begin{array}{l}\text { The absence of quantitative goals complicates the identification and reporting of } \\
\text { impacts. While not all of RBEP's goals are quantifiable, progress toward some basic } \\
\text { quantifiable goals would help the program sell itself to Congress. } \\
\text { The range of relationships between the RBEPs and the state programs makes tracking } \\
\text { the impact of the state proprams dificult. }\end{array}$ \\
\hline Impac & $\begin{array}{l}\text { - Can be useful in helping to establish quantitative measures, insure program } \\
\text { performance and continued funding. } \\
\text { - A system of tracking impacts could be established as part of this effort. }\end{array}$ \\
\hline
\end{tabular}





\section{ABSTRACT}

The U.S. Department of Energy (DOE) established the Regional Biomass Energy Program (RBEP) in 1983 to increase the production and use of biomass energy resources. Through the creation of five regional programs (the Great Lakes, Northeast, Pacific Northwest, Southeast, and West), the RBEP focuses on regionally specific needs and opportunities.

Oak Ridge National Laboratory (ORNL) conducted a process evaluation of the RBEP Program designed to document and explain the development of the goals and strategies of the five regional programs; describe the conomic and market context; assess the criteria used to select projects; describe experiences with cost sharing; identify program accomplishments; and offer recommendations. Information was collected on activities between 1987 and 1991 through a review of program documentation, individual interviews, a mail survey, and development of a project level data base.

Substantial similarities were found between the five regional programs. Each of the five regions receives funding from DOE and is supported by a host organization. Each has developed objectives that are consistent with DOE's goals. Program planning structures are similar, planning is highly participatory, and industry involvement at the technical advisory level is strong in all regions. Public solicitations promote industry participation in all regions, and strong similarities also exist in project selection criteria and proposal ranking. All the regions provide some level of support for a network of state bioenergy programs; this is one of the distinguishing characteristics of the RBEP.

Significant differences across the regions were also found. Project selection processes differ across the regions. Greater industry participation was observed when market mechanism approaches rather than top-down approaches were used. The mechanisms for support for state programs varied dramatically between regions. Furthermore, project portfolios and program activities across the regions are highly diverse and unique when considering technologies, project types, feedstocks, market targets, and contractors.

Nationwide, technology themes include biomass energy conversion, municipal solid waste disposal and alternatives, resiciential wood and pellet stove development, biomass derived liquid fuels, and anaerobic digestion technology development. Across the period of 1987-1991, the RBEP invested approximately $38 \%$ of regional project resources on technology development and demonstration projects; $14 \%$ on technology assessments; $14 \%$ on information development and dissemination; and the residual on environmental, economic, market, infrastructure, and resource assessments. Technology development was emphasized over technology demonstration. Most contractors were consulting firms and university researchers.

RBEP has been unusually successful, for a government program, in attracting outside investment resources. It has an opportumity to become a leader within DOE in establishing standards for the acquisition and reporting of leveraging.

A number of recommendations were made. These include continued support for state bioenergy programs; stronger DOE networking support and active brokering of relationships between the regional programs and DOE bioenergy development efforts; stronger emphasis on market-ready short-term projects; recognition for the program's success in the acquisition of outside resources and the development of guidelines for reporting resource leveraging; expanded incustry participation in regional contracting and in the highest level planning committees; enhancement of host relationships; reduced reliance on support services contracting; development of quantifiable goals for the regional programs; and an impact evaluation of the RBEP. 


\section{OVERVIEW OF THE PROGRAM AND THE EVALUATION}

The Regional Biomass Energy Program (RBEP) was established by the U.S. Department of Energy (DOE) in 1983. The RBEP seeks to advance the production of biomass energy feedstocks and their conversion to fuels and energy by the private sector, and to use municipal waste, through support of regionally specific biomass and municipal waste-to-energy projects. In 1992, DOE asked Oak Ridge National Laboratory (ORNL) to conduct a process evaluation of the RBEP. The process evaluation was commissioned to compile a broad range of information on the RBEP, including:

- goals--what are the goals of the RBEP and how do they differ across regions?

- market barriers and technology needs--what do RBEP program managers believe are the market barriers and technology needs that must be addressed to promote the development of a biomass energy?

- the planning process--what criteria are used to select projects and who is involved in the planning process?

- activities--what is the portfolio of projects and programmatic themes?

- resource leveraging--how much cost-sharing has been acquired from different sources?

- program achievements--what information dissemination and technology transfer accomplishments are particularly noteworthy?

Answers to these questions will provide DOE with preliminary indicators of the progress being made by the Program. This process evaluation will also lay the groundwork for conducting a more definitive impact evaluation, focusing on quantitative indicators of program achievements.

This chapter provides background on the RBEP, including an overview of its formation, its structure, and its goals and objectives. It ends with a description of the rescarch design of this process evaluation and an overview of the rest of the report.

\subsection{BACKGROUND}

In 1979, the Bonneville Power Administration (BPA) initiated a biomass energy program to develop regionally appropriate biomass technologies. Congress passed enabling legislation in 1983 instructing DOE to support regional biomass energy programs similar to the BPA effort. In particular, the enabling legislation recommended the creation of: 
"regional biomass energy programs, similar to the successful effort at the Bonneville Power Administration. In addition to providing support for activities at BPA and TVA [the Tennessee Valley Authority], the Department shall identify other regions of the country and develop a program to identify and plan for regionally appropriate biomass technologies." (Senate Report 97-673)

The FY 1983 budget was $\$ 4$ million.

During the FY 1984 budget debate, which also resulted in a \$4 million appropriation, Congress instructed DOE that:

"These RBEPs would carry out activities related to technology transfer, industry support, resource assessment, and matching local resources to conversion technologies."

Similar language has appeared in each year's legislation since FY 1984, including the current FY 1994 legislation. DOE responded by initiating the Great Lakes, Northeastern, Northwest, and Southeastern Programs in 1983. In 1987, DOE added a Westem program, which result in a RBEP that covers all states except Hawaii (see Fig. 1.1).

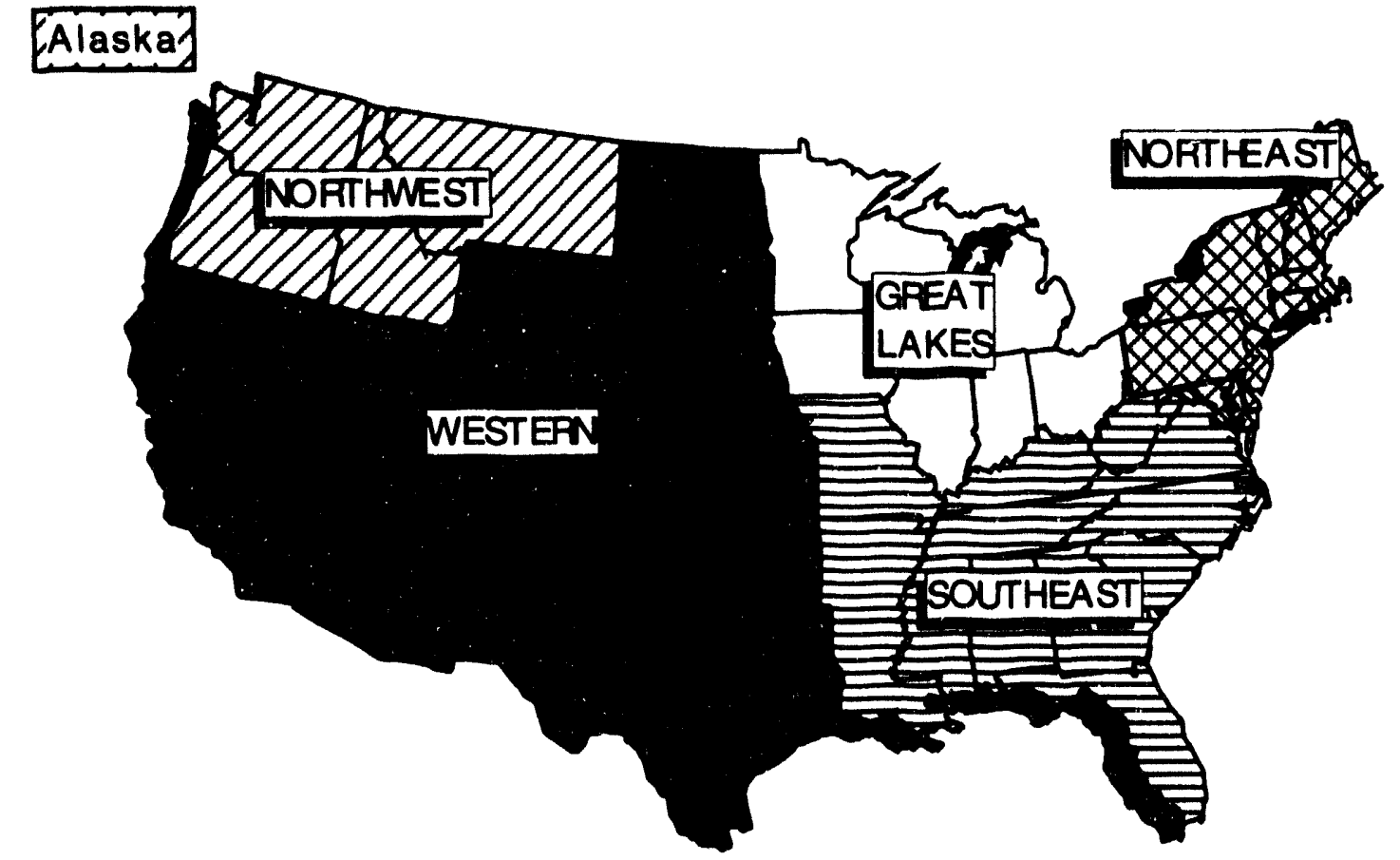

Figure 1.1 Regions of the Regional Biomass Energy Program 
Funding for the RBEP has been fairly steady, as has the individual funding received by each of the regions, except for fiscal year 1989, which saw a dramatic cutback (Table 1.1).

Table 1.1 Regional Biomass Energy Program Funding Profile (SOOO's Current Year Dollars)

\begin{tabular}{|c|c|c|c|c|c|c|}
\hline Why & WY & monosids & Wrots & FY, 1991 & FY 1992 \% & FX 1993 \\
\hline 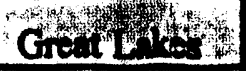 & 500 & 290 & 500 & 643 & 760 & 694 \\
\hline Nortaring & 650 & 335 & 600 & 775 & 785 & 717 \\
\hline 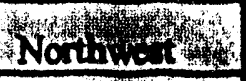 & 800 & 500 & 740 & 732 & 740 & 676 \\
\hline Souts-1 & 800 & 375 & 910 & 1,166 & 1,005 & 917 \\
\hline WES & 850 & 650 & 710 & 828 & 800 & 730 \\
\hline $\mathrm{DOE}-\mathrm{W}$ Lal & 400 & 0 & 540 & 300 & 410 & 374 \\
\hline Woth & 4000 & 2000 & 3,759 & 4,444 & 4,500 & 4,285 \\
\hline
\end{tabular}

\subsection{PROGRAM STRUCTURE}

When first created, the Regional Biomass Energy Program was located in the Biofuels and Municipal Waste Technology Division of DOE's Office of Renewable Energy. It was one of several components of the Division's biomass R\&D program. In 1990, the Office of Conservation and Renewable Energy (EE) was reorganized.' EE was divided into four energy end-use sectors (utility, transportation, industry, and buildings), and the Office of Technical and Financial Assistance (OTFA). The mission of OTFA is to support the EE mission across all end-use sectors and to provide linkages through its program delivery network with other federal agencies, State and local governments, as well as private and non-profit organizations. RBEP was placed within OTFA, in a newly established Office of National Programs (Fig. 1.2). Biomass/waste programs also were established under EE's utility, transportation, and industrial offices. This reorganization gives RBEP increased outreach capabilities under OTFA and a critical cross-cutting role in biomass via cooperation with the three end-use sector programs.

\footnotetext{
${ }^{1}$ The name of this office was recently changed to the Office of Energy Efficiency and Renewable Energy (EE).
} 


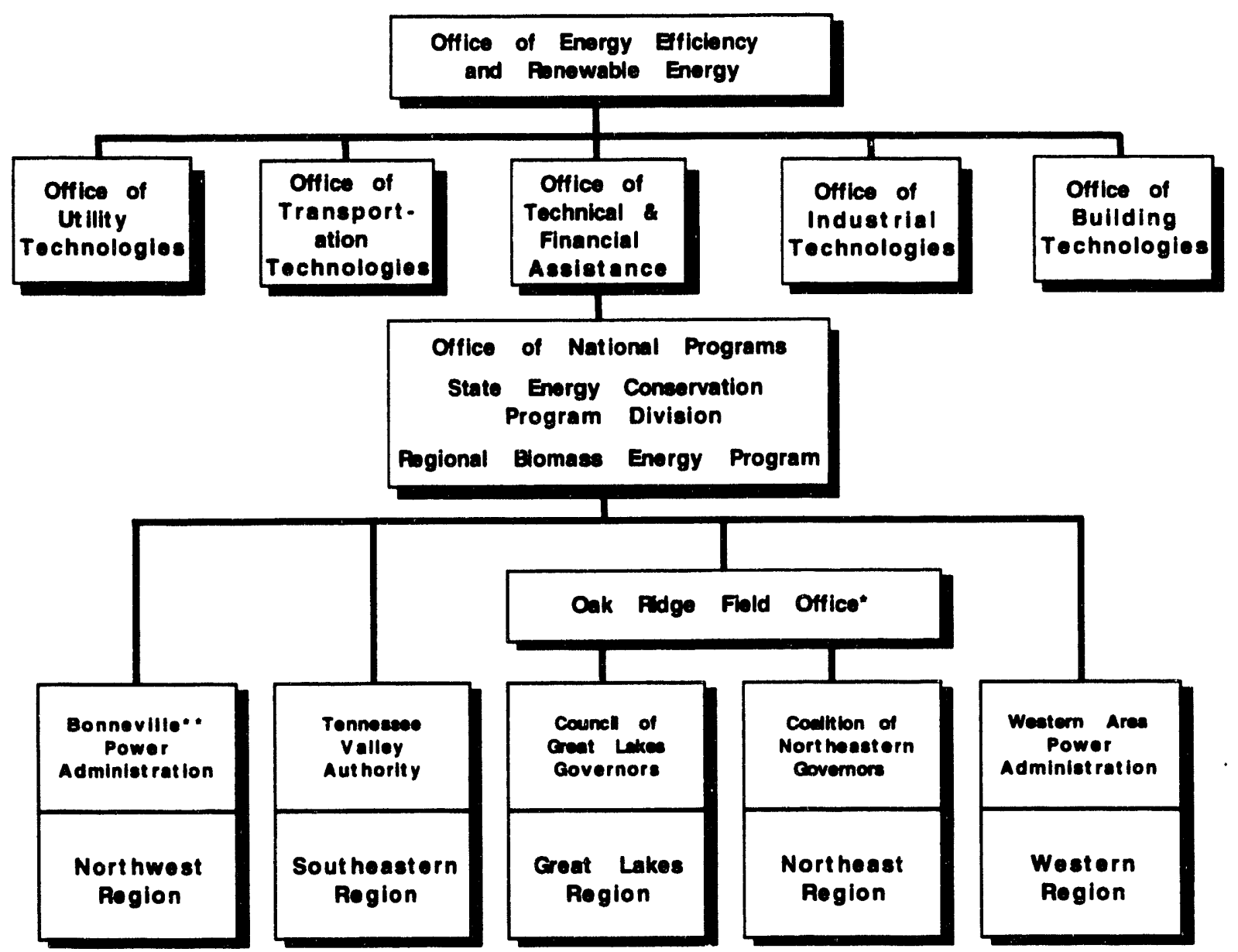

- In 1993, two of DOE's Regional Suppont Of ices were given over sight responsibility for these two regional programs, in place of the Oak Fidge Field Office.

-. In 19 93, DOE's Seatt le Support Otfice became the host o rganization for the North west Program.

Figure 1.2 Organizational Structure of the Regional Biomass Energy Program

Each of the Program's five regions is funded by DOE through a host organization which is responsible for operational management. Three of the host organizations are federal power authorities: BPA (in the Northwest), TVA (in the Southeast), and the Western Power Administration (in the Southwest). The host organization of the Great Lakes program is the Council of Great Lakes Governors (CGLG), and the host organization of the Northeast program is the Coalition of Northeastem Governors (CONEG). Both the Great Lakes and the Northeast regional programs have been formally administered by DOE's Oak Ridge Field Office. In FY1993, the administration of these regional programs was changed so that the Great Lakes and the Northeast 
regional programs would be administered by the DOE support offices in Chicago and Boston, respectively. This was done to facilitate transfer of funding to the programs and to enhance networking within the regions.

The RBEP has been designed and structured to focus on regionally specific needs and opportunities. Recognizing that such needs and opportunities are best identified at the regional level, the RBEP allows its regional managers the latitude to develop particular program activities appropriate to their regions. As section 1.4 illustrates, this has resulted in programmatic themes that differ significantly across regions.

In terms of program structure, however, there is great similarity across regions. In particular, each region generally has four types of projects (although during any specific year, one or more of these types may not be represented): (1) state grants; (2) competed contracts; (3) noncompeted contracts, and (4) supporting activities undertaken by host organizations and/or support contractors. Each region also has a planning committee that helps identify programmatic themes and selects competitively solicited projects. Finally, each region's funds are leveraged through cost sharing provided by state grantees and contract awardees.

\section{Table 1.2 Regional Biomass Energy Program Projects, By Type and Region}

\begin{tabular}{|c|c|c|c|c|c|}
\hline \multicolumn{6}{|l|}{ 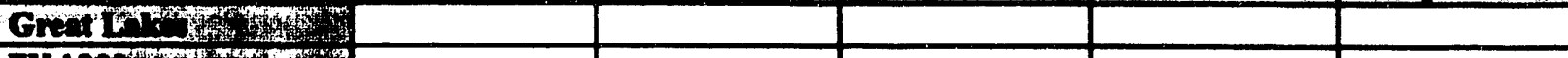 } \\
\hline 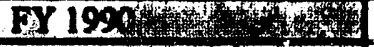 & $\mathbf{x}$ & & & & \\
\hline FI 1991, & $x$ & & & & \\
\hline FY 1992 & $x$ & & & & \\
\hline \multicolumn{6}{|l|}{ Northerow } \\
\hline 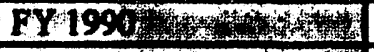 & $\underline{x}$ & $x$ & & $x$ & $x$ \\
\hline FY $1991 \%$, & $\mathbf{x}$ & $x$ & & $\mathbf{x}$ & $\mathbf{x}$ \\
\hline FY 1992 a & $x$ & $\mathbf{x}$ & & $x$ & $\mathbf{x}$ \\
\hline \multicolumn{6}{|l|}{ 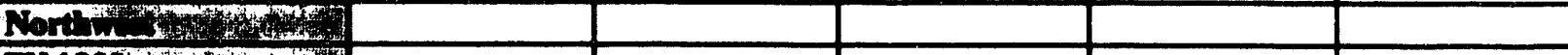 } \\
\hline 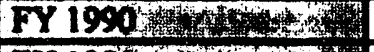 & $x$ & & & $\mathbf{x}$ & \\
\hline PY 1991 & $\mathbf{x}$ & & & $x$ & \\
\hline PX 19in & $\mathbf{x}$ & & & $x$ & \\
\hline 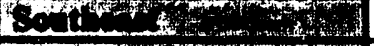 & & & & & \\
\hline DTIS, & $x^{\infty}$ & $x$ & $\mathbf{x}$ & & \\
\hline I ISA & $x^{2}$ & $\mathbf{x}$ & $\mathbf{x}$ & & \\
\hline 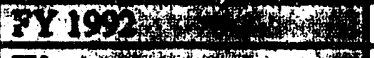 & $x^{2}$ & $\mathbf{x}$ & $\mathrm{x}$ & & \\
\hline \multicolumn{6}{|l|}{ Wad } \\
\hline 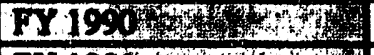 & & & & $x$ & \\
\hline FY 199] & & $x$ & & $x$ & \\
\hline FY 1992y & & $\mathbf{x}$ & & $\mathbf{x}$ & \\
\hline
\end{tabular}

"The Southeast program contracts with State agencies, while the other prograrns provide grants to States. 


\subsection{GOALS AND OBJECTIVES}

The goal of the RBEP is to increase the production and use of biomass energy resources (DOE/CE-0336P). ${ }^{2}$ The goal of each of the five regional programs is consistent with this program-wide goal:

- Great Lakes-to increase the production and utilization of biomass fuels in the Great Lakes states;

- Northeast-to increase acceptance and application of biomass energy technologies by the private sector and local governments;

- Northwest--to expand the use of biomass energy within the region, emphasizing cost-effective, environmentally sound options;

- Southeast--to encourage the production of biomass fredstocks and their conversion to fuels by the private sector; and

- West-to stimulate the use of biomass resources which are regionally important, technically and economically sound, and which address the energy needs of the Western States.

The four specific DOE objectives cited in the RBEP brochure (DOE/CE-0336P) are shown in Table 1.3. Similar objectives are commonly cited for the five regional programs. The two objectives that are only cited by a few of the programs deal with improving state and local and industry capabilities and effectiveness, and encouraging economic development through increased public and private-sector investment.

Three additional objectives are cited by at least two of the regional programs:

- to transfer results of government-sponsored biomass research and development to the private sector;

- to mitigate adverse environmental impacts of biomass use; and

- to match local biomass resources with conversion technologies and/or energy requirements.

\footnotetext{
${ }^{2}$ Biomass" is generally defined as any organic (carbon based) fuel; including wood, agricultural residue, animal waste, municipal solid waste (MSW), and refuse derived fuel ("derived" from MSW by mechanical means such as screens and air classifiers). It does not include fossil fuels such as coal, oil, and natural gas.
} 
Table 1.3 Objectives of the Regional Biomass Energy Program

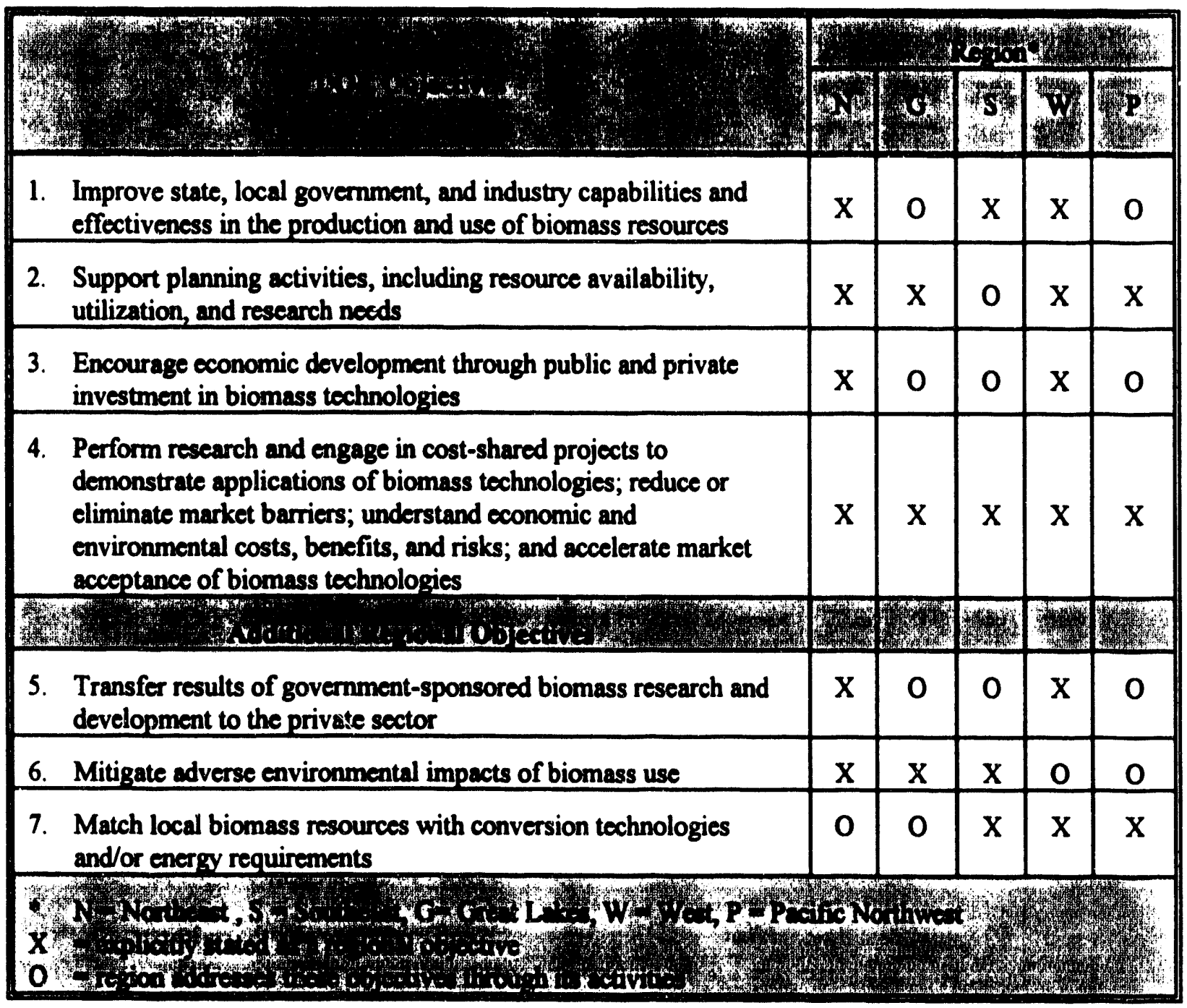

Each of these objectives is consistent with DOE's four objectives. By transferring the results of government-sponsored biomass R\&D to the private sector, the program is improving industry capabilities and effectiveness (Objective \#1). Mitigating the adverse environmental impacts of biomass use and matching local biomass resources with conversion technologies and/or energy requirements will accelerate the market acceptance of biomass technologies (Objective \#4). See Appendix A for a complete listing of each of the regional program's goals and objectives.

The breadth of RBEP goals and objectives has been established by the enabling legislation (Senate Report 97-673), and the RBEPs have undertaken a diverse array of activities to fulfill them (see chapter 4). 
The low level of funding for this program, however, has limited the resources available to help achieve these objectives. In the absence of additional sources of funding, the RBEPs should evaluate ways in which the scope of activities can be narrowed. In addition to increased focus, the RBEPs should also consider establishing measurable objectives and quantitative targets against which to evaluate progress.

\subsection{PROGRAM ACTIVITIES}

Each of the RBEP regions undertakes a unique portfolio of projects deemed important to that region. However, these activities must fit within the broad scope of activities defined by DOE. Table 1.4 reproduces the abstract of program activities provided to Congress by DOE for FY 1990 through FY 1992. In general, the programmatic activities undertaken by each RBEP region are consistent with the broad scope of activities defined by DOE.

Table 1.4 RBEP Activities: FY 1990 through FY 1992

\begin{tabular}{|c|c|c|}
\hline ow & $\therefore=4$ & Sizh \\
\hline $\begin{array}{l}\text { Provide technical assistance } \\
\text { tailored to States included in the } \\
\text { Regional Biomass Energy } \\
\text { Program. Continue: projects } \\
\text { geared toward establishing the } \\
\text { availability of biomass resources } \\
\text { within the various regions } \\
\text { through resource assessment } \\
\text { studies; transferring to the } \\
\text { private sector the results of } \\
\text { biofuel production and } \\
\text { conversion technology R\&D; } \\
\text { and encouraging cooperation } \\
\text { between industry and the } \\
\text { Department through cost-shared } \\
\text { projects that will build } \\
\text { private-sector confidence to } \\
\text { adopt biofuel technologies. }\end{array}$ & $\begin{array}{l}\text { Maintain biomass information } \\
\text { contacts in } 49 \text { states; promote } \\
\text { state-of-the-art biomass energy } \\
\text { through the transfer of biomass } \\
\text { technology; continue to provide } \\
\text { technical assistance at an } \\
\text { expanded level tailored to states } \\
\text { included in the Regional } \\
\text { Biomass Energy Program; } \\
\text { continue projects geared toward } \\
\text { establishing the availability of } \\
\text { biomass resources within the } \\
\text { various regions through resource } \\
\text { assessment studies; encourage } \\
\text { cooperation between industry } \\
\text { and DOE through cost-shared } \\
\text { projects. }\end{array}$ & $\begin{array}{l}\text { Maintain binmass information } \\
\text { contacts in } 49 \text { states. Conduct } \\
\text { resource assessment studies to } \\
\text { update information on the } \\
\text { availability of biomass } \\
\text { resources within the various } \\
\text { regions. Support state grant } \\
\text { programs in selected states, to } \\
\text { provide specific information } \\
\text { based on verified and consistent } \\
\text { data on a range of renewable } \\
\text { biofuels technologies, through a } \\
\text { coordinated and } 50-50 \\
\text { cost-shared effort. }\end{array}$ \\
\hline
\end{tabular}

Resource assessments, information dissemination, and funding of state programs have historically been key elements of the Great Lakes Program. This focus is reflected in the FY 1991 projects, which include the development of a secondary wood manufacturers directory (to help wood energy project developers identify sources of available wood residue supplies) and the distribution of biomass pelleting guidelines (to 
inform potential developers of biomass pelleting operations about factors that determine the success or failure of wood and agri-residue pellet plants). Recently the program has initiated a focus on developing the region's ethanol industry. This new direction is supported by two FY 1991 projects: the development of ethanol-fucled heavy engines for trucks and an effort to increase the efficiency (and hence reduce the cost) of ethanol production through the use of a membrane technology.

The Northeast Program emphasizes wood energy, both residential and industrial. This is reflected in its FY 1991 projects, which include the development of a stress test for advanced technology stoves, the creation of a database of information on cmissions from wood-fired boilers, and an assessment of which wood products may be acceptable to burn in direct combustion systems of medium and large-scale boilers. The Northeast Program also has undertaken a variety of projects to promote the use of municipal solid waste to energy, so as to offset some of the costs of managing waste in this highly urbanized region. Responding to the nation's increased concern over global climate change, the FY 1991 portfolio of projects also included the development of a document to guide local, state and regional policy-makers in developing strategies which consider biomass resources to mitigate global climate change. This document will assess the biomass feedstock management, direct combustion, and municipal solid waste technology strategies that mitigate the release of greenhouse gases.

The abundant forest resource in the Pacific Northwest and Alaska has focused the Northwest Program on wood energy. Early emphasis was on the fuel utilization of wood residues from logging operations on public lands. Subsequently the program broadened its scope with a series of projects associated with residential biomass combustion, including analysis of emissions and energy-efficient wood and pellet stoves. This focus is illustrated by two FY 1991 projects: a consumer education program aimed at reducing residential wood smoke emissions and a pellet stove testing and technology transfer effort. In 1990, the Northwest program turned its attention to the recovery of energy from municipal solid waste and mixed wastepaper. Reflecting this focus is a FY 1991 assessment of opportunities for using mixed waste paper and other fractions of municipal solid waste as a cellulose feedstock for ethanol fuel production. In the future, greater attention is expected to be given to landfill gas recovery.

The Southeast Program seeks to encourage the production of biomass feedstocks and their conversion to fuels by the private sector through support of regionally specific biomass energy projects. Considerable biomass wastes (agricultural wastes, wood, wood wastes, MSW, and animal wastes) go underutilized in the Southeast region. As a result, SERBEP has designed many projects to demonstrate concepts and the technical feasibility of utilizing these resources. In addition, the Program provides information and technical assistance to private and public decision-makers. 
SERBEP's portfolio of projects has evolved significantly over the past decade. Following the mandate to fund near-term projects, the portfolio of projects was weighted towards direct combustion technologies until 1987. With the consent of DOE Headquarters, the planning committee then began to expand the portfolio to include a broader range of technologies.

The Western Program is the newest of the five regional programs, and as such is in the process of assessing various programmatic foci. To date, the program has concentrated primarily upon resource assessments, planning activities, and feasibility studies. Indicative of this focus are the following FY 1991 projects: a biomass industry assessment, a biomass fuel supply inventory, state feasibility studies, a California facilities directory, and an assessment of municipal solid waste supply and refuse-derived-fuel processing options for a Texas utility.

\subsection{RESEARCH DESIGN}

The process evaluation involved three stages: (1) a review of program documentation and other available literature; (2) structured interviews with DOE and regional program managers; (3) a mail survey of regional program managers to verify the survey information, and (4) development of a project level database.

A varicty of program documentation was reviewed, including annual operating plans, project reports, conference proceedings, and minutes of key planning meetings. The DOE program manager and each of the five regional managers were interviewed, as were managers of host organizations and support contractors. Interviews with the five regional managers took place at each of the regional program offices and were conducted by a team of two investigators. The interviews were one-and-a-half to two days in duration. In addition to collecting a broad range of information spanning the lifetime of each program, the protocol collected detailed information about activities conducted during FY 1991. This year was selected because it was the most recent year for which complete information could be collected from each region.

Following each of the regional interviews, a completed protocol was mailed to the regional manager for review. This quality control step was intended to ensure the accuracy of the information collected from the program documents and surveying.

In order to address questions raised by DOE Headquarters management concerning longitudinal trends in the RBEPs, a project level database was developed. Information was collected on projects conducted between FY1987 and FY1991 for projects funded and supervised directly by the regional offices. In addition, similar information was developed on state-supervised projects which received DOE RBEP funds in the Southeast and Pacific Northwest. This data was used in the analysis of the project portfolios of the five regions. 


\subsection{OVERVIEW OF THE REPORT}

Chapter 2 discusses the program planning process, profiling the participants in program planning. Chapter 3 describes the project selection process. Chapter 4 describes the portfolio of projects that comprise each of the regional programs. Portfolio balance is characterized both in terms of type of project and programmatic themes.

Intermal and extermal resource leveraging is the topic of Chapter 5. Cost-sharing and inter-regional collaboration are both discussed. The report ends with a list of recommendations.

Appendix A provides an overview of the biomass energy contribution to the U.S. economy, and describes the major barriers that constrain the proctuction and utilization of biomass resources. This overview provides a context for the discussion of programmatic and technology themes undertaken by the RBEP. The remaining appendices provide supporting documentation. 
.1 


\section{PROGRAM PLANNING AND OPERATION}

This chapler discuseces the planning and operation of the regional programs. It begins by describing the involvement of policy and technical advisory groups in planning the activities of the regional programs (Section 2.1). Attention then turns to the roles of the host organizations (Section 2.2) and management support services (Section 2.3). The chapter concludes with a summary of the lessons learned (Section 2.4).

\subsection{PARTICIPATION IN PLANNING AND OPERATION}

\subsubsection{Overview of the Planning Process}

The five regional programs have similar processes for acquiring and assessing information for program planning purposea. In general, the managers of each of the five regional programs receive guidance from a plamning committec, stecring council, advisory group, task force, or ad-hoc committec. These planning committees often act on advice from various technical committces, who have expertise in specific biomass applications and/or tochnologies and represent a variety of interests that include research organizations and the private sector.

The overall guidance that RBEP program managers receive from their advisory committees includes:

- advice and direction regarding short- and long-term policy directions;

- input to annual operating plans and proposal solicitations;

- approval of annual operating plans; and

- guidance on specific programmatic or project activities.

To promote broad state representation, advisory committees are generally composed of representatives from each state. For some regions, appointment to the planning committee is done through the state govemor's office. The primary features of these planning processes are discussed below. Specific planning processes for each of the regional programs isdiscussed in more detail in Section 2.3 below.

\subsubsection{Planning Committees}

Each of the five regions has a planning committee (referred to as a steering council, advisory group, task force, or ad-hoc committec) which provides direction to the regional manager. Four features of the structure of the planning committees in the RBEP will be examined: membership, tenure, relationship to project proposals, and nature of industry input. 
Memberahip of the Planning Committec. While the planning committees of each of the five regions have different names and are composed of different types of members, some generalizations can be made. In four of the five regions, state bicenercy representatives have a prominent role in the planning committee. In the Northeast and Great Lakes, the entire membership of the planning committee is composed of state representatives, while in the Weat and Pacific Northweat they make up approximately one-half of the body. Federal agencies participate in each region in the form of a representative from a DOE support office in the region. Representatives from other foderd agencies (e.8., EPA, USFS, BLM) are also included in the planning committees in the Southeast and Pecific Northwest.

The planning committec has industry representation in only one region, the Southeast. In the other three regions, industry input into the planning committce occurs as a result of informal discussion, through briefings by industry personnel during planning committee meetings, and through the role of industry representatives on the tochnical edvisory groups.

Tenure of Members. The tenure of members on the planning committees tends to be extensive. Four of the five regions do not have an established tenure period. In the Northwest, for instance, several members have 10 or more years of experience on the planning group. And in the Northeast, a significant percentage of the current members are charter members, having been part of the council since the founding of the regional program in 1983.

The Southeast places a three year term limitation on planning committee membership. This enables the Southeast regional program to periodically adjust the membership of its planning committec to reflect changing conditions and also to inject fresh viewpoints into the planning council on a regular basis. Placing a term limitation on membership in the planning committec is made easier in the Southeast because the region does not in general provide staff support for state bioenergy representatives, and state representatives have played a lesser role on its planning committec.

Relationship to Project Proposals. While each of the five planning committes is responsible for providing regional direction, they have varying degrees of input into the nature of project proposals. Members of the planning committee in two regions have greater input into the development of project proposals than do their counterparts in the other regions. In the Northeast and Northwest, members bring informal project concepts as well as formal project proposals into the planning committec or its working groups for consideration. This gives these members a significant amount of input into the formulation of proposed projects. Members of the 
steering council of the Great Labes region may also bring in project concepts, although moat projects originate within the membership of the technical advisory committee rather than the steering council.

In the Southeast and West, moat projects are developed by university researchers, consultants, and industry perticipents in response to relatively generalized RFPs which establiah project areas but which do not specify projects. Planning committee members review recommendations of technical review committees extablished to screen responses to project RFPs. When directed solicitutions are employed, members of the planning committec may dovelop project work plans.

Table 2.1 Planning Structurea: Role of the Polley Group

\begin{tabular}{|c|c|c|c|c|c|}
\hline 4 & $\frac{1}{\text { Stcering Counoil }}$ & $\begin{array}{l}\text { Stoering } \\
\text { Committes }\end{array}$ & 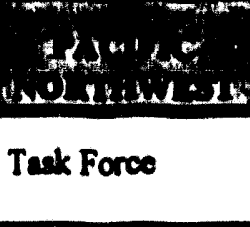 & Plenning Council & $\begin{array}{l}\text { Nond } \\
\text { Ad Hoc } \\
\text { Committes }\end{array}$ \\
\hline 4 & Sule blomingy & & 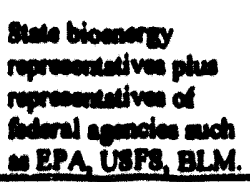 & 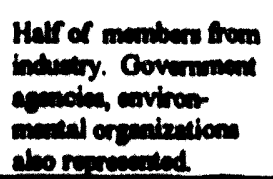 & 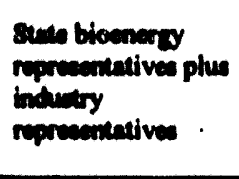 \\
\hline$\frac{7}{7}$ & No tmume priod. & 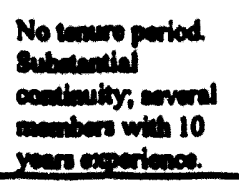 & 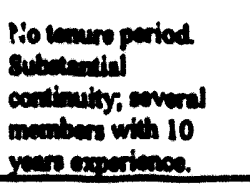 & Thes yen them & No temure period \\
\hline 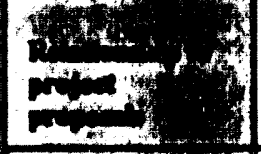 & 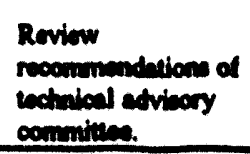 & 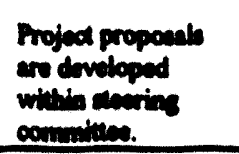 & 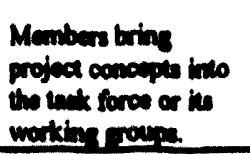 & 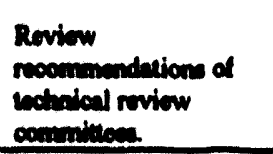 & $\begin{array}{l}\text { Holp recruit project } \\
\text { propoenals in } \\
\text { repones to the } \\
\text { PON. }\end{array}$ \\
\hline 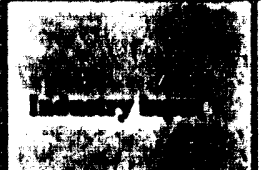 & $\begin{array}{l}\text { No monburmip on } \\
\text { anving ocumail. }\end{array}$ & No monberitip on & 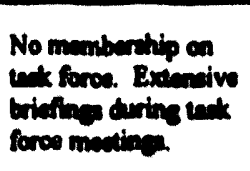 & 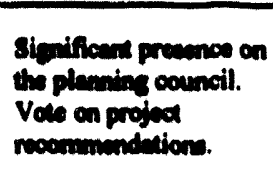 & $\begin{array}{l}\text { Mamberchip on the } \\
\text { ad hoc committee }\end{array}$ \\
\hline
\end{tabular}

Industry Input into the Planning committee. Two regions, the Southeast and West, have substantial industry representation on their planning committec. The other three regions do not place industry representatives on the planning committee. In these regions, industry input into the planning committee occurs as a result of informal industry discussion with planning committec members and through briefings by industry personnel during planning committee meetings. 


\subsubsection{Technical Advisory Groups}

Each of the five regions employs a technical advisory group with expertise in specific biomass applications and/or technologies. These advisory groups make technical recommendations to the planning committee and represent a variety of interests that include representatives from state government, research organizations, and the private sector. Three features of the structure of the technical advisory groups in the RBEP will be examined: membership, role of the advisory group, and nature of industry input.

Membership and Role. The technical advisory groups in all five regions include representatives from governmental agencies, universities, and industry. In the Southeast and Northeast, working groups are set up on an as-needed basis to investigate specific issues. In the Northeast, project-specific groups are formed to oversee individual projects. Standing working groups have been developed in the Northeast to deal with issues associated with wood stoves, in the Southeast to address anaerobic lagoon digestion, in the Great Lakes to examine forestry, municipal waste, and agricultural issues, and in the Northwest to provide direction concerning technology transfer, municipal solid waste, biofuels, and residential combustion.

Induatry Inpurt into the Technical Advisory Groups. Each of the five regions receives significant industry input into the technical advisory groups. Industry representatives in these advisory groups are able to critically examine regional program activity and suggest future directions. Input into these advisory groups is tochnically oriented in general, although in the Northeast region industry representatives had significant input in the strategic planning process in 1984, 1989, and 1993.

\subsubsection{Role of the Planning Committee and Technical Advisory Groups in Project Selection}

The regions display considerable diversity in the degree to which members of their planning committees and technical advisory groups are involved in project selection, but two primary patterns exist. In two regions, general project areas are established by policy and technical advisory groups, and project proposals are solicited via RFPs. In these two regions (Southeast and West), technical review teams select from project proposals submitted in response to competitive solicitations.

In the remaining three regions (Northeast, Great Lakes, and Northwest), the planning committec and/or its technical advisory groups identify project areas and define specific projects for the region to pursue. In the Northeast, the steering committee identifies projects, and then sets up a working group to select a contractor via an RFP process. In the Great Lakes region, project concepts are discussed and project proposals developed within TAC subgroups. The steering committee selects project proposals from those 
developed by the TAC, RFPs are issued, proposals are reviewed by members of the TAC and the planning committee, and the planning committee selects contractors to undertake the projects. In the Northwest, proposals are written by a variety of partice and brought before task force subgroups for review.

Table 2.2 Planning Structures: Technical Advisory Groups

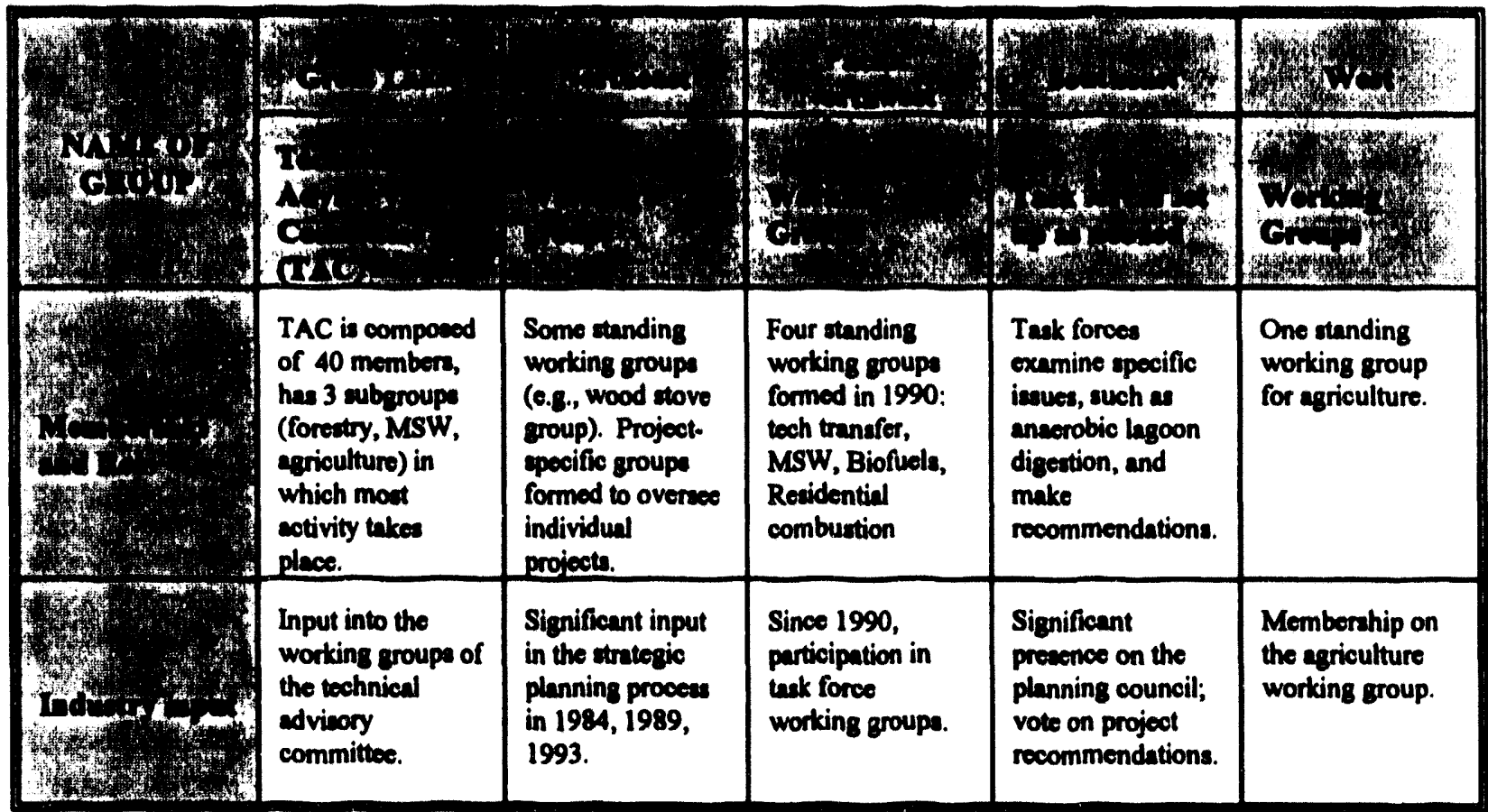

Between 1984 and 1988, the Pacific Northwest also solicited projects via RFPs. Project areas for which proposals were solicited in the Northwest were more tightly defined than in the Southeast and West. During this time period, a technical review panel composed primarily of task force members was formed to review responses to the RFPs. Between 1989 and 1993, the Pacific Northwest region conducted most of its projects through the states; in 1993 it reestablished an RFP process.

Industry Input into Project Selection. Industry input into project selection comes in a variety of forms. In all five regions, incustry representatives are able to influence the context of discussions about project areas and project selection through their networking activity, industry briefings in planning committee meetings, and their role in technical advisory groups. 
In the Northeast, Great Lakes, and Northwest, projects are identified and developed within the technical advisory groups. Industry participants can impact project selection by submitting project proposals to these groups, through membership on these groups, and through presentations to the planning committee.

In the Southeast, industry input into project selection is multi-faceted. Industry members of the planning committees help to set broad policy directions and project areas, and along with representatives on the working groups have input into the structure of project solicitations. Broadly defined project solicitations open up opportunities to participate in RBEP contracts to a wide audience. Representatives on the planning committec have the opportunity to approve the recommendations of the technical review teams that sort out responses to project solicitations. This multi-faceted approach gives industry better access to these two programs than to the remaining three.

In the Westem region, incustry input into the technical advisory groups helps to shape general program direction and select the project areas described in project solicitations.

Table 2.3 Participation in Project Selection

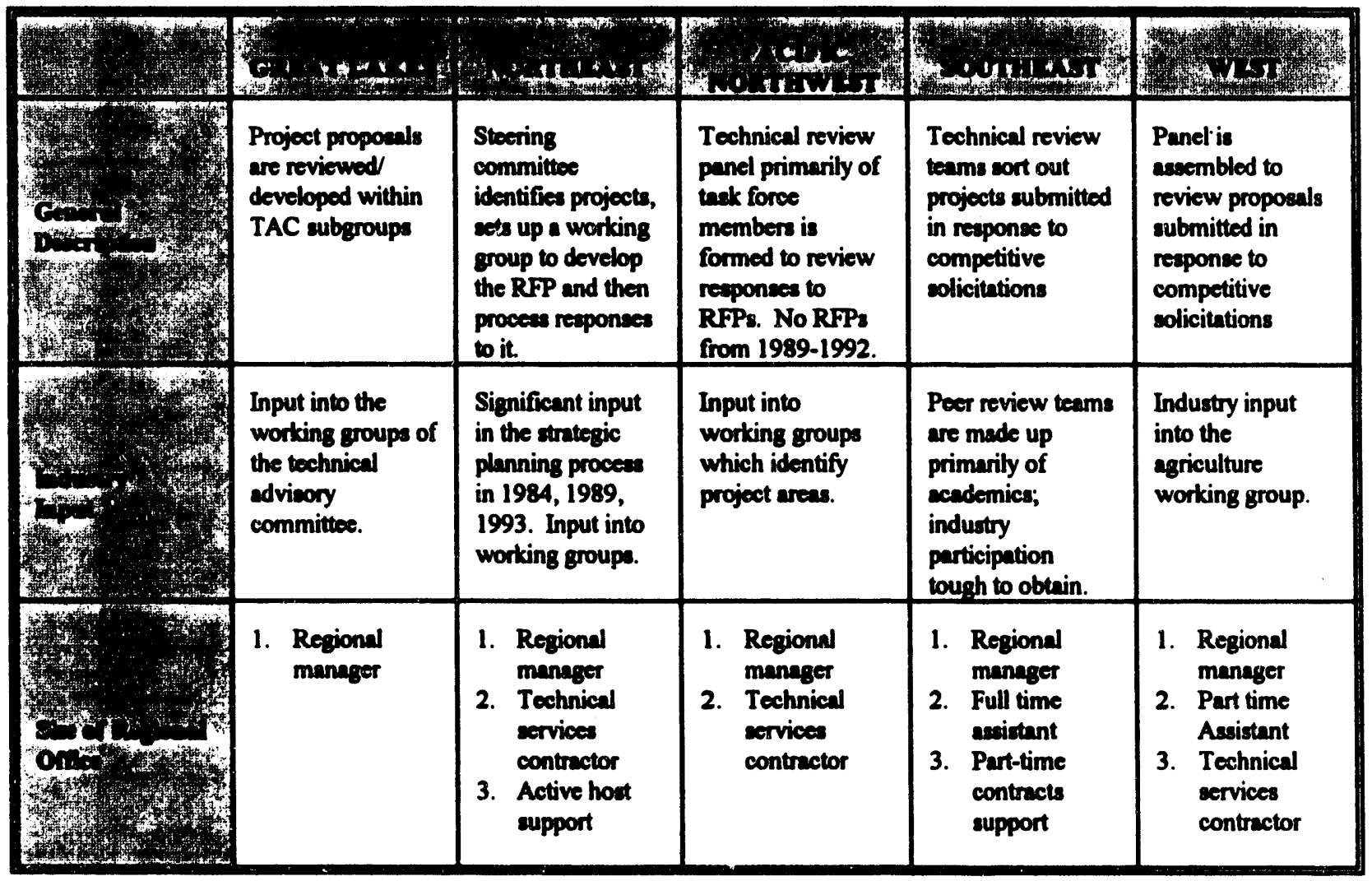




\subsection{RELATIONSHIPS WITH HOST ORGANIZATIONS}

This section describes the type of support that host organizations provide, their program oversight, and the reporting requirements. While each of the host organizations has provided similar types and amounts of support services, they differ in the level of managerial involvement with the RBEPs and in the level of impact they have had on the regional programs they host.

\subsubsection{Nature of Host Organization}

The host organizations have had an impact on the structure and operation of the regional bioenergy programs. Two of the regional programs (the Great Lakes and Northeast) are hosted by regional conferences of governors, whose primary task is regional policy development. In these two regions, the regional programs have been more directed towards the development of information and policy documents than in the other three regions.

The other three regions (Southeast, West, and Pacific Northwest) are housed within federal power marketing agencies. These regions have been more oriented towards technology development and deployment than have the other two regions. This is especially true of the Southeast and West, which are structured to direct significant amounts of their annual funding into solicitations for bicenergy projects.

\subsubsection{Host Involvement with and Impact on the Regional Program}

Two of the host organizations (Northeast and West) have been actively involved in courseling and promoting the regional bioenergy program they house. The support the Northeast regional program has received from the Coalition of Northeastern Governors has helped to provide linkages into state governments as well as foderal agencies and other organizations in Washington, D.C. It has also helped provide continuity for the regional program during times of transition. In the Western region, the active interest and planning guidance provided by the host produces a nurturing environment for bioenergy development. The desire of a host manager to see a "ribbon-cutting" bioenergy event in the Western region has helped to provide vision for the program.

In three regions, hosts have had little recent involvement with the regional program. TVA sets some operating parameters and provides an organizational structure. While it did provide some guidance at the inception of the program, and TVA staff members serve as chairpersons on technical review teams at the request of the regional manager, TVA has had little recent interaction. The same is true of BPA's involvement with the Pacific Northwest. The Council of Great Lakes Governors has provided access to state executives, but has shown little involvement in the regional program and has not followed through on some of the 
commitments it has made to the regional program. In 1987 it undertook two in-house technology transfer activities related to bioenergy which languished for four years because the host was unwilling or unable to allocate staff resources to complete the project. Ultimately the regional program hired a consulting firm to complete these tasks. Recently, recognition of the potential importance of ethanol fuels in the region has improved support from the Council of Great Lakes Governors. The host has helped the program acquire additional staffing and has assisted recently with in-house projects.

The experiences of the five regional programs illustrate that the level of support and involvement from an organizational host can have a significant impact on the nature of the activities the program conducts. The host organization can also enhance access to resources from federal agencies and state government.

Table 2.4 Relationships with Host Organizations

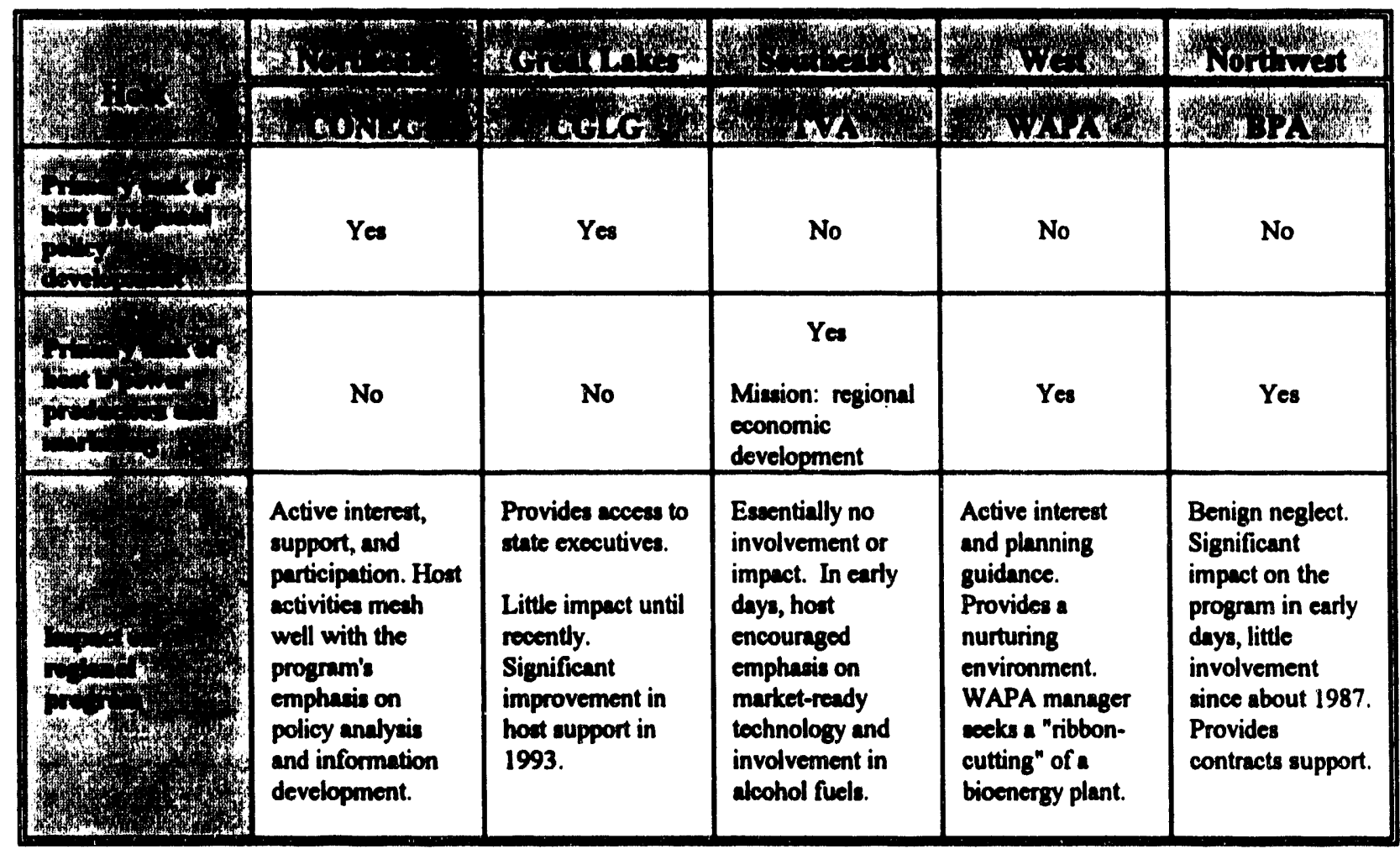

\subsection{MANAGEMENT SUPPORT SERVICES}

Three of the five regions employ a support services contractor (SSC) to assist the program manager in the development and implementation of strategic plans (Table 2.5). The regions with SSCs employ them in significantly different ways and devote dramatically different proportions of the annual budget to them. 
The Western region, which is the youngest of the five RBEP programs, uses the SSC in a wider variety of ways than do the other regional programs. In this region, $38 \%$ of the annual budget in 1991 was funneled through the SSC, which provides direct technical assistance to the states, makes travel arrangements, helps to set up conferences, and coordinates resource assessment activities and other regional studies, and maintains a certain amount of regional program data. In this respect it serves as a financial intermediary and contracting agency.

Table 2.5 Use of Management Support Services

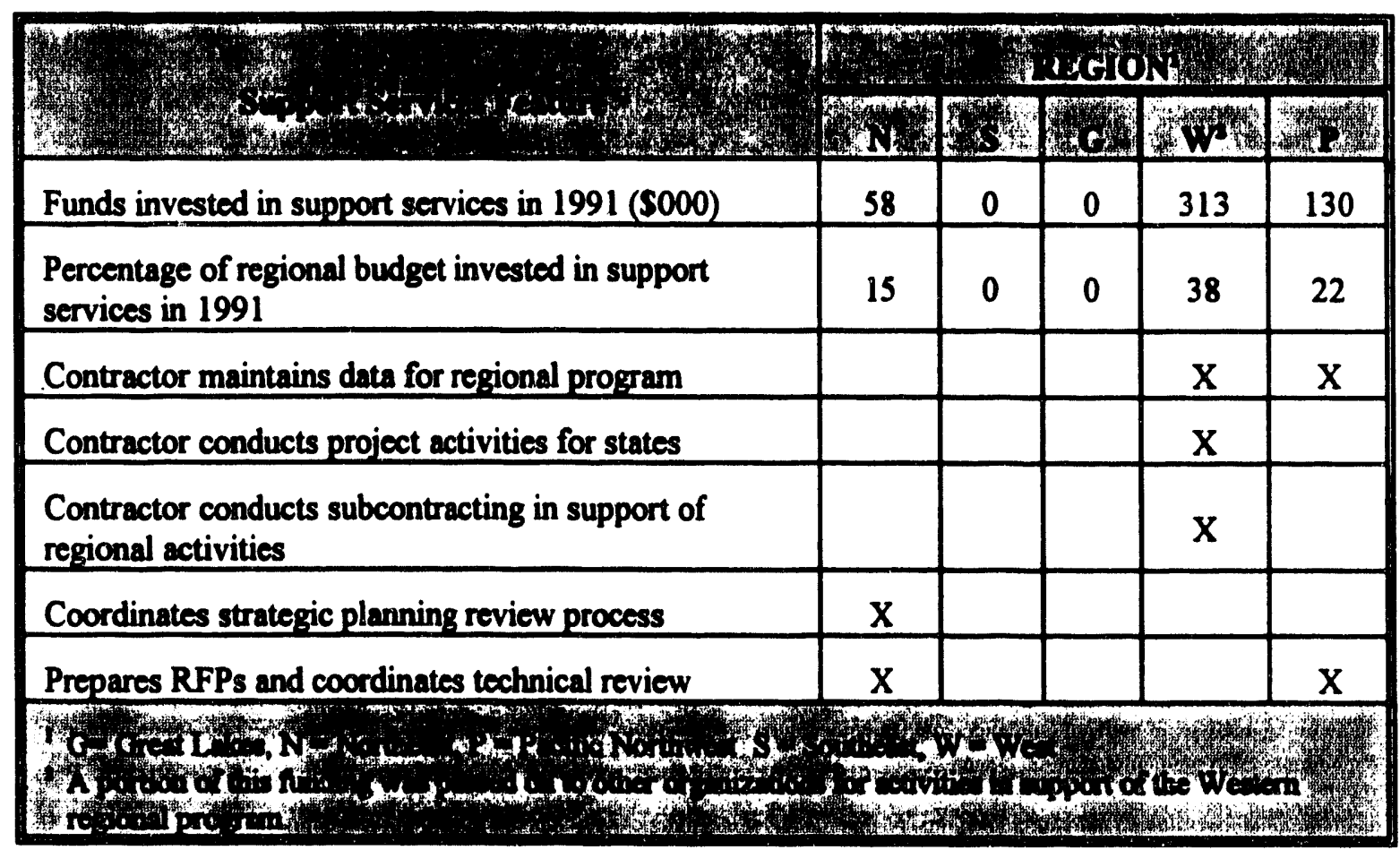

In contrast, the Northeast region has a fairly specific technical role for its support services contractor, who coordinates strategic planning and technical review efforts, and prepares technical RFPs. About $15 \%$ of the annual budget in the Northeast is allocated to the SSC.

The Pacific Northwest, which allocated 22\% of its annual budget to its SSC in 1991 (slated at 25\% for 1993), employs the SSC in numerous activities. The SSC, in continual communication with the Pacific Northwest manager, maintains data for the program, assists in the preparation of RFPs, writes briefing materials for the task force on issues related to environmental concerns or legislative actions, attends 
conferences and trade shows as a representative of the Pacific Northwest, and performs site visits and statelevel program reviews for the Pacific Northwest.

The Pacific Northwest and Westem regions should consider reducing their level of dependence on support services contractors by bringing some of these activities in-house. While it may be useful in early stages of program development to farm out these activities to outside contractors, coordination and control could be enhanced by internalizing some of these activities.

\subsection{LESSONS LEARNED}

- The five regional programs have similar program planning structures.

Each of the five regional programs has a planning committee that helps determine programmatic goals, objectives, and activities. Each of the regional programs also has subject-specific technical advisory groups.

- RBEP program planning is highly participatory and has particularly strong involvement of state bioenergy representatives.

Interagency participation and industry involvement is characteristic of all five regional programs. Four of the five regions place state bioenergy representatives on the planning council. All five regions have industry input into the planning process, and two of them place industry representatives on the planning council. The regional programs have also made an effort to involve the managers of the other regional programs in their planning and project selection processes.

- Technical advisory groups in each region have strong industry input and have helped insure a portfolio of projects that is adapted to regional needs.

In all regions, participation in the technical advisory group is balanced and broadly based, so that governmental, academic, and industrial viewpoints are incorporated into regional planning.

- Industry involvement in RBEP program planning, while strong at the technical advisory level in all regions, could be improved in the highest level planning committees.

While industry input is substantial in all five regions, there is direct industry representation in only one region, the Southeast. The other regions bring industry perspectives into program planning in a variety of ways, including placing industry representatives on technical advisory committees, informal discussions, 
networking activity by state bioenergy representatives, and through briefings by industry personnel during planning committee meetings.

- Host organizations have had a significant impact on the structure and activities of the regional programs.

All five regional programs receive funding from DOE through a host organization which has responsibility for operational management. These host organizations have influenced the structure and activities of the regional programs housed within them. The Northeast and Great Lakes, for instance, have planning councils composed primarily of state bioenergy representatives. In the case of these two regions, this has developed in part because of their linkages with regional governors' organizations. The Southeast and West, by contrast, have structures in which state bioenergy representatives have a less central role.

Host organizations have provided a variety of inputs for the regional programs. CONEG, the host for the Northeast region, has been especially active. It has helped the Northeast region develop linkages with state government, federal agencies, and non-profit groups. Host organizations in the West and Southeast provided vision in the early years of the program. By contrast, host organizations of the Great Lakes and Pacific Northwest regions have been significantly less visible in their promotion of their regional bioenergy program.

Host organizations have influenced the way in which the regional programs have supported technical development and deployment. The Northeast, housed with in the CONEG Policy center, has directed a great deal of its resources toward the development of policy documents to guide activity within the states. By contrast, the West and Southeast regions, which are housed within federal power marketing agencies, have dedicated a significantly greater percentage of their overall resources into technology development and deployment projects

- Flexibility in the composition of the planning council is constrained by organizational history and host structure. It is greatest in the Southeast, less in other regions.

The organizational flexibility of the five RBEPs is constrained somewhat by their historical structures and linkages with host organizations. Three of the RBEPs have planning committees which are made up in significant measure by state bioenergy representatives from the region. These relationships are reinforced by the nature of the host organization, by long tenure on the part of the planning committee membership, or both. Changing the composition of the planning council in a major way would require careful coordination and implementation. The Southeast region, which has a three year term of membership on the planning council, has the greatest flexibility to adapt the planning council to changing regional needs. 
- Investment in support services in two regions (West and Pacific Northwest) is considerable.

This may create problems of coordination and control, which could be prevented by reducing this reliance on outside contractors and expanding in-house staff responsibilities. The Northeast region, by contrast, employs support services in more specific tasks and invests a smaller portion of the regional budget in support services.

- Support for a network of state bioenergy representatives is one of the distinguishing characteristics of the RBEP.

Relationships with state agencies have been strong. All five regions conduct activities to maintain a network of state bioenergy representatives, although they do so in different ways. These means include providing technical assistance grants for general program support (Northeast and Great Lakes), funding spocific projects (Southeast), providing both (Pacific Northwest), or conducting resource assessments (West). As a result of this RBEP funding, state bicenergy representatives provide the RBEP with a nationwide network of agents who are responsible for communicating technical information and assisting bioenergy conversion. This network is one of the distinguishing characteristics of the RBEP. 


\section{PROJECT SELECTION}

The Regional Biomass Energy Program identifies and selects projects in similar, but distinct ways across its five regions. These strategies and procedures, as well as the nature and scope of projects selected, have evolved along with the regional programs as a result of changes in technology, the economic climate, program budgets, regional infrastructure, and increasing experience with project selection. These strategies, and their evolution, are described below.

\subsection{OVERVIEW OF THE PROJECT SELECTION PROCESS}

For purposes of discussion, we can characterize the project selection processes of the five regional programs and their associated State programs according to the three themes illustrated in Table 3.1: TopDown, Market Mechanisms and Entrepreneurial.

The Top-Down approach has been used by a majority of the regional programs: the Northeast, Pacific Northwest, and the Great Lakes programs. In this approach, the planning and technical advisory committees, in coordination with the regional manager, decide in detail the nature of the projects to be conducted. This gives regional program management maximum control over project design. While project concepts may come from a variety of sources, they are typically referred to a technical advisory group for evaluation and proposal development before being forwarded to the planning committee. An RFP process typically is then employed to select contractors.

While the Top-Down approach has a number of significant strengths, it needs to be managed to encourage broad industry participation in the RFP process. Because top-down project selection tightly specifies the work to be performed, it is vulnerable to a tendency to define project terms so tightly that the breadth of potential contractors is restricted. Programs using a Top-Down approach need to set up processes to insure broad participation in the planning process as well as broad notification of potential bidders. Participation in the planning process in those regions using a top-down approach has been enhanced by industry representation on the technical advisory committees. Notification of potential bidders has been accomplished through the Commerce Business Daily, publication in Biologue, networking by state representatives, and, in the Northeast, the ongoing maintenance of a potential bidders list.

The Market Mechanisms approach is a more open approach to project selection. It involves defining general activity areas for RFP's, rather than tightly defining them, as in the "top down" approach. In addition, both the project and contractor are selected by the RFP process. The success of this approach is critically dependent on the quality of project proposals submitted in response to the RFP, and it may take several years 
Table 3.1 Comparison of Approaches to Project Selection

\begin{tabular}{|c|c|c|c|}
\hline & $\begin{array}{l}\text { Northeast, Great Lakes, } \\
\text { Pecific Northweet }\end{array}$ & Southeart, Weat & $\begin{array}{l}\text { Most stute bioenergy } \\
\text { proprems }\end{array}$ \\
\hline & \multicolumn{3}{|c|}{$\begin{array}{l}\text { Project areas may be identified by regional management, planning committec, tochnical advisory } \\
\text { committec, or industry spokespersons. Project areas reviewed by technical advisory and } \\
\text { planning committees. }\end{array}$} \\
\hline & $\begin{array}{l}\text { Concepts for specific projects } \\
\text { are brought to rogional } \\
\text { management and the planning } \\
\text { committee by various } \\
\text { intereated parties. }\end{array}$ & $\begin{array}{l}\text { General project ectivity areas } \\
\text { are broedly defined. Specific } \\
\text { projects are identified as part } \\
\text { of the RFP review process. }\end{array}$ & $\begin{array}{l}\text { Projects identified by } \\
\text { entrepseneurial agent (e.8., } \\
\text { State bioenergy } \\
\text { representative). }\end{array}$ \\
\hline & $\begin{array}{l}\text { Projects are selected by } \\
\text { planning committec, with } \\
\text { support from the technical } \\
\text { advisony committee. }\end{array}$ & $\begin{array}{l}\text { Projects are selected } \\
\text { competitively as part of the } \\
\text { RFP review process. }\end{array}$ & $\begin{array}{l}\text { If agent has identified a } \\
\text { number of potential projects, } \\
\text { a formal or informal } \\
\text { screening process is } \\
\text { conducted. }\end{array}$ \\
\hline & $\begin{array}{l}\text { A formal RFP sulicitation } \\
\text { process is used to select } \\
\text { contrector. }\end{array}$ & $\begin{array}{l}\text { Formal RFP solicitation } \\
\text { process identifies good } \\
\text { matches between proposed } \\
\text { projects and contrectors. }\end{array}$ & $\begin{array}{l}\text { Contrector is often } \\
\text { determined by the seloction } \\
\text { of project. }\end{array}$ \\
\hline$+4 x$ & $\begin{array}{l}\text { Agents may suggest project } \\
\text { areas and identify project } \\
\text { concepts for exploration by } \\
\text { planning committee or } \\
\text { technical sdvisory committec. }\end{array}$ & $\begin{array}{l}\text { Can suggent strategic thrusts } \\
\text { and influence project area } \\
\text { identification. Can encourage } \\
\text { individuals to submit } \\
\text { proposals. }\end{array}$ & $\begin{array}{l}\text { Agent maintains contact with } \\
\text { industry, identifies best } \\
\text { prospect(s) for funding, and } \\
\text { shepherds a project through } \\
\text { the approval process. }\end{array}$ \\
\hline 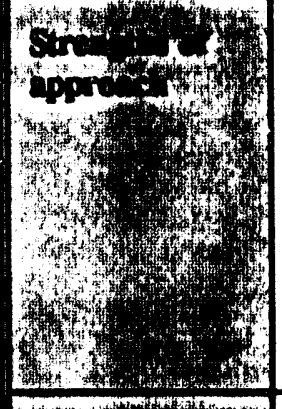 & $\begin{array}{l}\text { Maximum control over } \\
\text { content and quality of project } \\
\text { proposals. } \\
\text { Projects that would not } \\
\text { develop if left to market } \\
\text { forces can be pursued. } \\
\text { Process allows lead time to } \\
\text { bring in multiple parties and } \\
\text { leverage resources. }\end{array}$ & $\begin{array}{l}\text { Can bring in broad input from } \\
\text { industry, and enhance } \\
\text { industry acceptance and } \\
\text { participation. } \\
\text { If properly used, can help } \\
\text { insure projects are groundod } \\
\text { in economic reality. }\end{array}$ & $\begin{array}{l}\text { Maximum flexibility, } \\
\text { minimum red tape. Agent } \\
\text { with open playing field can } \\
\text { arrange multi-party } \\
\text { participation and arrange } \\
\text { leveraging. }\end{array}$ \\
\hline 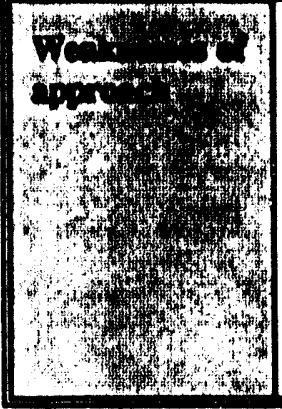 & $\begin{array}{l}\text { Depends upon active } \\
\text { involvement of program } \\
\text { management with industry. } \\
\text { Subject to selective bias of } \\
\text { planning committec. }\end{array}$ & $\begin{array}{l}\text { Critically dependent on } \\
\text { market forces. Quality of } \\
\text { projects is only as good as the } \\
\text { quality of proposals } \\
\text { submitted. Time limits for } \\
\text { response to RFP can } \\
\text { constrain leveraging \& multi- } \\
\text { party participation. }\end{array}$ & $\begin{array}{l}\text { Depends upon active } \\
\text { involvement of agent within } \\
\text { industry. Subject to selective } \\
\text { bias of agent. }\end{array}$ \\
\hline
\end{tabular}


to institute an effective RFP system. The Southeastem Regional Biomass Enersy Program and the Western Regional Biomass Energy Program both employ a market mechanisms approsch.

Several of the regions have experimented with verious appronches to project selection. When SERBEP got underway in 1983, it used a Top Down approsch, but switched later to a Market Mechanisms approach. The Pacific Northweat has had experience with a variety of approaches, and initiated a Market-Mechanisms RFP in 1993. The Great Lakes region will be employing such an approsech in 1994.

The State bicenerey programs which the RBEP supports have employed project identification and selection approaches independent of those employed for RBEP-supervised projects. Most State bicenergy programs employ an Entreprencurial approsch to the identification and selection of projects for funding by the Regional Biomass Energy Program. Through their network of contacts with in-state organizations, they identify project opportunities and may 80 to considerable effort to package a project proposal for presentation to their regional program. This approach, unfettered by administrative checks and balances, can provide an opportunity for an active and creative state bioenergy representative to identify more cost sharing opportunities and set up more projects than might bs possible under conditions of greater structure.

\subsection{COMPARISON OF SELECTION PROCESSES ACROSS REGIONS}

In comparing project selection processes across regions, we discuss the following: the general approaches used, project area identification, contractor selection, the selection of the management services contractor, the use of public solicitations, and the selection of state projects.

\subsubsection{Overview of Regional Programs}

General features of project planning processes are illustrated in Table 3.2. All of the five regions of the RBEP have a planning committee to help establish progranmatic goals and objectives. All five have subject-specific working groups with industry participation. One region (the Southeast) places industry representatives on its central planning committee. Strategic planning reviews have recently been conducted in three of the five regions.

In the Northeast and Great Lakes regions, a regional council of govemors provides structure for the regional program. Within the context of these councils, the State bioenergy programs and the State bicenergy representatives take on a more central role in planning within the regional program.

Across all five regions, most informational projects are specified in some detail by the planning committee and RFPs are issued to identify contractors to perform specific statements of work. In contrast, the regions vary significantly in the way in which they treat contracting for technology demonstration projects. 
Two of the regional biomass programs (Southeast and Western) use a Market Mechanisms approach to identify good projects, while the remaining three (Northeast, Great Lakes, and Pacific Northwest) employ a top-down approach, in which projects are specified by a planning committec and contractors are selected on the basis of a bidding process open to the general public. In the Weatern and Southeast regions, contractors for technology demonstration or dovelopment projects are identified as a result of responses to a relatively undirected RFP that specifies general areas of sctivity but not specific projects. In the Northeast, regional funds have not been apecifically directod toward tochnolosy demonstration and development projects; these types of projects have been undertaken by the States. Technology development projects in the Great Lakes region are fower in number and fairty tightly specified prior to the issuance of an RFP. In the Northwest prior to 1989, contractors were identified for closely specified regional projects via an RFP process; since 1989, the selection of contrectors for projects findod outside of the technical assistance grants to the States has been conducted by the States themselves.

\subsubsection{Praject Aren Identifiention}

Each of the regional programs has employed a planning committce along with subject area technical advisory eroups to help identify programmatic goals and project areas. In three regions (Northeast, West, Northwest), these groups have been involved in an intensive strategic planning review that has brought industry and agency representatives together to identify goals and suggest project areas.

Beyand these similarities, however, are some significant differences. In the Northeast, most regional projects are recommended by state representatives on the steering committec. These proposed projects are subjected to a selection process by the steering committee. Selected projects are then closely defined by the steering committee before the development of an RFP to identify a contractor. In the Great Lakes region, project ideas are typically developed by members of the Technical Advisory Committee and are brought into the working groups of the advisory committec in the form of brief project outlines. Project ideas that survive initial discussion are then fleshed out by the submitter, rated by the working groups, and voted on by the steering committec. An RFP is then issued for contrector selection. In the Southeast, general program areas are established through discussions within the planning council. An RFP is issued to solicit projects in these program areas. These projects are then evaluated by the peer review teams and voted on by the steering committce.

The planning committee in the Northwest has played a number of roles over the history of the program. Between 1981 and 1987, the regional program was guided by a steering committec composed of representatives from various agencies, such as BPA, EPA, USFS, BLM, as well as state government. During 
this period, mny of the projects conducted by the regional program (0.8., dovelopment of advanced logging techniques, teating of emissions arising from slash buming, assessments of logging residue) were developed by members of this seering committee. Interngency agreements were doveloped between the regional program and these agencies. In many cases, the lead agency also served as a contractor to perform the work. During this period the planning committee was assistod by a task force that supported it with technical information and project suggeations.

Involvement by memben of the steering committee declined during the mid-1980's due to a variety of factors, and in 1987 the group ceased to meet as a planning body for the regional program. Between 1987 and 1990, the tack force began to assume the responsibilities of the former steering committec. In 1990, as part of the dovelopment of a strategic planning proceas in the Pacific Northweat region, four subject area working groupe were cetablished to apport the tack force. During the time frame of 1989 through 1992, most of the projects conducted by the Northweat region were identified by members of the tuak force.

Role of Stratedic Planuine. Three regions (Northeast, West, Northweat) have undergone strategic planning exercises that have influenced the seloction of projects. The Northeastem region undertook extensive review of its activity areas and strategy in 1984 and 1989, and initiated another review in 1993. The planning task force in 1984 recommended broed strategic outlines that are still being followed today. These include involvement in the setivity aress of MSW, commercial and industrial wood conversions, domestic wood stoves, and forest resource management.

In 1990, as part of a reviow of goals and strategies, the Northwestem region established four working groups to assist in stratesy development. These working groups targeted the activity areas of technology transfer and education, municipal solid wate, biomass derived liquid fuels, and residential wood combustion. For each of these areas, the working groups developed specific project recommendations that described project purposes, tasks, schedules, funding, performance criteria, and expected outcomes.

In the Westem region, program managers docided to implement a strategic planning process at the time of program inception. This attention to the planning process has helped the Westem region develop a significant level of formality in the planning process, along with quantitative and explicit criteria for the project selection process. The time required for the development of explicit procedures and practices may also have contributed to a significant time lag between the inception of the program and the issuance of the first Program Opportunity Notice for the solicitation of project proposals from the region. 
Table 3.2 Praject Area Identification and Praject Selection

\begin{tabular}{|c|c|c|c|c|c|}
\hline $\begin{array}{l}\text { Central planning group/stcering committee that identifies } \\
\text { prorermmatic thrusts and project areas }\end{array}$ & $\mathbf{x}$ & $\mathbf{x}$ & $\mathbf{x}$ & $\mathbf{x}$ & $\mathbf{x}$ \\
\hline Industry representation on steering committee & & $\mathbf{x}$ & & & \\
\hline Subject-specific working proups with induetry perticipation & $\mathbf{x}$ & $\mathbf{x}$ & $\mathbf{x}$ & $\mathbf{x}$ & $\mathbf{x}$ \\
\hline Recent Strateric plemnin reviow procese & $\mathbf{x}$ & & & $\mathbf{x}$ & $\mathbf{x}$ \\
\hline $\begin{array}{l}\text { Regional council of govemors with significent influence on the } \\
\text { directions taken by toering committee }\end{array}$ & $\mathbf{x}$ & & $\mathbf{X}$ & & \\
\hline
\end{tabular}

\subsubsection{Contractor Selection}

In each region, contractors are selected on the basis of a bidding process open to the general public. Informational projects are typically apecified in some detail by the planning group and RPFs are issued to identify contractors to perform specific statements of work. In contrast, the regions vary significantly in the way in which they treat contracting for tochnology demonstration projects. In the Westem and Southeast regions, contractors for technology demonstration or development projects are identified as a result of responses to a relatively undirected RFP that specifies general areas of activity but not specific projects. In the Northeast, regional funds have not been specifically directed toward technology demonstration and development projects; these types of projects have been undertaken by the states. Technology development projects in the Great Lakes region are fewer in number and fairly tightly specified prior to the issuance of an RFP. In the Northwest prior to 1989, contrectors were identified for closely specified regional projects via and RFP process. Since 1989, the selection of contractors for projects funded outside of the technical assistance grants to the states has been conducted by the states themselves.

\subsubsection{Management Support Services}

Three of the five regions employ an SSC to assist the program manager in the development and implementation of strategic plans (Table 3.3). In each of these regions the support services contractor is selected by means of a formal RFP, and notices conceming the RFP are published in the Commerce Business Daily. In the two regions (Western and Pacific Northwest) in which the regional biomass program is housed 
within a federal power marketing agency, the selection of the contractor proceeds under a stringent set of federal procurement rules. The Northeast, while not bound by these standards, makes a significant effort to distribute the RFP for this contract to interested parties, seeking out new bidders on an ongoing basis and culling its bidder's list annually.

Table 3.3 Contractor Selection Processes for Regional Projects

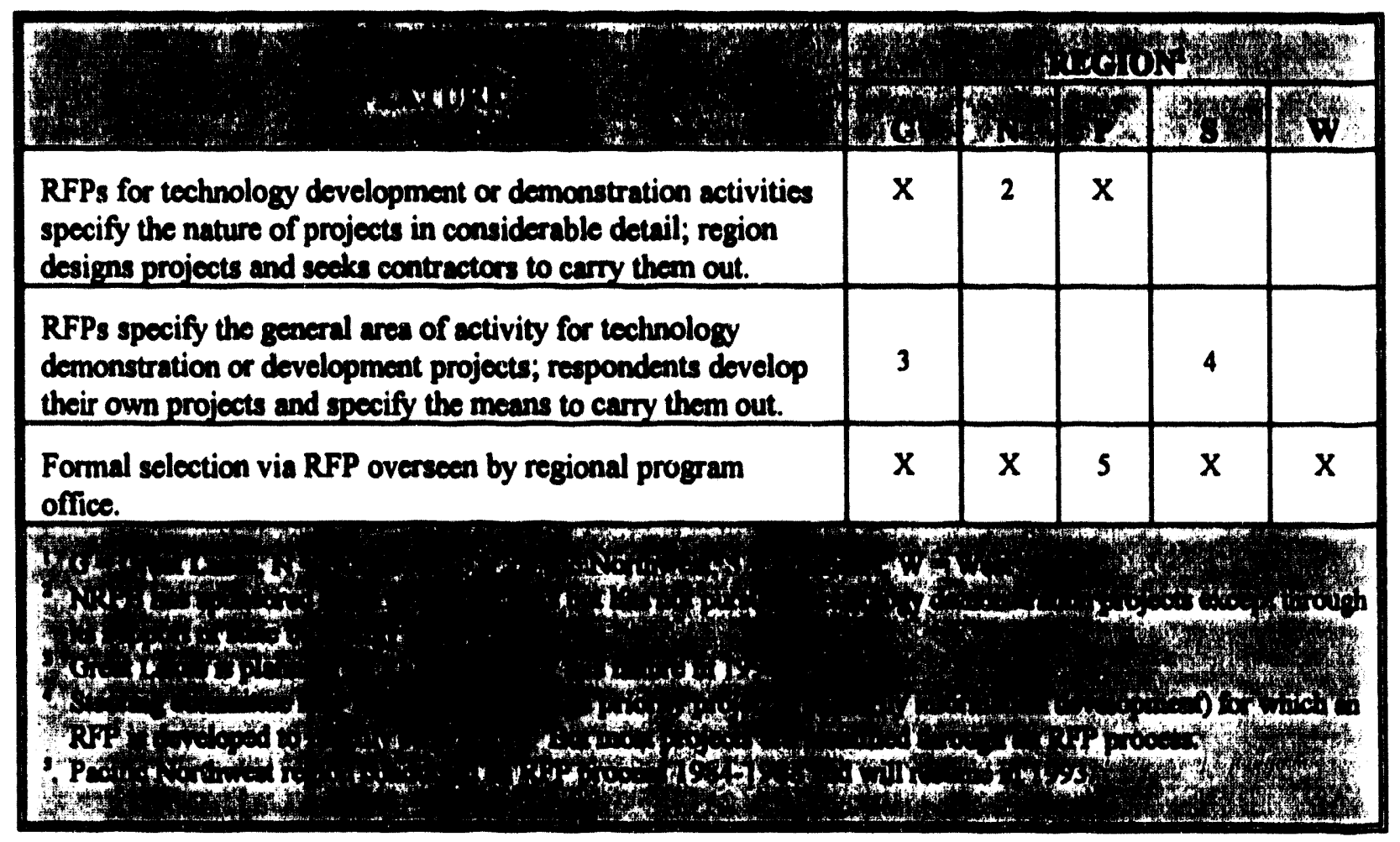

\subsubsection{Public Solicitation Processes}

While project aress are identified and selocted in each of the regions by the respective regional manager with the assistance of policy and technical advisory groups, regions have different procedures for selecting the specific projects that will be funded (Table 3.4). Four of the five regions have routinely used RFPs in the last five years. Two regions have searched widely and publicly for project ideas, while three regions have narrowly defined their project areas.

The RFP process in the Southeast and Westem regions is structured to solicit competing technology development projects and to select potential contractors. In the Northeast, the RFP process is used to select contractors for closely defined informational projects, while in the Great Lakes region RFPs are used to identify contractors for both informational projects and a relatively small number of technology development 
projects. In the Northwest, the RFP process has been used at various times (1984-1988) to identify contractors for tightly defined technology development and information development projects. The annual bicenergy project RFP was not employed from 1989-1992 but will be reinstated in 1993.

Table 3.4 Use of Public Solicitation Processes

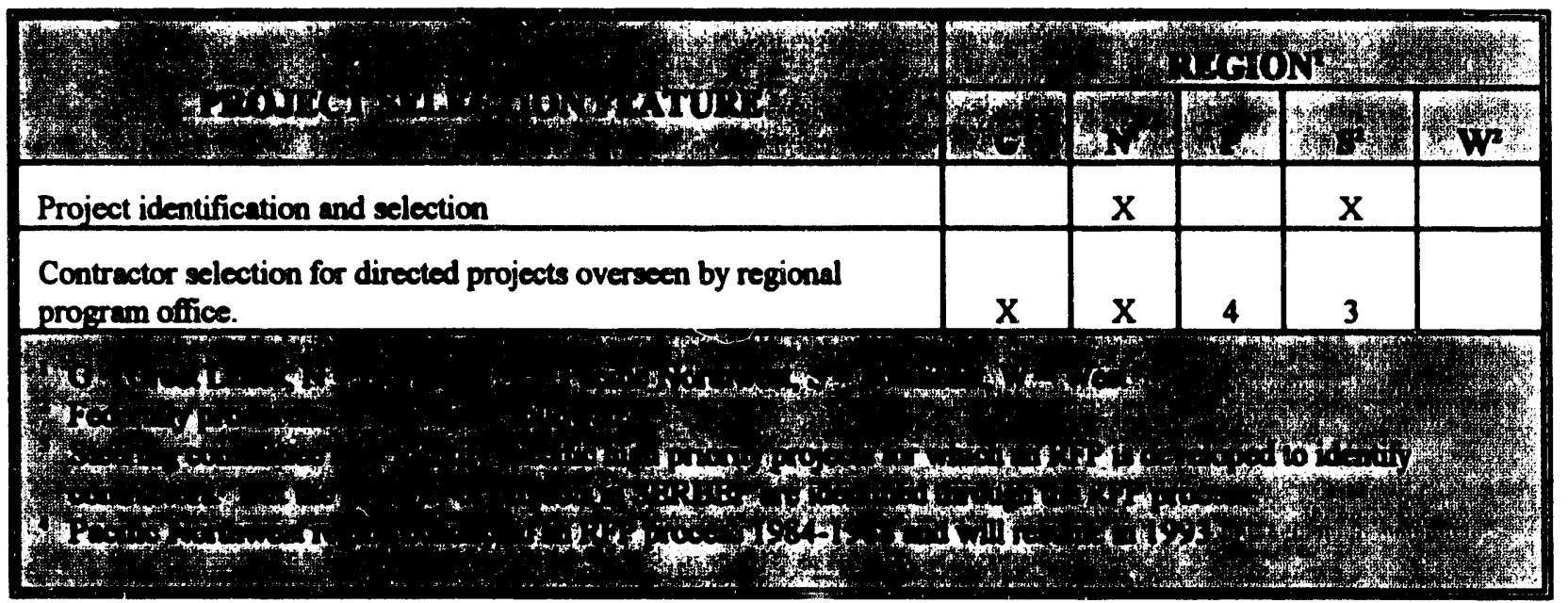

\subsubsection{The Selection of State Projects}

In all five regions, the regional program supports bioenergy projects that are conducted by state agencies (Table 3.5). The Northeast and Great Lakes regions provide technical assistance grants to states for general program support. The Pacific Northwest provides state projects but does not provide general program support. The Western program supports states in a more limited fashion, primarily to conduct resources assessments. As a result of this RBEP funding, state bioenergy representatives provide the RBEP with a nationwide network of agents who maintain responsibility for communicating technical information and assisting bioenergy conversion. 
Table 3.5 Selection of State Projects

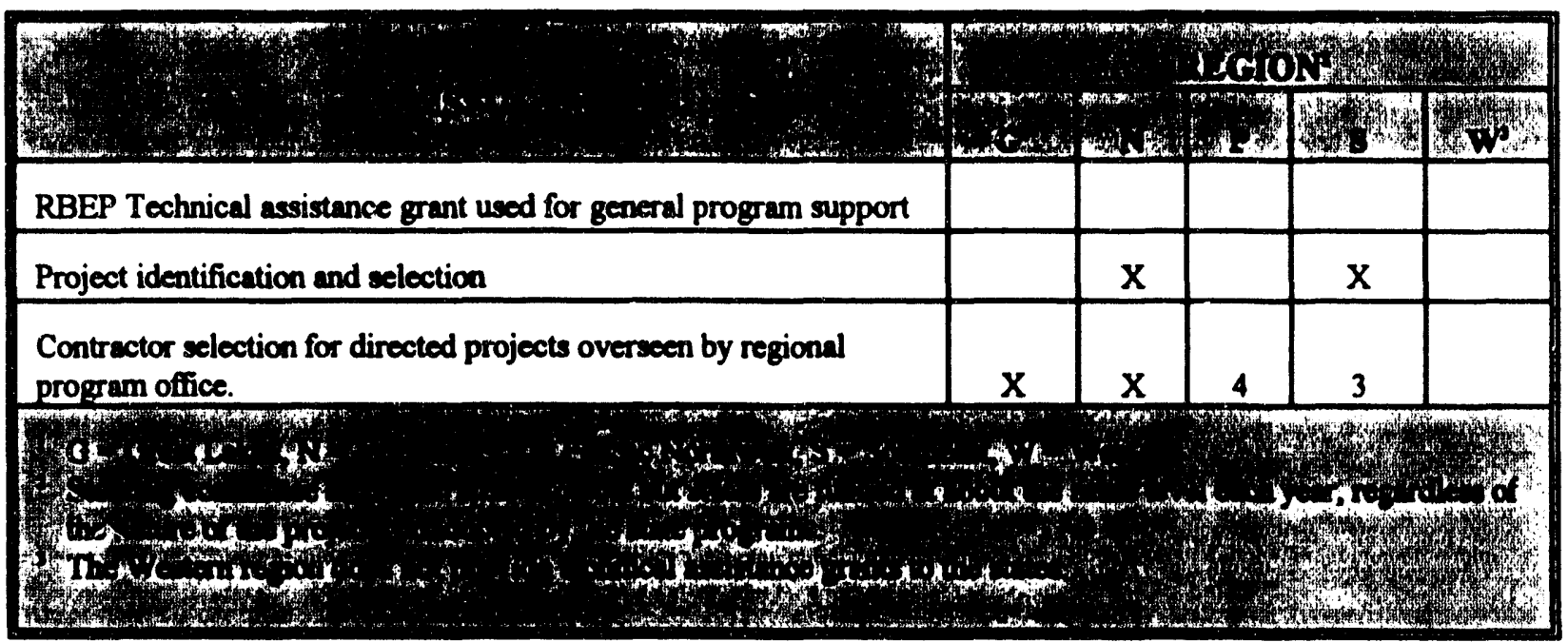

Since there is significant variation in the magnitude and character of state bicenergy efforts, a variety of relationships have arisen between the regional programs and their member states. The Northeast region provides a dramatic illustration. While the state of New York typically budgets over \$2 million annually for bioenergy projects and may conduct dozens of projects, other states in the Northeast might not have any bioenergy program at all without the sponsorship of the Regional Biomass Energy Program. In recognition of this difference in state capability, NRBP receives a highly detailed proposal each year from the state of New York and accepts proposals from other states in which no projects are conducted and the primary biomass energy activity conducted within that state is the support of an individual who can provide information and technical assistance to industry.

In the Great Lakes region, the stecring council is involved in the selection of state projects. However, the states in the region are funded more or less at the same level each year. Important criteria in the recommendation of state projects are the degree of state inter-agency participation and in-kind resource match, the technical feasibility of the project, the breadth of anticipated impacts, and the magnitude of conventional fuel savings.

In the Northeast, each state negotiates a contract with the regional program that specifies the nature of the bioenergy projects that will be conducted over the coming year. Some of he states (e.g., New York) may decide to direct NRBP's financial contribution into a specific project or projects. Other states may use the NRBP support for staff salaries and may choose projects that require investments of staff time rather than 
financial resources. Depending on the nature of the state's bioenergy program, these contracts may or may not specify the proportion of NRBP's technical assistance grant that is allocated to specific projects.

The Pacific Northwest has had a number of types of interactions with the states in the region. It supports each bicenergy program with a technical assistance grant, which is used for general program support and may be directed towards specific projects. In addition, it has from time to time funded specific projects administered by the five states in the region.

In the Southeast, the regional program promotes hardware installations and demonstration projects over resource assessments and informational projects. Potential demonstration projects come to the attention of the state bioenergy coordinator in several ways, then are proposed as state projects. From time to time, promising projects that are not selected by the regional RFP process are referred to the states as potential projects.

The Western region does not have a state project program per se. I has supported a resource assessment project, coordinated by the region's support services contractor (NEOS), that has employed an agency within each state in the region to tally bioenergy resources.

\subsection{PROJECT SELECTION CRITERIA}

Across the five regions there are strong similarities in the systems that are used to rank and select projects. Each region evaluates the strengths and weaknesses of proposals according to a set of criteria and then ranks the projects against each other. Each region also conducts a post-scoring discussion that functions as a "reality check" on the outcome of the scoring process.

The five regional programs describe their selection criteria in different terms, but in essence many of the same criteria are used. Financial criteria, for example, have been expressed in terms of "net present value," the anticipated "payback period," and the likelihood of "project benefits commensurate with cost." In order to facilitate comparison, the selection systems of the five regions were mapped onto a standardized set of selection criteria that include the following: market potential, market readiness, financial justification, capabilities of project participants, cost sharing, multi-agency participation, use of low or negative value feedstocks, and environmental implications. Each of these is discussed below.

Market Readiness. Since a primary function of the regional biomass energy program has been to demonstrate bioenergy applications, it is not surprising that market readiness would be an important criterion for RBEP project selection. The degree to which the regions have implemented this criterion in the identification and selection of project, however, varies considerably. 
Two regions have emphasized market readiness or the anticipation of near-term market impacts in their project selection processes: the Southeast and Northwest. In the Southeast, market readiness has traditionally been an important factor in project selection. This was such a strong characteristic of the selection system for several years that the project portfolio was heavily weighted with near-term, direct combustion projects. With the approval of RBEP Headquarters management, the region decided to create a more balanced portfolio by shifting emphasis away from near-term demonstration so that its portfolio is further from the market than was the case in the program's early years.

The Northwest program considers market readiness one of its more important criteria for technology demonstration projects, and expresses the criterion in terms of "short lead time." While the region has sponsored state projects with both near-term and long-run potential during the past five years, a significant number of the state projects involve efforts with low degrees of technological risk and market-ready technology.

The Northeast region, by contrast, has chosen to direct its efforts towards market conditioning, which can rarely be expected to have an immediate impact on the marketplace. This represents a tradeoff for the Northeast between activities that can be expected to have an immediate market impact for those that confront barriers to the application of biomass energy technologies. In the long run, efforts by the Northeast region to remove or minimize barriers could have significant impact.

It should be kept in mind that an emphasis on "market readiness" as a selection criterion does not directly translate into investment in market-ready technologies. The Great Lakes region, while considering market readiness one of its most important project selection criteria, has also been developing a focus on ethanol production methods. In practice, this means that considerations of market potential have taken precedence over market readiness as regional emphasis has shifted towards technology development projects with an expectation of long-run rather than short-run impacts.

In the Western region, in which market readiness was the second most important criterion (with a weighting of $16 \%$ ), the first round of Program Opportumity Notices produced a set of projects whoise estimated time to market is five years or greater. Application of the selection process to the pool of inconing proposals resulted in the selection of a set of projects that involved more sophisticated technologies with somewhat longer-run impacts. This outcome was also influenced by the nature and distribution of biomass resources in the arid West. Thus, this region appears to have fewer opportunities for bioenergy projects with short-term payback. 
Market Potential. Selecting projects with high market potential frequently means accepting projects at an earlier stage of development. These earlier stage projects may face significant market barriers and require additional development. The regional programs have taken different approaches concerning this selection criterion.

By emphasizing near-term projects with proven technology, the Southeastem region has selected few projects that promise dramatic long-run market impact. In keeping with this mindset, the Southeast has avoided gasification processes, which still must resolve a number of technical issues. This region, however, has also taken a proactive role in the development and promotion of anaerobic lagoons systems for the production of methane, which promise a significant impact. The trend over the last two years has been to include more longer-nun projects to draw in some tochnologies with higher market potential that are at present a little farther from the market.

The Northwest and Westem regions take intermediate positions in terms of their emphasis on market potential. The Northwest has sponsored both long-run, high impact projects (e.g., biodiesel), as well as a number of pellet plants and direct combustion installations. The Western region ranked market potential as its third most important criterion (weighting of $15 \%$ ) in its first round of solicited projects. Some of the Western region's projects (e.g., the Craytec gasifier) might have significant long-run impacts if they are successful.

In deciding to focus the efforts of the Great Lakes program on ethanol production, the Great Lakes has chosen a programmatic thrust that emphasizes the significant market potential of ethanol. As previously mentioned above, this also represents a decision to invest in technology that cannot be considered market ready or commercially viable at the present time.

In the Northeast region, regional projects are designed to develop information rather than demonstrate technology. Projects are chosen that may increase use of biomass energy by resolving informational problems or establishing standards and benchmarks. Market impact is anticipated to occur in the long-run as a result of market conditioning.

Economic Justification. The importance of economic justification as a criterion in project selection varies with program goals, the type of projects being considered, the financial soundness of the pool of proposed projects, and the maturity of the project selection process.

In the Northeast, for instance, the level of emphasis on economic justification is influenced by both program goals and tradition in the types of projects undertaken. Regional projects are information based, and calculations of "payback period" are not especially relevant. Accordingly, while the region accesses, in a 
qualitative way, whether project benefits are likely to be commensurate with project cost, it directs less attention towards considerations of financial justification than other regions.

In the Northwest, despite the abundance of biomass resources, bioenergy facilities have had difficulty justifying themselves on a cost basis. In its earty days, the Northwest bioenergy program conducted numerous feasibility studies, most of which resulted in an unfavorable assessment of the relative costs of bicenergy conversion. This operating environment has persuadod the Northwest to emphasize the economic justification of bioenergy projects as well as to specify cost factors more precisely and in more different ways than the other regions. In the Northwest, "present value of life cycle cost" is an important criterion. Furthermore, cost effectiveness relative to opportunity and need is also assessed. These criteria are being implemented in the selection of state projects funded in part with RBEP pass-through funds.

The Southeast and Great Lakes regions both place an intermediate importance on economic justification, but do so for different reasons and to difierent effect. In the Southeast, emphasis has been placed on near-term projects that become part of ongoing operations for firms. In the funding of direct combustion projects especially, projects that were justifiable in terms of market readiness also tended to produce acceptable financial payback. All proposals for demonstration projects in the Southeast include case flow analyses and payback information. The Southeast anticipates that it will be looking more closely at payback in future efforts at project selection.

While the Great Lakes region considers economic justification one of the more important criteria in project selection, financial justification must be considered to be subordinate to the desire to achieve the market potential of ethanol production technology, since the ethanol technologies of the Great Lakes are not ready for market entry.

In the Westem region, cconomic criteria were ranked as the 8th most important criterion in PON-1 (the region's first Program Opportunity Notice), with a weighting of $7 \%$. This weighting was reduced to $5 \%$ for PON-2. The region has docided not to emphasize short-term payback potential. Potential projects with rapid payback characteristics appear to be in short supply in this region.

Degree of Cost-Sharing. Differences in regional infrastructure and in the historical development of the regional programs account for much of the difference in approaches to cost sharing between regions. The Northeast region appears to devote more attention to the development of cost-sharing than any of the other regions. located in Washington, D.C., it is able to maintain contact with national headquarters offices of numerous agencies and foundations and has opportunities to put funding packages together. Since it is housed within the Coalition of Northeast Governors, it not only has good access to the executive branches of state 
government throughout its region, but an ability to issue contracts rapidly also helps it become the lead organization in cost-share projects. For these reasons, the Northeast pays close attention to the development of cost sharing. An attempt to identify potential sources of cost sharing takes place at the time of initial discussion of projects, and becomes part of the project proposal.

In the Northwest and Southeast, the amount of proposed cost sharing is a prequalification criterion. Proposals with less than the specified amount of cost sharing are considered to be non-responsive. The Northwest program has a tradition of emphasizing cost sharing. Early in its history, it conducted most of its activities as interagency agreements with larger and deeper-pocketed agencies such as the U.S. Forest Service, the Environmental Protection Agency, and the Bureau of Land Management. These agencies brought significant amounts of external funding into Northwest RBEP projects. While the Northwest has a cost sharing tradition and requires a threshold level of cost sharing in proposed projects, it does not emphasize cost sharing ratio as a project selection criterion. The Southeast has also established an amount of cost sharing as a prequalification criterion.

Like the Northeast, the Great Lakes region specifies in some detail the projects that will be conducted as regional projects. Yet it does not attempt to draw together potential cost sharing partners prior to the decision to proceed with regional projects. Instead, it evaluates potential contractors based on the degree of cost sharing which they can product. In the Great Lakes region, cost sharing, while not a project selection criterion, becomes a criterion in the selection of contractors.

The importance of cost sharing has changed dramatically in the Western region between its first and second Program Opportunity Notices. Cost sharing was the 8th most important criterion in PON-1 (weighting of $8 \%$ ), but became the second most important factor in PON-2. The magnitude of this change is indicative of the greater importance being place on cost sharing by governmental agencies at several levels and a degree of experimentation with the project selection process.

Participation of Multiple Organizations/Agencies. The regions differ significantly in terms of the degree to which they have explicitly selected projects based on the participation of aultiple organizations or agencies. This can partly be attributed to the linkage between cost-sharing and multi-party participation. If a region specifies a cost-sharing ratio, it insures a certain amount of multi-party activity in its projects. And it may not deem it necessary to specify multi-party participation as an explicit criterion for project selection. Other reasons for these differences are rooted in interregional differences in the way projects are proposed and developed, in orientation towards coalition building, and in the use of public solicitation processes. 
When projer is are identified by the regional steering committce or planning council, the stecring committee may be able to apply their collective knowledge and networking skills to the task of building a coalition to support a proposed task. The development of broad, multi-party support can then become a central criterion in the project selection process. This approach has been employed actively by the Northeast region and was used extensively by the Northwest region to fund resource assessments and environmental studies earty in its history. By contrast, when public solicitation processes are used to identify projects as well as contractors, the responsibility for the development of multi-party participation rests on the developer of the proposal. In this context, it may be difficult for proposers to organize sigrificant multi-party participation, and regional program might be wise not to overemphasize multi-party participation.

To regions, the Northeast and West, give considerable emphasis to multi-party participation in their project selection. The Northeast region, with a tradition of coalition building and multi-party participation, attempts to build coalitions around proposed projects before they are voted on by the steering committee. It places a high level of importance on multi-party participation, reflected in the nature of support its projects have received. In the Western region, participation of multiple organizations was the highest rated criterion (with a weighting of $20 \%$ ) in PON-1. In order to give more weighting to other project features such as contractor capabilities, the importance of this criterion was dramatically reduced in the development of PON2.

Three regions choose not to emphasize multi-party participation in their project selection criteria. Relatively little attention is directed toward the development of multi-party participation in the Southeast, where it is assumed that multi-party participation will follow as a result of cost-sharing criteria and the adoption by the state energy offices of positive attitudes toward multi-party participation. Multi-party participation in the Great Lakes region serves as a criterion at the contractor selection phase rather than in project selection.

Use of Low or Negative Value Feedstocks. Although RBEP wants to promote the use of low or negative value feedstocks, the current economic climate makes it unnecessary to explicitly specify this feature as a criterion in project selection. Biomass resources that have higher value uses frequently become unavailable for energy recovery and the price of competing sources of energy often makes it necessary for bicenergy projects not only to produce energy, but also to address environmental issues (e.g., waste disposal). This is clearly seen in the experience of several regions. Disposal issues are driving the Northeast region's interest in MSW. In the Northwest, where programmatic emphasis is shifting toward municipal biomass resources and away from logging and mill residue, the use of low value feedstocks is a de facto criterion even though 
it is not an explicit one. The same is true in the Southeast, where the economic driving factor of anaerobic lagoon systems as well as may direct combustion projects is the need to dispose of negative value feedstocks. Following similar logic, use of low or negative value feedstocks has become a prequalification criterion in the Western region for PON-2. The Great Lakes region, however, is an exception to the general pattern. They have moved away from an orientation toward low value feedstocks as they have begun to focus on ethanol from grain.

Environmental Implications. The importance of environmental considerations in project selection is important in all five regions. As a selection criterion, environmental implications appear to be given somewhat more emphasis in the Northeast, Great Lakes, and Northwest regions than in the West and Southeast. These small interregional differences may be attributed in part to the degree of scrutiny to which the regional programs are likely to be exposed. Environmentalist organizations are well organized and vocal in the Northeast, but less so in the Southeast.

Capabilities of Project Participants. It is difficult to compare the regions' use of "participant capabilities" as a selection criterion, because of differences in the processes of project identification, project selection, and contractor selection. Two regions, the Northeast and Great Lakes, have a two-stage selection process in which projects are first selected by the steering committee and then contractors are selected via public solicitation. While it is possible that this approach directs more scrutiny towards the characteristics of contractors, it is difficult to assess whether this process results in better or poorer matches between projects and the contractors selected to carry them out.

In the three regions in which project contractors are selected along with their proposed projects, contractor capabilities play an important role in the selection process. The Southeast region explicitly examines two subcategories of participant characteristics: a) project management and organization, and b) personnel, facilities, and other resources. In the Northwest, "project sponsor evaluation" includes the assessment of the amount of matching money, project risk, permitting risk, availability for tours, time frame, and commercial potential. The Westem region ranked contractor capabilities as its fourth most important criterion (12\%) in PON-1, and elevated this feature to the status of most important criterion for PON-2 (30\%).

Other Issues. In addition to these criteria, the Northeastern region seeks to establish itself as a lead organization in regional planning efforts. If the Northeast region identifies an important issue that it perceives needs to be addressed and determines that no other coordinating group is likely to take the lead, it may decide 
to undertake the initiative itself. The "leck of other coordinating groups to lead the effort" is a criterion in the

- Northeast, but is not present in the selection considerations of the other regions.

\subsection{LESSONS LEARNED}

- A variety of project selection methods have been employed, each with atrengths and wealonesses.

The RBEPs use three different project selection methods, each with its strengths and weaknesses. A top-down approach is employed by the Northeast, Pacific Northweat, and Great Lakes, the Southeast and West use a market mechanisms approach, and entrepreneurial methods are employed by most state bioenergy programs. Each of these methods can be effective, and each faces its own threats and opportunities.

The top-down approsch gives the planning committee the opportunity to control the content and quality of project proposals, as well as the opportunity to build multi-party participation and leveraging into the project design. This approsech is enhanced if the planning committee is actively involved with industry, and the program makes broad efforts to maintain an appearance of openness and participation.

The market mechanism approach can bring in broad input from industry, and enhance industry acceptance and participation. Because it is critically dependent on the quality of proposals received in response to RFPs, several years might be required to get such as system established. Time limits for response to RFPs can constrain leveraging and multi-party participation.

- Project selection takes place in stages that difier between regions using market-mechanism vs top-down approaches. Recommendations for change in project selection criteria must consider the overall system.

General project areas are identified in all regions by regional managers and planning committee members, and by industry spokespersons in some cases. These project areas are subjected to strategic review by the planning committec. In those regions employing a top-down process, concepts for specific projects are developed within the planning council or brought to it by various interested parties. Projects are selected by the planning council and a formal RFP solicitation process is used to select contractors. In those regions employing a market mechanism approach, general areas are established by the planning council, but the specific projects are selected competitively as part of the RFP process. Contractors are selected along with projects in this approach. Changes in project selection criteria can be expected to have different impacts in these different types of systems. 
- Public solicitations promote industry participation in all rejions. The market mechanism approach used by Southeast and Weat draws in more participation than the top-down approach used by the other three regions.

Public solicitation is used differcntly in different regions. In two regions it is used for project identification and selection, while it is used for contractor selection in the other three regions. Two approaches toward the use of RFPs for regional projects are seen within the RBEPs. Two regions (the Southeast and Weat) have searched widely and publicly for project ideas reflecting their market mechanism approach. The other two regions (the Great Lakes and Northeast) have narrowly dofined the project areas of their RFPs, reflecting their top-down approsech.

- The activities supported at the State level vary dramatically between regions and between states within regions.

RBEP support for state programs ranges from providing technical assistance grants for general program support (Northeast and Great Lakes), funding specific projects (Southeast), providing both (Pacific Northwest), or conducting resource assessments (West).

- Strons similarities exiat in project selection criteria as well as systems for ranking and selecting proposals.

The systems used to rank and select projects are similar across the five regions. Each region evaluates the strengths and weaknesees of proposals acoording to a set of criteria and a scoring system. In addition, each region conducts a post-scoring discussion that functions as a "reality check" on the outcome of the scoring process.

Although the five regional programs describe their project selection criteria in differint terms, many use the same criteria. These include: market potential, market readiness, financial justification, capabilities of project participants, cost sharing, multi-agency participation, use of low or negative value feedstocks, and environmental implications. Project portfolios are not determined primarily by selection criteria but by broader decisions by the regional programs.

- The Northeast's approach toward the establishment of leadership positions and multiparty participation is unique.

The Northeast region has attempted to identify project areas in which there is breadth of interest but in which no other agency has taken a coordinating role. 


\section{PROJECT PORTFOLIOS}

A review of RBEP funding allocations reveals a wide range of state and regional projects and activities. Projects encompass applied rescarch as well as technology development, feasibility assessments, demonstrations and information development and dissemination. Projocts are varied both in terms of the impediments being addressed and the time horizon of project impact. Many of the regional projects are long-term in nature with little or no immodiate regional economic benefits forescen. Others are designed to have more short-term irapects.

This chapler chenceterizes the project portfolios of the five regional programs in terms of the balance of projoct types, fecodtocks, tectmologies, market targets, and contractors. Reasonably complete information on regional projects is available for the period from 1987 to 1991. Information on state projects, on the other hand, is available only for the Pacific Northweat and Southeast programs. Thus, the portfolios of regional and state projects are discussed separately, and the analysis of state projects does not cover all five regional programs.

The chapter concludes with a section on leasons leamed. Appendix $D$ provides an overview of the project portfolios of each region.

\subsection{TYPES OF PROJECTS}

The projects conducted by the five regions may be grouped into a set of six broad categories: tochnology dovelopment and demonetration; technology assessments; information development and diffusion; resource assessments; cconomic, market or infrastructure analyses; and environmental analyses. These categories are briefly described below:

- Technology Development and Demonstration include those projects which are aseociated with the advamcement of bioenergy tochnologies, processes, and systems. This category includes site specific feasibility assessments.

- Technical Asecsament activities include those projects in which a set of technologies are compared against one another. Since most technology development or testing efforts contain a component of technology assessment, at least at the component level, this category contains those projects in which the comparison and evaluation of alternative technologies is a predominant component of the project design. The development of testing methods and standards for feedstocks is also classified as a technical assessment function. 
- Information Development and Dimusion includes a broad renge of activities, such as the development of modis materials, business guides, and doaign manuals, and the dissemination of information through conferences and workshops.

- Resource Acesaments include state and region-wide tabulations of available bicenergy resources.

- Economic, Market or Infrastructure Analyses are designed to produce information that can asiat project managers in targeting apecific audiences or in coping with institutional barriers. Directories of biomass facilities and equipment munufecturers are included in this catogory. Also included are assessments of rate of uage of bioenergy and the dovelopment of software tools to aseses cconomic impacts.

- Environmeatal Anabses include thowe projects whose primary focus is to address issues related to the preservation of the natural environment or to enable project managers to address regulatory issues.

Table 4.1 prewents the region-by-region breakdown of expenditures on regional projects, by project type. It illustrates the overall dominance of technology development and demonstrations projects, which represent $38 \%$ of the investment in regiond projosts. The remaining categories are quite similar in their level of funding.

Table 4.2 presents the breakdown of expenditures on state projects, by project type, for the Pacific Northwest and the Southeast programs. It documents an even greater emphasis on technology development and demonstration projects at the state level. In the Pacific Northwest they represent $76 \%$ of the investment in state projects (compared with $22 \%$ for regional projects), and in the Southeast they represent $75 \%$ of the investment in state projects (compred with $44 \%$ for regional projects).

\subsubsection{Technolosy Feasibility, Development, and Demonstration.}

Many of the regional projects are associated with efforts to enhance bioenergy tochnology and help it advance toward the marketplace (Table 4.1). The Southeast, Western, and Great Lakes regions have each invested more than a third of their regional project funds in technology feasibility, development, and/or demonstration projects, while the Northwest and Northeast have invested about one-fifth. In the Southeast and Western regions, this is accomplished via open-ended RFPs that set broad general guidelines for submitters of project proposals. In the Great Lakes and Northwest, these projects have been fairly tightly specified by a steering committee. In the Northeast these project activities consist of site specific feasibility studies. 
Table 4.1 Percent of Expenditures by Project Type: Regional Projects from 1987 to 1991

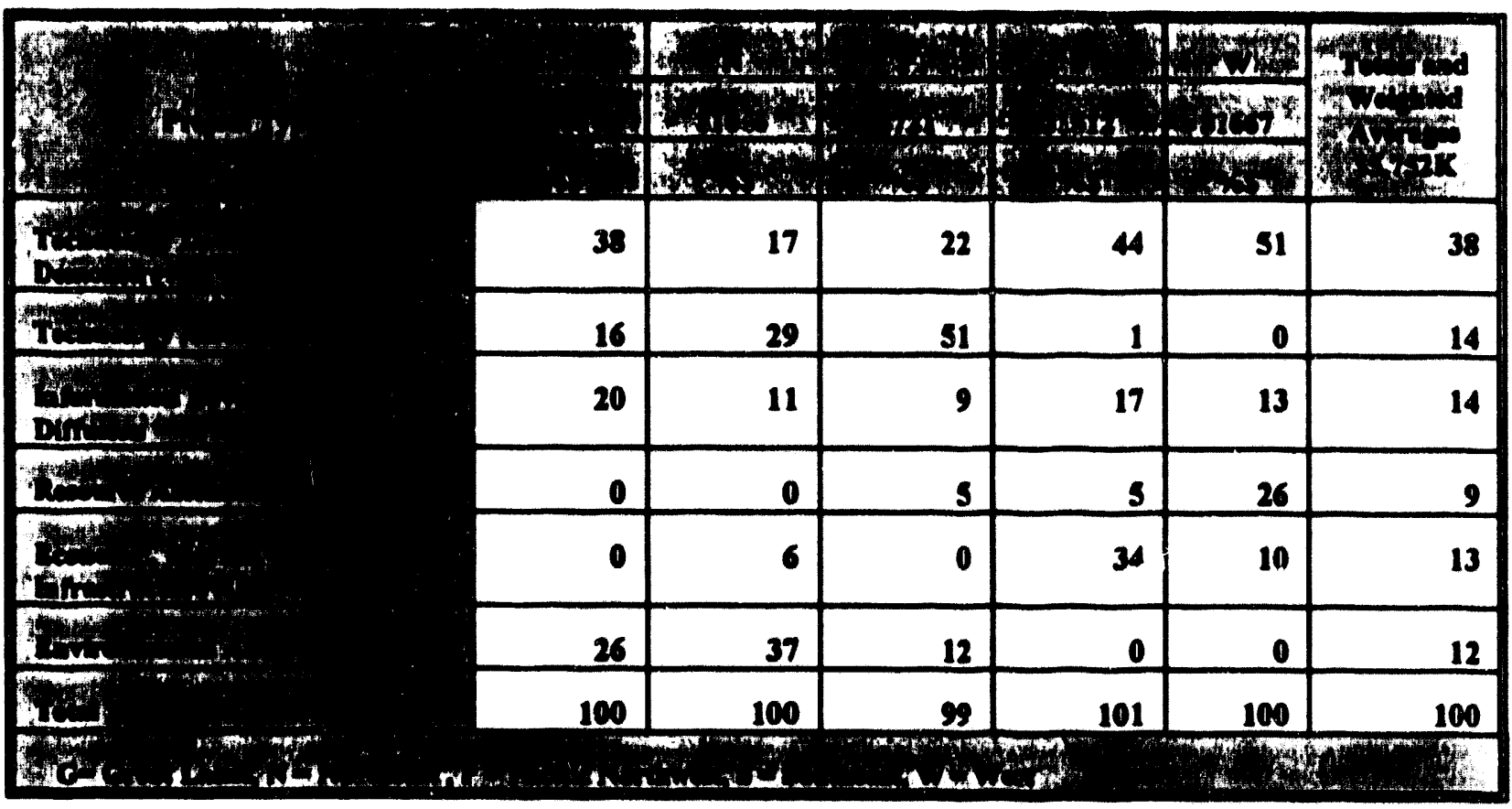

Table 4.2 Percent of Expenditures by Project Type:

State Projects from 1987 to 1991

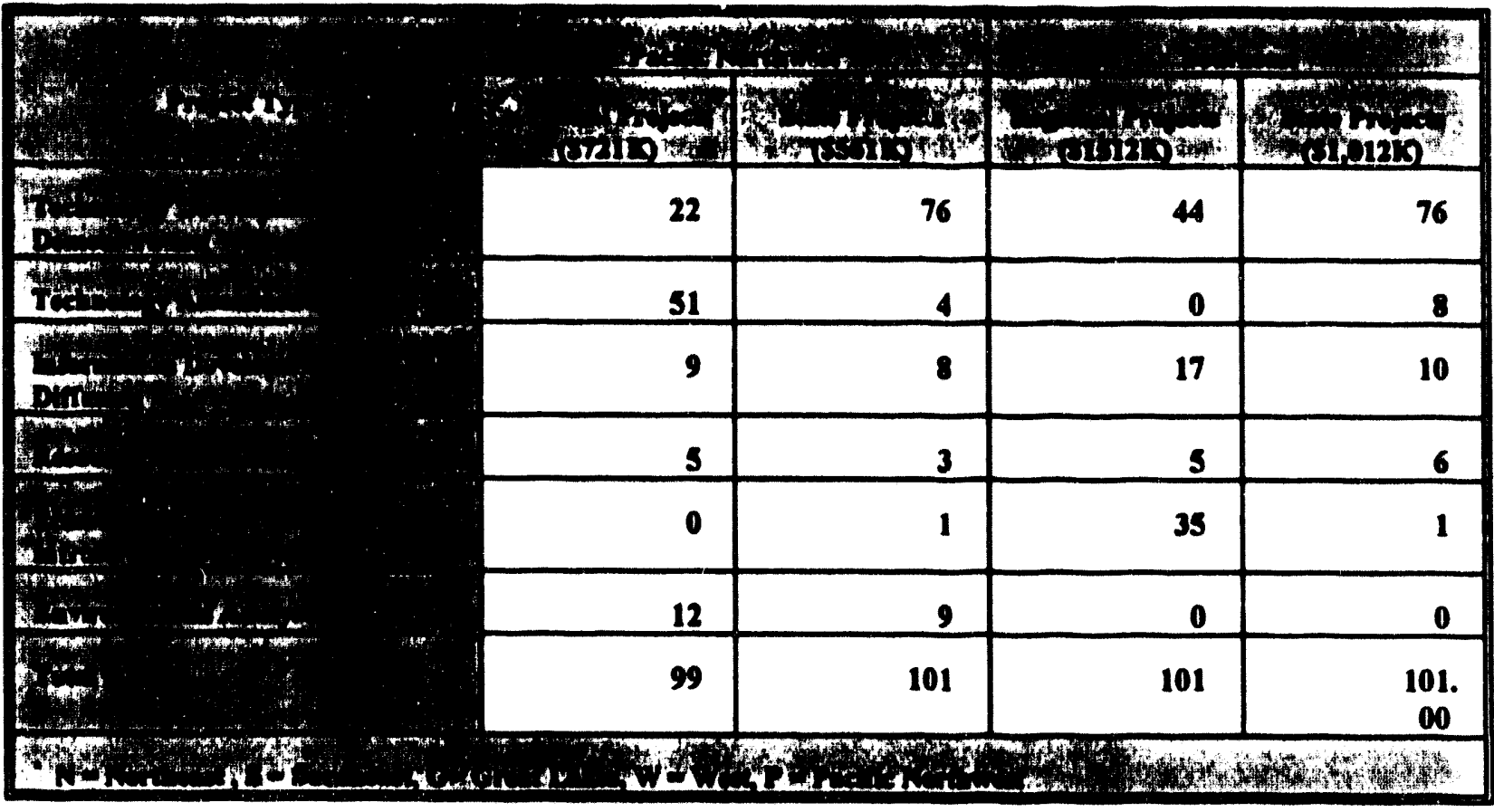


The regional programs have taken a number of approaches toward the use of RBEP funds to support the development and demonstration of bicenergy technologies. The Western region, for instance, has invested in projects that are in early stages of development. Among the projects in their PON-I, some $68 \%$ were development, design, or modeling projects, while $32 \%$ involved prototype testing or field studies, and there were no demonstrations of market-ready technology. Faced with a general lack of bioenergy resources relative to other regions of the country, the Western regional program is attempting to attain major advances in technology that will render bioenergy in the arid West economically feasible.

The Southeast region has been attempting to diversify its project portfolio over the last few years so that it would not be overweighted with direct combustion technologies and projects. As a result, it has moved away from the marketplace somewhat. Over the period of 1987-1991, 41\% of its technology development and demonstration projects involved technologies that might be considered market ready. Since $44 \%$ of its overall projects involved technology development and demonstration, this represents $18 \%$ of its overall portfolio of regionally based projects, the highest of any region.

In the other three regions, technology development and demonstration has been conducted by the member states but has not been actively undertaken by the regional program. During this five-year period, the "ethanol fleet" demonstration was the only project supervised from the Great Lakes regional office that could be considered a demonstration. Its support of membrane separation of dilute ethanol streams and its funding of heavy engines represent technologies that will require significant development and testing before they reach the marketplace. The Pacific Northwest funded the field testing of harvesting processes and equipment in 1987, but since then has delegated all technology development and demonstration activities to its member states. The Northeast has not conducted technology development activities.

State projects have, in general, tended to involve technology deployment rather than technology development. This is the case in each of the two regions in which RBEP dollars have been explicitly attributed to specific projects. In the Southeast, demonstration of market-ready technology was associated with $41 \%$ of the \$666K in RBEP funds invested in state projects. In the Pacific Northwest, some $43 \%$ of the \$469K of RBEP funds that have been directly attributed to specific projects have been invested in demonstration activities. 


\section{Table 4.3 Percent of Expenditures on Technology Development and Demonstration, by Developmental Stage: Regional Projects from 1987 to 1991}

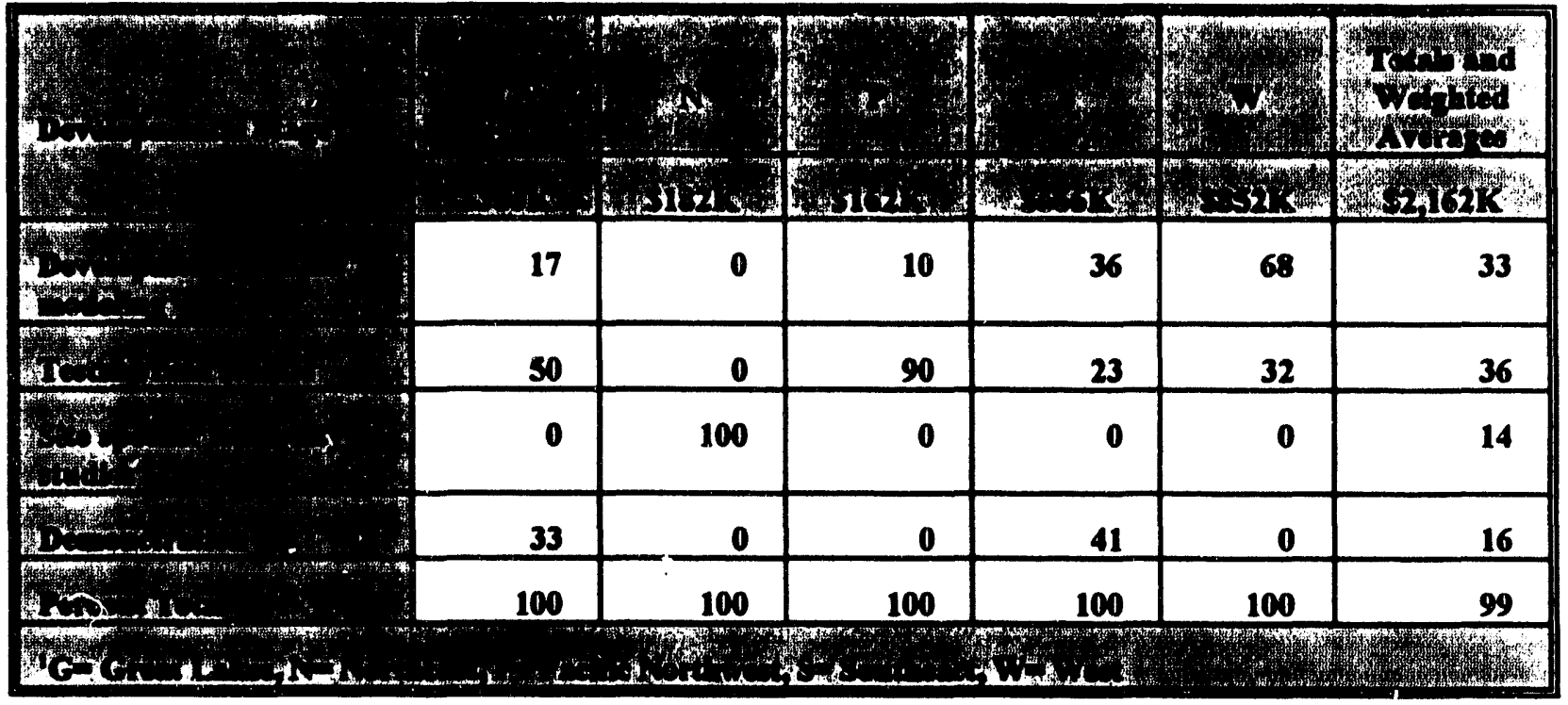

Table 4.4 Percent of Expenditures on Technology Development and Demonstration: State Projects from 1987 to 1991

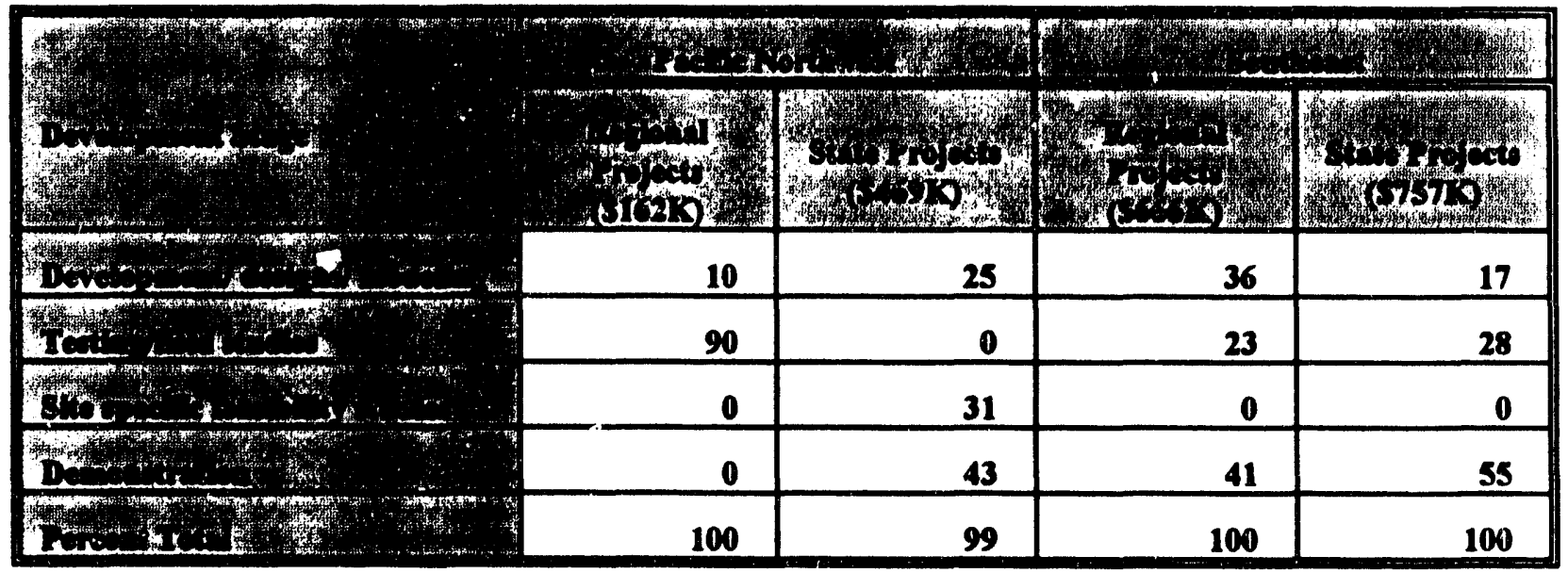

\subsubsection{Technology Assessments}

Because most technology development and demonstration efforts involve some technology assessment, especially at the component level, few projects were classified as being primarily technology assessment efforts. The regions vary significantly in the degree to which they have conducted these technology assessments. The Pacific Northwest program spent more than half of its regional project dollars on a multi- 
year assessment of biomass fuels, which attempted to develop data on combustion characteristics and establish fuel standards. This information is expected to be useful to potential users of waste wood and refuse derived fuel.

\subsubsection{Information Development and Difiusion}

The development and dissemination of information on biomass resources and technologies are major activities of the RBEP and its regional programs. Many of the barriers to bioenergy production and use (including perceived environmental risks and skepticism about technical and financial feasibility) are caused by information gaps and misinformation. Recognizing the noed for market conditioning through the provision of information, RBEP has invested a considerable amount of its resources in information-related activities. Regional projects that involve information development of diffusion represent between $9 \%$ and $20 \%$ of expenditures on regional projects in recent years. Every region undertakes information-oriented projects. Table 4.2 suggests that the state projects place somewhat lower emphasis on this type of project.

Information development. Information development stivities span a wide spectrum and include, but are not limited to those shown in Figure 4.1.

\begin{tabular}{l}
\hline Directories of bioenergy facilities and contacts \\
- Databases of technical biomass-related information \\
- Biomass resource assessments \\
- Economic impact assessments of biomass production, conversion, and use \\
- Environmental issues analysis \\
- Analysis of biomass risks and institutional constraints \\
- Development of guidebooks and handbooks \\
- Case studies of bioenergy facilities
\end{tabular}

Figure 4.1 RBEP Information Development Activities 
Information Dissemination. One distinguishing characteristic of the RBEP approach to information dissemination is its reliance on state energy offices and other state agencies as vehicles for reaching the program's various audiences. In almost every state in every region, a person exists who is responsible for biomass energy. The existence of biomass contacts is, at least in part, due to RBEP support. ${ }^{3}$ The state $^{2}$ agencies in which RBEP contacts are located have established mechanisms for reaching and working with the public; they also have networks and contacts that give them access to industry, regulators, communities, and most other key bioenergy-related audiences. By helping to create and maintain this state infrastructure, the resources of the national program are multiplied several times over.

RBEP-supported information dissemination activities include, but are not limited to, those shown in Figure 4.2. Because each region has a different biomass resource base and associated conversion technologies and users, each region has augmented its reliance on state agencies as outreach networks with a variety of other information dissemination activities. As a result, each region has developed a unique approach to information dissemination. These approaches are described in Appendix D.

\begin{tabular}{|l}
\hline - National and regional newsletters \\
- Targeted mailings of reports \\
- Conferences, seminars, and workshops \\
- Brochures and fact sheets \\
- Television and radio shows \\
- Education programs and curriculum materials \\
- Stakeholder coalition building \\
- Technical assistance \\
- Use of advisory committces \\
- Technology demonstrations
\end{tabular}

Figure 4.2 RBEP Information Dissemination Activities

${ }^{3}$ In contrast, the States do not have similar contacts for solar energy. 


\subsubsection{Resource Assessments}

Nationwide, the RBEPs have sponsored resource assessments that now essentially cover the nation. Much of this activity took place before the 1987-1991 time frame that is being analyzed here. Many resource assessments take place at the state level, and some of this is conducted by the states without financial involvement by RBEP. About $26 \%$ of regional funds in the Western region were directed towards resource assessment projects, compared to only $5 \%$ in the Northwest and Southeast and none in the Great Lakes and Northeast.

\subsubsection{Economic, Mark et, and Infrastructure Analyses}

Many technology projects contain a component of economic, market, or infrastructure analysis. Two regions invested a significant proportion of their resources in this type of analysis during the time frame of 1987-1991. The Southeast's efforts (representing 35\% of its budget) include three economic impact studies, the development of a methodology for site-specific economic impact, surveys of fuelwood consumption, examination of alternative uses of wood pellets, and the development of a state-wide strategic plan for wood energy for the state of WV. In the Western region, these efforts included development of a database of potential bioenergy users, study of constraints facing bioenergy, and a facilities directory for the region. Two other regions, the Northeast and Northwest, have invested in these sorts of analyses prior to 1987, but not since then, and so none of their efforts fell within the sampling frame.

\subsubsection{Environmental Analyses}

The responsibility for deploying bioenergy technologies in an environmentally responsible manner, and the need to address increasingly restrictive environmental emissions standards and siting regulations have motivated the RBEPs to invest significant resources in environmental analyses. These have included studies of emissions characteristics of bioenergy technologies, environmental impacts of bioenergy technologies, and guides to environmental regulations at the state level. The Northeast region has been especially active in the last five years at addressing these issues; nearty half of its projects have had a strong environmental component. In the words of the technical services contractor, "the whole program addresses environmental issues. Air emissions regulations and concerns provide a critical constraint for wood waste and MSW combustion, while concerns over solid waste make this combustion more feasible." These projects include a multi-year effort associated with wood stove emissions; ongoing study of issues associated with MSW as a bioenergy resource, including separation, combustion, and facility siting; impacts of harvesting techniques on standing timber; and a compilation of regulatory requirements for the states within the region. 
During the early and mid-1980's, the Pacific Northwest made significant investments in studies of environmental impacts, both in regard to air emissions resulting from slash burning and also various impacts resulting from harvesting activities. During the time frame of 1987-1991, they invested in a study of the impact of intensive harvesting on site productivity, which represents $12 \%$ of their investment in regional projects. In addition, their ongoing effort to develop fuel standards for various biomass fuels may facilitate the planning of waste separation systems.

Addressing environmental impacts or emissions has not been a primary thrust of the Southeast and Westem regional programs during this time period. This has been due in part to the relatively rural nature of the Southeast and Western regions, the lesser significance of MSW as a bicenergy resource in these areas, and less active environmental coalitions than in other parts of the country. That is not to say that these regions have been insensitive to environmental concerns. Both these regions have funded development of technologies that would use negative value foedstocks. In the Southeast, the development and dissemination of anaerobic lagoon digestion systems could potentially alleviate water pollution from feedlots and food processing plants in the region. The Southeast has also provided cost sharing for projects initiated by the Pacific Northwest and the Northeast regional programs, and has placed an environmentalist on its steering committee to make sure that environmental issues are well treated during policy discussions.

While the study of environmental implications has not been a primary thrust of the Great Lakes program, it has invested in studies of emissions from burning densified refuse-derived-fuel (d-RDF) as well as agricultural residues.

\subsection{TYPES OF FEEDSTOCK}

The regional programs have sought projects that address multiple feedstock sources and types. Most resource assessments and facility directories, for instance, are designed to collect information on resources and installations that span a variety of feedstock types. Studies that characterize ash and emissions may be designed to be applicable to a variety of types and sources of wood residues, and compilations of permitting regulations may be useful for those considering several different feedstock types. Accordingly, projects addressing multiple biomass feedstocks or feedstocks in general have received significant funding, ranging from as little as $6 \%$ in the Great Lakes region to as much as $37 \%$ in the Western region (Table 4.5 ).

Projects associated with non-woody biomass or MSW ranged from $62 \%$ for the West and $55 \%$ for the Great Lakes to $24 \%$ for the Southeast and $18 \%$ for the Northeast. The arid nature of the West and its relative lack of forest residues accounts for the high percentage in the Western region. Non-wood related residues in the Great Lakes region were associated with agricultural residues and corn-to-ethanol projects. The low 
percentage of non-wood related projects in the Northeast reflects the investments the region has made into emission studies associated with residential and industrial wood burning.

Table 4.5 Percent of Expenditures on Woody vs Non-Woody Biomass: Regional Projects from 1987 to 1991

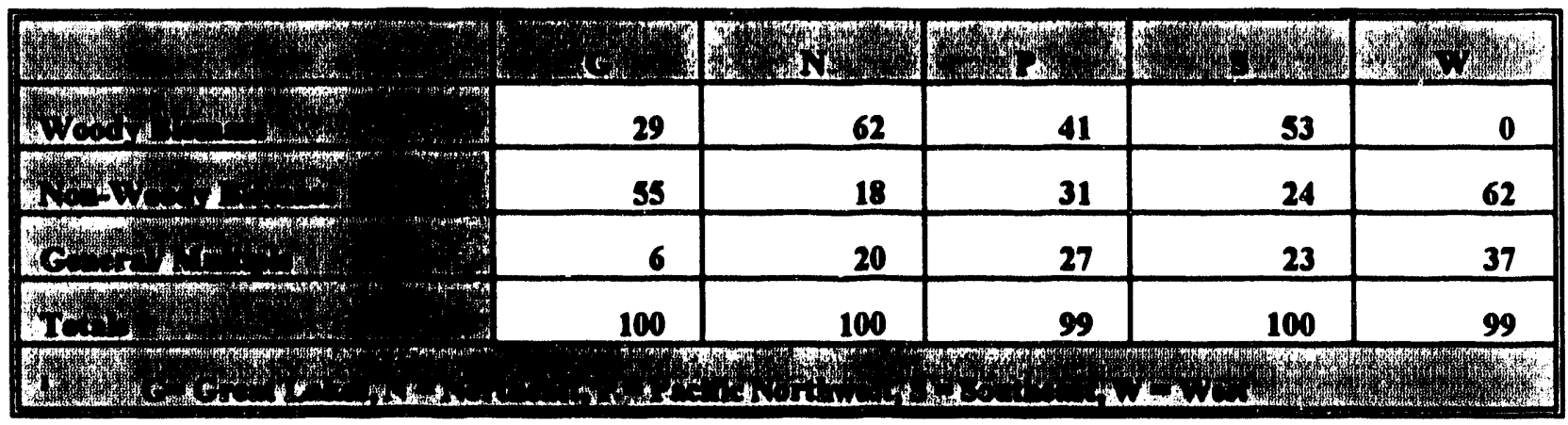

Residential firewood was specifically addressed during this time frame by the Southeast and the Northeast. The Northeast region has conducted an ongoing series of studies of wood stove performance, while the Southeast has conducted economic impact studies of residential wood combustion during this period. During the mid-1980's, the Northwest conducted a series of studies into the emissions generated by wood stoves, and several of its member states have conducted educational campaigns directed at the reduction of residential wood smoke in targeted airsheds.

Forest residue has been addressed by the Northeast and Northwest. Both regions have funded studies of environmental impacts of harvesting activities, and the Northwest also funded the field testing of a harvesting system during this time frame.

Mill residue has been targeted for investment of regional project dollars in the Southeast, which has allocated funds for the development of several demonstration projects in various forest products firms. Other regions have also addressed mill residue through their conversion assistance efforts, but have not explicitly funded projects with regional program dollars during this time frame. At the State level, several States in the Northwest and Southeast have employed RBEP grant funds to target mill residues. Agricultural residues have received a significant amount of funding from the Western region. In PON-I, five projects employing agricultural residues as a feedstock received $41 \%$ of the funding from that solicitation. The Great Lakes region has also conducted some work of agricultural feedstocks, conducting studies of agricultural emissions studies of emissions from the combustion of agricultural residues and byproducts. 
Municipal solid waste is growing in importance as a feedstock in all regions. The Pacific Northwest has invested a significant amount of its regional project dollars in studies to characterize the combustion characteristics of municipal waste. In the Western region, three of the projects in PON-I employ municipal waste as a feedstock. Great Lakes funding activity is linked to characterization of dRDF emissions. The Northeast has addressed MSW in several ways: as a primary feedstock in some $18 \%$ of its projects, and also in a more generalized way in its studies of emissions, ash disposal, and wood waste.

Table 4.6 Percent of Expenditures by Type of Feedstock: Rejional Projects from 1987 to 1991

\begin{tabular}{|c|c|c|c|c|c|c|}
\hline 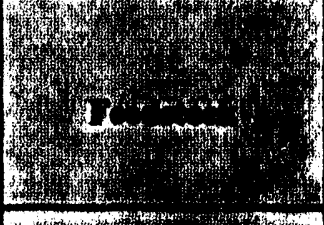 & $x_{1}$ & 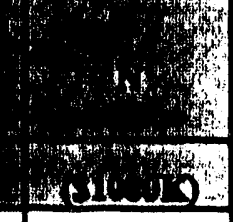 & 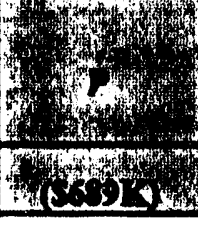 & 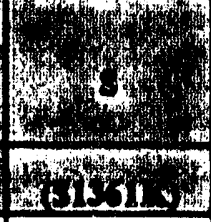 & 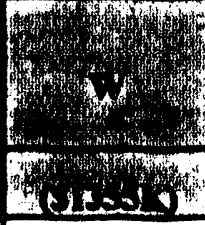 & 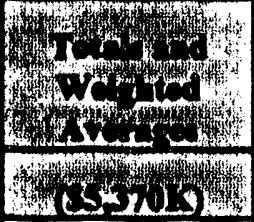 \\
\hline 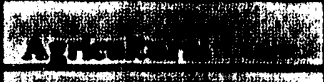 & 19 & 0 & 0 & 5 & 28 & 12 \\
\hline 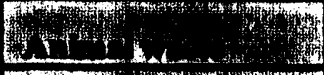 & 0 & 0 & 0 & 6 & 14 & 4 \\
\hline Whis & 0 & 14 & 2 & 14 & 0 & 7 \\
\hline 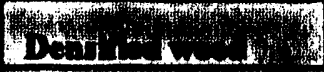 & 3 & 0 & 0 & 3 & 0 & 1 \\
\hline 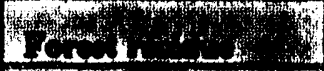 & 0 & 10 & 34 & 0 & 0 & 6 \\
\hline W & 0 & 0 & 0 & 16 & 0 & 4 \\
\hline 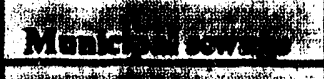 & 0 & 0 & 0 & 3 & 0 & 1 \\
\hline (1) & 13 & 18 & 31 & 10 & 20 & 18 \\
\hline 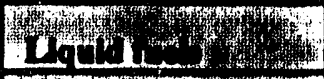 & 33 & 0 & 0 & 0 & 0 & 6 \\
\hline twe & 29 & 38 & 5 & 20 & 0 & 18 \\
\hline 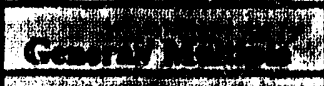 & 6 & 20 & 27 & 23 & 37 & 23 \\
\hline Whe & 100 & 100 & 99 & 100 & 99 & 100 \\
\hline
\end{tabular}




\subsection{TECHNOLOGY THEMES}

This section provides an overview of biomass technologies associated with the regional programs. Table 4.7 summarizes the technology themes that characterize each of the regional programs. Illustrative projects are described below.

\subsubsection{Biomass Energy Conversions}

Energy conversions for process heat and power using biomass foedstocks has been a major programmatic area for some of the RBEPs. Programmatic efforts are diverse ranging from information development, emissions characterizations, developing new fuels, co-firing of biomass fuels with coal, and the development and refinement of fuel handling and conversion technology. These efforts are all aimed at making biomass energy conversions more competitive. However, the low-cost of the conventional energy options remains a significant market barrier.

Table 4.7 Summary of RBEP Technology Themes

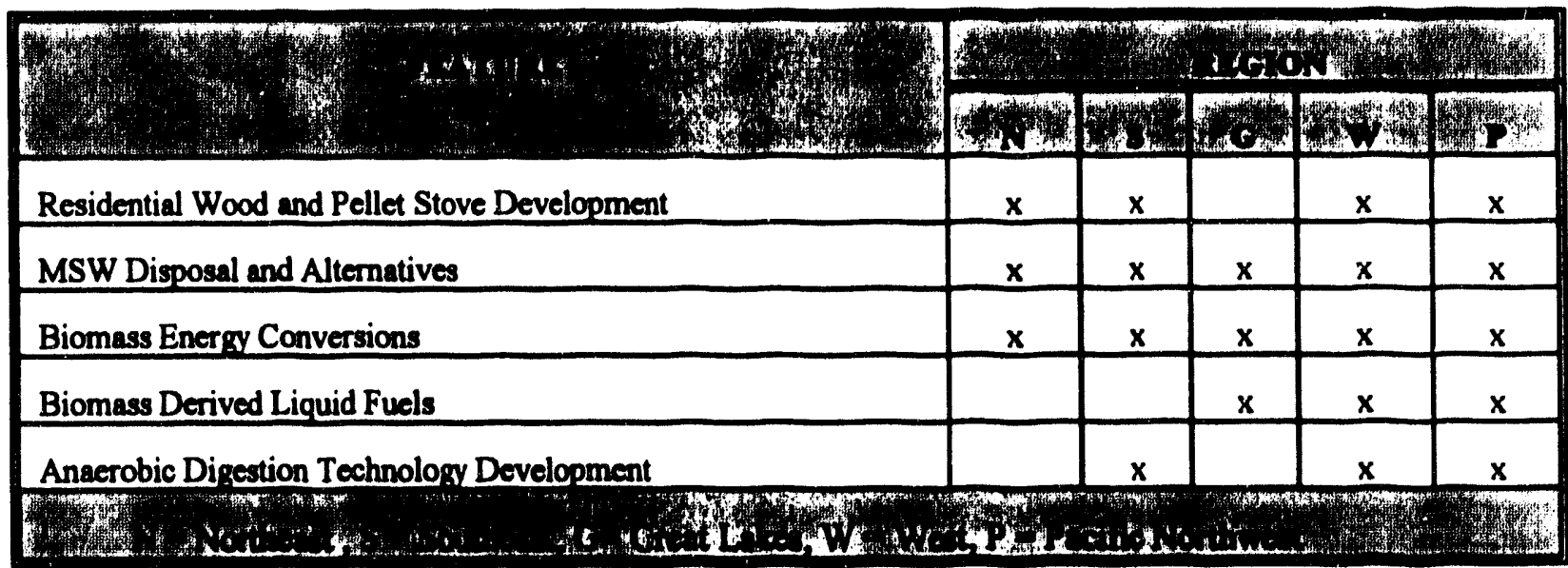

Biomass energy conversion projects in the Great Lakes region have centered on developing information. These projects have included a biomass facilities directory and numerous state supported projects involving information transfer and technical assistance.

Information development has been the focus of the Northeast program's efforts in biomass energy conversions. Key projects have included guidebook for industrial wood energy conversion and a directory of biomass using facilities. The Northeast program has also provided technical assistance to encourage additional conversions and undertaken through state activities studies on wood-fired electric plants and conversions of public buildings to wood heat. 
Since lack of detailed information on the behavior of biomass fuels within combustion systems has slowed the development and diffusion of these technologies, the Pacific Northwest region has conducted a multi-year effort to characterize the combustion characteristics of biomass fuels. Examining a variety of feedstock sources and operating parameters, this project has produced information that should prove useful to design engineers in industry who are considering the use of these fuels. This information has already proved useful in distinguishing promising applications of refuse derived fucls and in helping to set future program directions for the Pacific Northwest program.

The Southeast program has supported a number of projects that could serve to increase the amount of biomass-fired electric generating capacity in the region. One of these projects is to convert the mothballed TVA Watts Bar facility to wood and another is to demonstrate the co-firing of coal with biomass. Both projects would not only provide a low-cost source of power but would have favorable environmental benefits in the form of rectuced sulfur emissions. SERBEP has developed design guides for industrial, commercial, and agricultural systems, including a cogeneration guidebook and a docision maker's investment guide and computer program. SERBEP has funded activities related to process heat implementation as well as cogeneration projects.

Watts Bar retrofit. Energy Performance Systems, Inc. (EPS) has developed and patented innovative wood combustion technology (whole-tree burner) that increases thermodynamic efficiency by using excess heat to dry batch-cut trees before they are bumed in a stagedcombustion furnace. The higher efficiency is attained at capital costs approximated those of a conventional wood-fired boiler. In addition, the implementation of the proposed project would have more favorable environmental emissions relative to coal-fired capacity because wood contains little sulfur. The proposed project will look at the economic and technical feasibility of modifying the Watts Bar Power Station to utilize whole trees, baled waste-wood, and hybrid grown trees as primary fuel sources. This project will focus on two major objectives - the economic and technical feasibility of converting the Watts Bar Plant and the availability of an acceptable, long-term supply of wood energy feedstocks.

Utilizing Woodwaste Biomass to Upgrade High Sulfur Coal for Power Generation in Kentucky - Co-firing wood and coal can reduce sulfur emissions from combustion and may have significant potential to assist utilities to meet Clean Air Act requirements. This project will determine the sources and quantities of wood waste available in Kentucky, determine the volume of wood needed by the state's utilities to upgrade non-compliance coal to meet new air quality regulations, and will identify and quantify the economic factors involved in using woody biomass fuel to upgrade non-complying plants.

Three biomass energy conversion projects have been funded by the Western program. All of these projects involve the use of gasification technology. 
Integrated Gasifier/Gas Turbine Biomass Power Plant -- The purpose of this project is to demonstrate the reliability of a gasification system for producing pressurized, clean fuel gas, allowing its integration into the combustion system of a gas turbine. The development of this technology would improve the efficiency and cost-effectiveness of small biomass power plants and the cont-effectiveness of generating electricity.

Commercialization of a Small-System Biomass Gasifier -- This project attempts to optimize a small gasifier's ability to use a wide variety of foedstocks. A modified, two-stage, cross-draft gasifier with an innovative cleaning element, will be used to produce a low Btu gas. The project involves testing the performance of the gasifier using different feedstocks, and providing recommendations for performance improvement.

Biomass Firing for Cotton Drying (OK Cotton Gin Plant) -- The purpose of this project is to demonstrate the economic advantages of using biomass (cotton gin trash) as a fuel source. Cotton gin trash will be tested using a commercially available gasifier at a cotton gin facility. The rate of biomass consumption versus energy production will be monitored and recorded.

\subsubsection{MSW Disposal and Aternatives}

Municipal solid waste disposal and the attendant problems with alternatives is perhaps the most critical issue facing the regional programs. Landfills are rapidly being used and alternatives are fraught with a host of regulatory and public perception barriers. All RBEPs have ongoing projects on MSW disposal and combustion. These projects are mostly informational in context as they deal with non-tochnical barriers such as regulations and public perceptions. Some of the MSW projects involving technical issues are summarized below.

The Great Lakes program has had a number of MSW projects that have been mostly funded at the state level. An important and high impact region-wide project involves the separation of MSW waste streams.

Separation of Municipal Waste to Prevent Environmental Problems of Combustion Facilities - This project was intended to address the major barriers to increased use of MSW combustion technology. These barriers are largely related to environmental quality regulations. If particular materials are separated and recovered before combustion then emissions will be reduced and the resultant ash less hazardous. The project has produced a serics of reports concerning waste stream separation technology, a mass balance model of waste streams, and reports on separated materials and their specific impacts on combustion emissions and how they can be reused and/or recycled.

MSW disposal is a major concern in the Northeast and has been a major area of involvement for the Northeast program. Two such projects having a technology dimension include: 
Wood Products in the Waste Stream -- There have been increasing concerns about the effects of treated wood in the waste stream. Treated wood contains glues, resins, and preservatives. These contaminants in the waste stream along with stricter environmental regulations could threaten the viability of future wood waste combustion facilities. This project has characterized the resource and the possible contaminants, determined waste screening methods, identified combuation variables and pollution control technolosy options, and designed a feld teat program. Because its potential benefits nationwide were recognized, this project received cofunding from the other RBEPs.

Wood Ash Diaposal and Recycling - The aim of this project was to facilitate the dovelopment of low-cost and environmentally acceptable uses for wood ash. NRBP studies indicate that landfilling ash from a 25MW combustion facility costs around $\$ 400,000$ annually. Land-spreading of the ash costs about one- to two-thirds less. This project developed a source-book that summarizes the disposal options, regulations, and research on the effects of spreading ash on agricultural lands.

Extending back to the carty days of the program, the Pacific Northwest has been involved in planning for the use of MSW as a fuel. In 1990, the Pacific Northwest program decided to increase its involvement in the recovery of energy from MSW. The following projects illustrate Pacific Northwest activities in MSW.

Sitka Waste-to-Energy Steam Turbine -- The city of Sitka had an operating MSW plant producing steam for district heating. A project was developed to retrofit the facility with the capability to produce power.

MSW-to-Energy (Tacoma) - The Pacific Northwest became involved in the early 1980's in the renovation of an existing steam plant to burn a three fuel blend of RDF, coal, and wood. The repowering of the plant included adding fluidized-bed combustors, heat-recovery stream generators, and fuel handling equipment. The plant has been successfully started and is expected to produce $45 \mathrm{MW}$ of power.

MSW disposal has not been a major programmatic activity area for the Southeast program relative to other activity areas. Two of the more important projects has been the testing of fuels derived from MSW and the recycling of wood waste.

Commercial Scale Testing of Fuels Derived from MSW - This project was designed to develop data that could be used to pre tict the environmental and economic performance of fuels derived from MSW and industrial wastes. These fuels were co-fired with high sulfur and waste coals. Results to date indicate that a combiration of MSW and coal will not exceed Clean Air Act emissions levels.

Recycling Wood Waste for Use as Biomass Fuel -- In this project, the City of Anniston established a wood recycling center that would remove all wood wastes (construction and demolition debris, yard waste, etc.) from the MSW stream. Landfill requirements could be reduced by $25 \%$ if there was an effective way to remove wood wastes. The recycled wood 
wastes would be ueed as boiler fivel in an industrial park. The components of the wood waste not suituble as boiler fiel would be mulched and sold as compost. The wood recycling center went into operation at the end of 1992 . The project has an enormous potential for providing a partial colution to landfilling of MSW.

One MSW project that came from the Western program's firat PON solicitation is briefly described below.

Piantice-free RDF for Institutions and Small Municipalities -- While eeparation systems remove most plastic from municipal solid waste at refuse-derived fuel (RDF) piovessing plants, some invariably eacapes. RDF that includes plastics can produces toxic waste when bumed, including hydrochloric acid and dioxin. This project involved testing and demonstrating flash pyrolysis to remove fugitive plastics from the municipal solid waste stream. After classification and grinding, feedatock will be blown through an entrained bed reactor with a starved-air pyrolysis unit. Flame tubes will radiantly heat the reactor. Since plastics pyrolyze 10 times more quickly than paper, the proceas will pyrolyze the plastics and dry the cellulosic waste. A gravity separation system will remove the plastics-free municipal solid waste from the entraining gas stream, and it will be cooled by spraying with a com stillage binder. The flue gas stream containing the toxins will be treated with a water scrub and baghouse filter before recycling it into the entraining stream. There are no project results to date.

\subsubsection{Residential Wood and Pellet Stove Development}

A major focus of some of the regional programs has been the use of wood by the residential sector for space heating. As noted earlier, residential wood energy use has doclined throughout most of the U.S. during the 1980s. However, the number of households buming wood has increased. Regardless of the specific amounts of wood consumed, woodstove use has created numerous air quality problems. Woodstove use has also impacted the availability of wood fuels and driven-up costs in some areas. In addition, woodstoves have posed public health and safety concerns through increased incidence of carbon monoxide poisoning and fires.

In most areas of the U.S., a host of regulations passed restricts woodstove emissions either by requiring post combustion control devices, increasing conversion efficiencies, and/or developing alternative combustion techniques and fuels. The regional programs have been on the forefront of those issues and many significant projects have been undertaken.

The Northeast program has funded projects on every issue associated with the use of residential woodstoves. A significant multi-year project for the NRBP has been their series on woodstoves (Phases I - V).

Woodatove Investigation (Phases I-V) -. Under phase I of this series of studies, a testing methodology was developed and sixty-eight stoves were tested. Results showed that emissions were higher under actual operating conditions than in the lab. The stove firebox 
was a major factor in emiscions, but they could be controlled with add-on devices. The tests also indicated that the durability of the catalytic dovices uned on the stoves varied widely. The most significant outcome of this project was a chanee in EPA regulations. Under phases II and III, twenty-five stoves were tested to determine the adequacy of now EPA regulations. These results showed that manufacturers made significant improvements in their stoves and that emissions were reduced. Phase IV of the investigation developed a methodology that could be used to predict more accurately field operation from lab tests. Phase V, which is in progress, is a consumer oriented technology transfer program explaining how to use the second generation stoves.

The Pacific Northweat program has conducted numerous applied research, feasibility, and demonstration projects related to reaidential woodstoves. The most notable of these are the studies undertaken by Omni Environmental Services.

Environmental Impacts of Advanced Residential and Institutional (Woody) Biomass Combuation Systems - In this sudy Omni Environmental tested four woodstoves (catalytic, natural druft refractory, pellet, and conventional) and a pellet-fired stoker boiler. Emissions varied widely among the stoves but tended to be lowest for the pellet and refractory woodstoves. Overall, the woodstoves tended to emit about 10 to 1000 times more carbon monoxide, particulates, and hydrocarbons (depending on the woodstove type) than oil, gas, or electricity. Moreover, the study concluded that these stoves were not cost-effective uniess used for a high heating demand and the user had a relatively low-cost supply of wood fuel. The results of this study have been controversial and have been vigorously assailed by the woodstove industry.

Omni Environmental Services seven part series (Estimating the Volume of Residential Wood Burning in the Pacific Northwest and Alaska; Mitigation Measures for Minimizing Environmental Impects; Cost/Benefit Analysis of those Mitigation Measures; Estimating Carbon Monoxide Air Quality Impacts for Woodstoves; Identification of Factors Which Affect Combustion Efficiency and Environmental Impacts from Woodstoves; Woodstove Emission Sampling Methods Comparability analysis and In-Situ Evaluation of New Technology Woodstoves; Compendium of Environmental and Safety Regulations and Programs Affecting Residential Wood Heating Appliances)-- These studies were initiated to provide regulators, manufacturers, and consumers with unbiased information regarding woodstove use. As with the previous study, these reports have been criticized by the woodstove industry for being inaccurate and damaging to the industry.

The Southeast program has undertaken numerous projects aimed at wood fuel use in the residential and commencial sectors. One area has been the development of biomass fuel pellets. The production of pellet fuels from wood and other wastes for residential heating markets provides several energy, environmental, and cconomic development benefits. However, high capital costs and seasonal markets make investment in these facilities risky. Summarized below are some recent pellet fuel projects. 


\begin{abstract}
Atternative Uses of Wool Fuel Pellets for Energy Cost Reduction -- This project supports the development of co-products and additional markets for pellet fuels. For example, wood pellets could be utilized as fillers for fertilizer blending and as a carrier for micronutrients and pesticides. The potential market is estimated at over 1 million tons annually. Evergreen Chemical Company will construct a pellet mill to densify waste wood materials into pellets.

Production and Distribution of Wood Pellets -- The goal of this project is to produce and market wood pellets to a residential market (Leslie, Georgia). There is a underutilized wood residue resource (sawdust) and there is a residential market for wood-burning stoves in this vicinity. When this project was initiated, there were no wood pellet plants within several hundred miles of this location, and an inadequate supply of wood pellets in the SERBEP region.
\end{abstract}

\title{
4.3.4 Biomass Derived Liquid Fuels
}

Given current technology (conversion efficiencies and process costs), ethanol production exists only because of subsidies given for its production. The RBEPs have sponsored numerous projects designed to promote greater use of biomass for ethanol production. In addition to ethanol production, the RBEPs are supporting projects to derive diesel fuel from selected agricultural crops and MSW.

The Great Lakes region produces the vast majority of the nation's ethanol. The use of ethanol will likely grow in importance. This importance is due in part to the passage of the Clean Air Act requiring greater use of oxygenated fuels and to continued production subsidies. Any improvement in conversion efficiency can serve to reduce required subsidies and/or lower costs. The GLRBP has sponsored projects aimed at promoting greater use of ethanol and one recent project to increase ethanol conversion efficiency. This project is highlighted below.

Increasing the Eficiency of Ethanol Production Through the Use of a Membrane Technology -- This project will demonstrate, test, and evaluate the use of a membrane technology in the recovery of ethenol from aqueous solutions. The membrane technology will be installed in a pilot scale plant or as an adjunct to a larger distillation system. If successful, this project would lower the costs of producing ethanol by increasing overall process efficiency while also reducing the energy costs of production.

The Pacific Northwest program has an active subprogram in biomass derived liquid fuels using MSW for ethanol production and oil seed crops for the production of diesel fuel substitutes.

Demonstration of biodiesel in on-the-road vehicles - To collect data based on actual operating conditions and enhance public awareness and acceptance of diesel fuels from biodiesel, the University of Idaho outfitted two pickup trucks with blending systems that could automatically biend biodiesel (rapeseed oil and rapeseed methyl esters). This project will monitor such engine performance characteristics as power output, engine wear, and emissions 
over a multi-year period as the vehicles are operated under nomal highway conditions. The data should help answer questions about the impact of biodiesel fuels on engine performance.

Safflower Oil Development Program -- The Pacific Northwest program has cofunded a multi-year series of projects with the Montana Department of Natural Resources and Conservation that address several aspects of the development and use of safflower oil and its derivatives in diesel engines. These projects include efforts to improve the oil yield of safflower plants, development and use of byproducts, the examination of extraction methods, and tests of the performance of safflower products in diesel engines. Efforts are underway to qualify blends of safflower oil for use in locomotive fuel.

The Western program is currently funding two projects involving liquid fuels.

Conversion of Rice Hulls to Diesel Fuel -- Rice hulls are an example of an abundant low-value biomass resource. The intent of this project is to perform a technical and economic evaluation of a process to convert rice hulls to marketable high quality diesel fuel and other hydrocarbon products (naphtha, waxes). By demonstrating successful conversion technology, the commercial implementation of the process would be driven by cost/credit for the rice feedstock, the price of diesel fuel, and environmental regulations.

Bioconversion of Cellulosic MSW to Ethanol Fuel -- Past ethanol projects depended on seasonally-available feedstocks that required extensive pretreatment. Using a readily-available negative-cost feedstock that requires no pretreatment would reduce production costs, increase acceptance of the technology, and encourage use of ethanol as an alternative to fossil fuels. This project demonstrates the technical and economic feasibility of converting cellulosic MSW to ethanol. A ethanol processing plant will be designed and built.

\subsubsection{Anaerobic Digestion Technology Development}

A final technology theme of the RBEPs has been the promotion of anaerobic digestion technology. This technology has considerable potential to produce low and medium Btu gas from a variety of biomass feedstocks including animal wastes and sewage sludge. RBEP efforts have been directed at demonstrating digestors and in making efficiency improvements in the technology. Not all programs have funded projects in this area.

The Pacific Northwest region has recently initiated several projects to develop anaerobic digestion technology.

Tillamook Methane Energy and Agricultural Development -- The Pacific Northwest region has recently undertaken a project in the Tillamook Valley in Oregon that represents an effort to draw together local, state and federal entities to explore regional solutions to the generation of animal wastes in agricultural communities. This system would achieve economies of scale by processing at a central facility animal wastes collected from numerous farms within an agricultural district. Initiated with a $\$ 5,000$ prefeasibility study and $\$ 67,000$ 
investment in preliminary system design from the Pacific Northwest program, the project has garnered a \$750,000 grant from the EPA to enable it to begin construction.

The Southeast program has had a substantial programmatic effort in anacrobic digestion. This effort is consistent with the potential of the resource in the region. Two recent projects are briefly described below.

Psychrophilic Anserobic Digestion of Livestock Manures -- The objective of this project is to evaluate biogas production using different livestrck wastes over the range of temperatures experienced by anaerobic lagoons in the Southeast Regicus. Various loading rate and temperature conditions will be evaluated for dairy and flushed swine wastes. The resulting data on biogas yield as a function of digester temperature can then be used to properly size earthen digestors for livestock enterprises.

Anaerobic Digestion of Swine Wastes Demonstration Project -- Anaerobic lagoons provide low-cost, efficient means of animal waste treatment and energy (methane) recovery. The wide-scale adoption of this tochnology would reduce emissions of methane (a major climate change gas) to the atmosphere. The feasibility of a covered anaerobic lagoon digester with methane recovery at a typical swine facility in Arkansas will be demonstrated with this project.

One anaerobic digestion project was funded by the Western program from their first project solicitation.

Bioconversion of Feedlot and Dairy Industry Wastes -- Agricultural residues and animal manure have more potential to damage the environment and water quality than urban and industrial wastes. Finding economical ways to use this waste for energy production would reduce water contamination, displace fossil fuel use, and produce high-nutrient organic fertilizer for crops. This project demonstrates a two-phase digestor for mixed dairy wastes.

\subsection{MARKET TARGETS}

The five regional programs have devoted significant resources to the dissemination of information on bioenergy options and the provision of technical assistance to potential adopters of bicenergy. Many of these activities have addressed general audiences. However, some market targeting is taking place in all regions.

Innovation diffusion theory suggests that broad market targeting is effective at informing decisionmakers about the availability and general features of new technologies, but narrow market targeting is required to promote and sustain adoption (Figure 4.3). Five stages in the technology adoption process are generally recognized. Decisionmakers must (1) first become aware of the technology; (2) become persuaded of its net positive benefits; (3) docide to adopt; (4) actually implement the technology, which may involve sitespecific customization; and (5) retain the innovation in the presence of pressures that might persuade the

4 Everett M. Rogers. Diffusion of Innovations, 3rd edition. Free Press, New York, 1983 
decisionmaker to discontinue use. The regional programs have addressed the needs of decisionmakers at each of these various stages, although perhaps greater emphasis on the earlier stages. RBEP activities have included generating awareness (e.g., through technical reports, newsletters, press releases, and radio and television presentations), persuading decisionmakers of the feasibility and advantages of bioenergy technologies (e.g., by providing assistance with site-feasibility analysis, conducting site visits, disseminating results of demonstration projects, and providing referrals to consultants), and providing assistance with the adoption decision and implementation (e.g., cost-shared demonstrations).

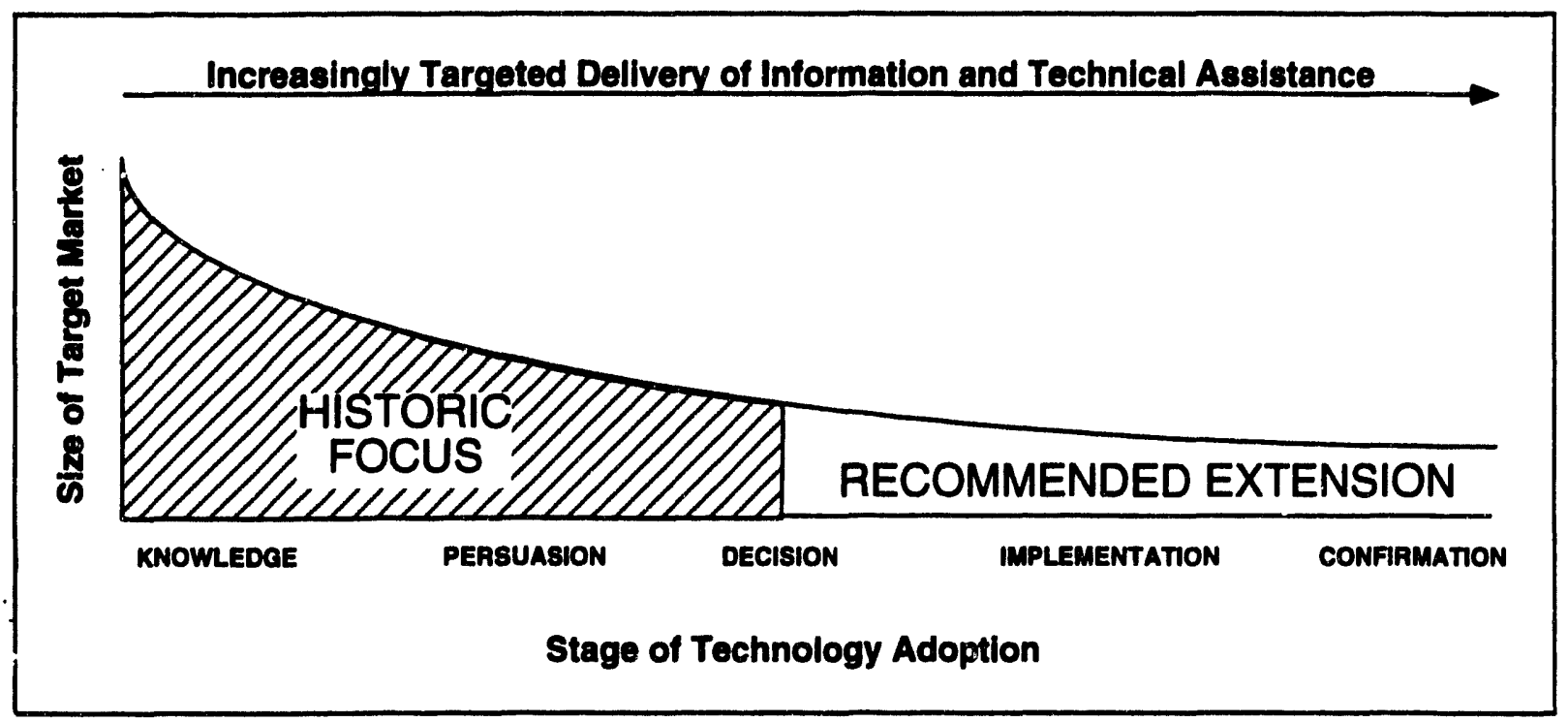

Figure 4.3 Size of Target Market and Stage in
the Technology Adoption Decision

Nationwide, increased benefits could be derived from reducing some of the information dissemination activities that deal with broad market groups and focusing more on specific technical information and implementation assistance for narrowly targeted market segments. The following projects illustrate some of the more targeted market activities that are taking place and that can lead directly to the deployment of bioenergy options.

- In the State of New Jersey, the state bicenergy representative provided direct assistance to prime conversion candidates, including detailed feasibility analysis, system recommendations, financial analysis, and information on regulations, permits, and potential fuel supplies. 
- In the State of Ohio, a Geographic Information System was used to integrate residue availability data with information on $\mathbf{8 , 0 0 0}$ boiler operators to identify some 2.000 likely candidates for conversion. Representatives from some 70 of these organizations attended a wood energy conversion workshop and were provided information and conversion assistance.

- In Minnesota, grain elevators were surveyed to identify a set of promising candidates. A sitespecific plan was developed for the most promising case. This installation would have had approximately a 5-year payback. Further progress toward installation was recommended.

- A facility directory in Oregon identified those wood products firms with wood-fired boilers who could benefit from the installation of cogeneration systems. An effort was made to follow up with these firms and persuade them to install electric generation equipment.

The groundwork for this redirection could be laid by integrating on a regional and nationwide basis the various RBEP resource as,essments with directories of residue producers, consumers, and potential candidates for conversion to bioenergy. The level of detail required to identify and serve potential candidates varies dramatically across technologies and industrial sectors. In some cases, this specification can be quite simple. In the development of biodiesel, for instance, an industrial partner was identified who would be willing to pay a premium for clean-burning diesel fuel and who could provide an entry market during the process development phase. Targeting the delivery of services to likely adopters of wood-fired boilers, however, requires more analysis. In the Southeast, for instance, it was found that those industrial firms that were likely to convert to wood energy were those with existing boilers having the following characteristics: a boiler age of at least 20 years, an annual operating rate of at least $6000 \mathrm{hr} / \mathrm{yr}$, a capacity between 1 and $280 \mathrm{MMbtu} / \mathrm{hr}$, a turndown ratio of 3:1 or less, a response time of at least 20 minutes, and a process heat temperature not greater than $800{ }^{\circ} \mathrm{F}$. Firms with boiler systems not possessing these characteristics were thought to be less likely to benefit from wood energy use and therefore much less likely to convert.

\subsection{TYPES OF CONTRACTORS}

Consulting firms and university researchers have been involved in the great majority of contracts for regional projects (Table 4.8). Over the time frame of 1987-1991, consulting firms have received about three quarters of project funding in the Northeast region, two-thirds in the Great Lakes, about half from the Southeast, and a third in the Western region. University researchers received seven of every eight dollars invested in regional projects during this period from the Pacific Northwest, about two-fifths of the funding from the Western region, and nearly a third of the project funding from the Southeast and Great Lakes regions. Other types of entities represented in contracting during this period include: (1) non-profit organizations, which have been important in the Northeast region; (2) industrial firms, which have played an important role in the 
Southeast; and (3) state agencies, which have played an important role in the Western region in the conduct of resource assessments.

Table 4.8 Percent of Expenditures by Type of Contractor: Regional Projects from 1987 to 1991

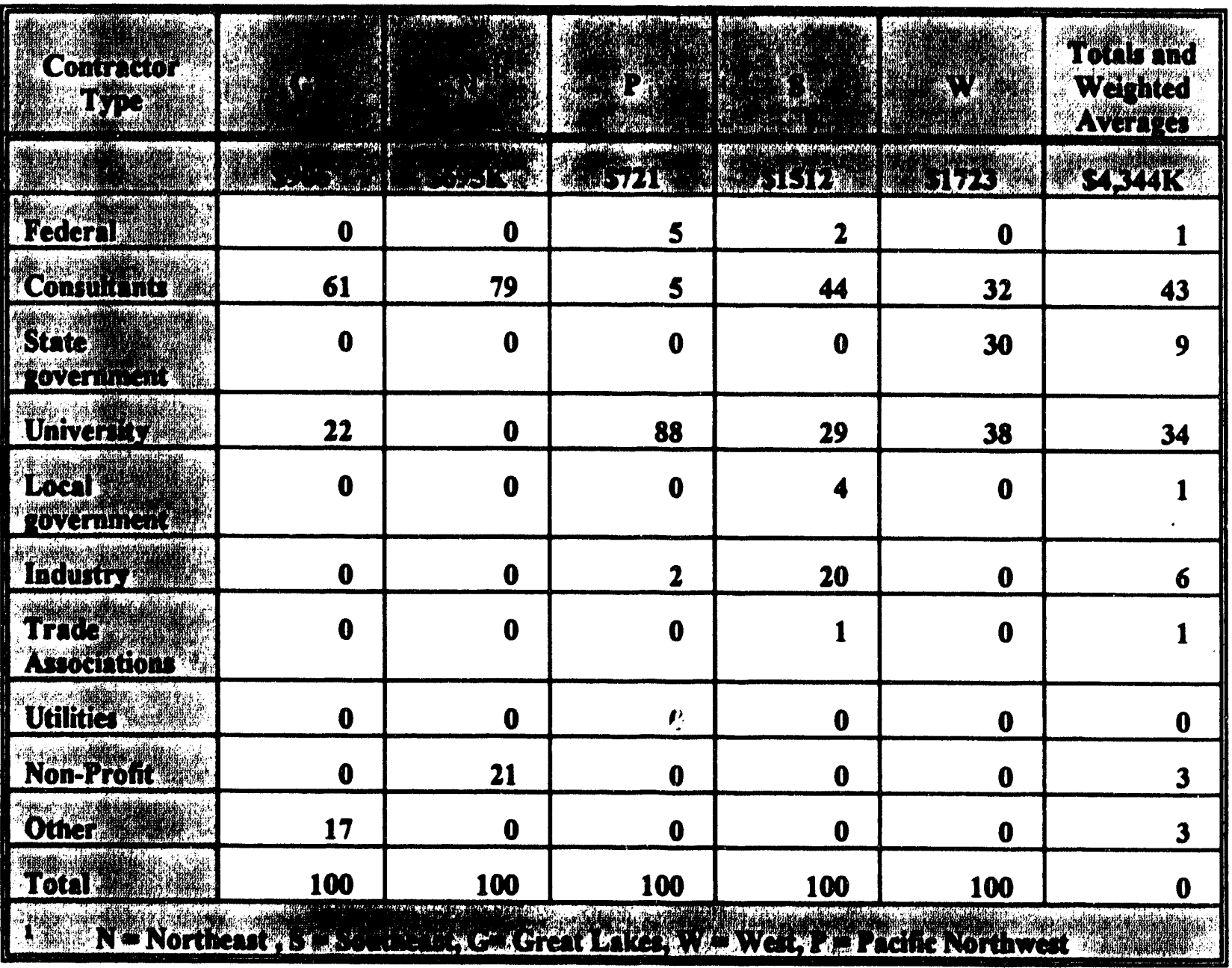

Consulting firms were employed in the Southeast for 13 projects, about half of which were associated with economic impact assessments or the development of assessment tools. Consulting firms also developed market analyses, case studies, and a site-specific feasibility study in the Southeast. In the Northeast, consulting firms were involved in the development of almost all of the region's informational products, including their wood stove studies, characterization studies of wood ash and wood waste, and studies of comparative risk and facility siting. In addition, the Northeast contracted with a consulting firm to provide technical assistance to potential converters to wood energy. Similarly, the Great Lakes region has employed consulting firms to 
develop most of its informational products, including the compilation of data on emissions from densified refuse derived fuel, the development of case studies on emissions, ash disposal, and waste-to-energy, an assessment of opportunities for cogeneration in the region, and materials to help promote pellet manufacture in the region. The Western region has employed consulting firms for "tochnology brokering" activities. One of these was a site-specific feasibility and design project, while another involved developmental work on a gasifier-turbine system.

University researchers have played an important role as contractors in four of the five regions. In the Pacific Northwest, where most of the project funding during this period was allocated to university researchers, about half the funding was directed towards fuel characterization studies of biomass fuels and MSW. The Northwest also employed university researchers in field testing an innovative harvesting system and in studies of the impact of harvesting activities on forest productivity. The Southeast has employed university researchers in technology development efforts and in the development of materials for information dissemination. Represented among these projects are the development of a small gasifier, a sawdust dryer, co-firing studies, tests of hybrid lagoon performance, design manuals, and educational curricula. The Western region has employed university researchers in technology development efforts. While university researchers have been associated with some two-fifths of its overall project expenditures, they received $68 \%$ of the funding from PON-I, the first project solicitation. The Great Lakes region has employed chemical engineering faculty for its developmental work in support of ethanol separation technology.

Industry participants have been significant in regionally-based projects in the Southeast involving approximately one-fifth of the project dollars. These projects include the installation of a wood gasifier for kiln drying and a turbine for electrical generation at wood products firms, support for firms entering pellet manufacturing and distribution, a waste to energy system, and a cogeneration system at a dairy. Industry involvement in contracting with the other four regional programs has been minimal.

State projects reły on a different portfolio of contractor types (Table 4.9). University contractors are not nearly as important as contractors for state projects in the Pacific Northwest, while industrial contractors represent nearly a quarter of total expenditures in that region. In the Southeast, consultants are not nearly as important as implementers of state projects, while state agencies are contractors for approximately one-third of the state project expenditures. 
Table 4.9 Percent of Expenditures by Type of Contractor:

State Projects from 1987 to 1991

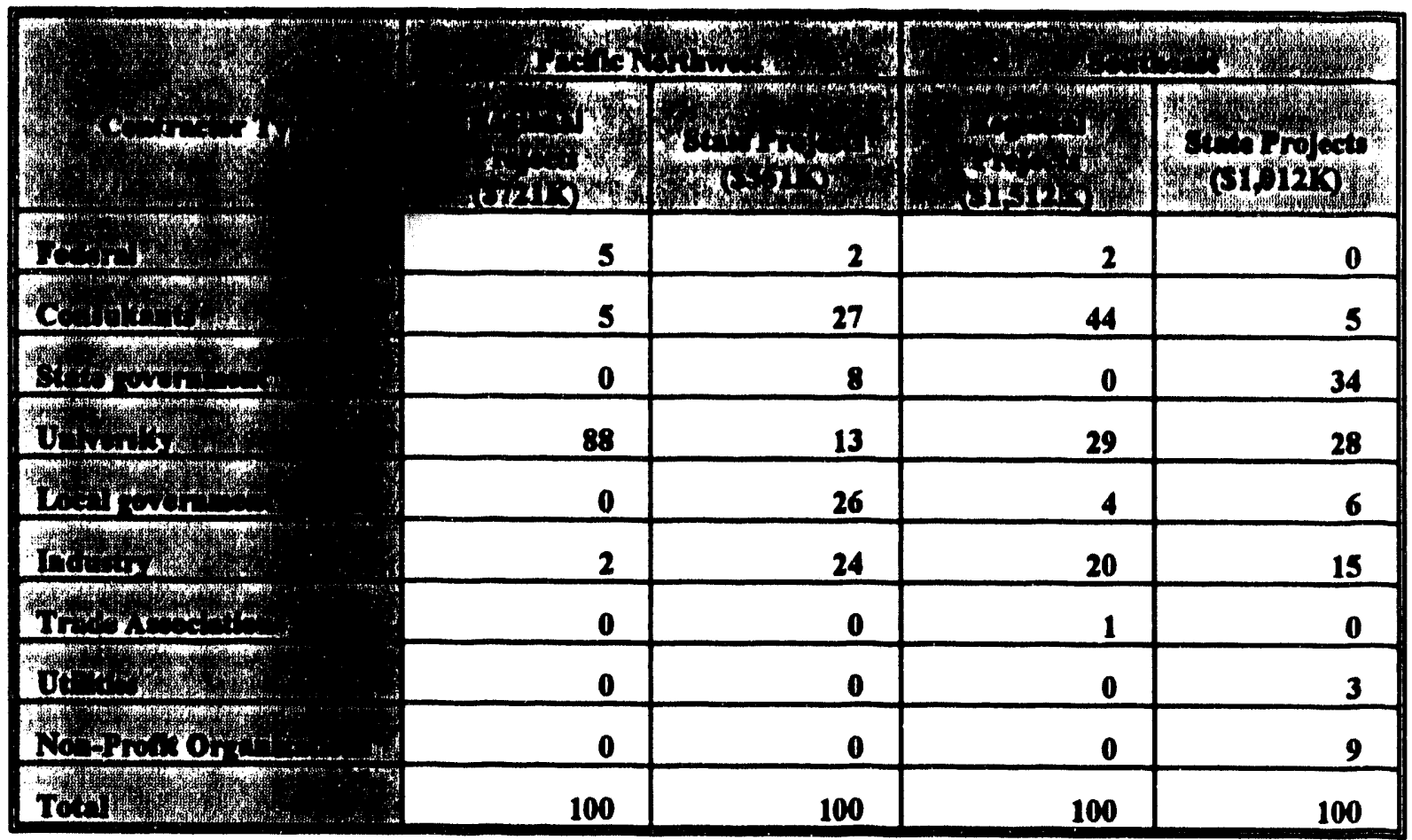

\subsection{LESSONS LEARNED}

- Each region concentrates on a difierent set of biomass technologies.

The most common technology themes of the program nationwide are biomass energy conversion, municipal solid waste disposal and altematives, residential wood and pellet stove development, biomass derived liquid fuels, and anaerobic digestion technology development (Table A.2). The diversity across regions is great. Only the first two toctinology themes are common to all five regions, and each region concentrates on a different set of technologies.

- RBEP has conducted a wide variety of project activities in the pursuit of its objectives.

Nationwide, RBEP has focused approximately $38 \%$ of regional project resources on technology development and demonstration projects; $14 \%$ on technology assessments; $14 \%$ on information development and dissemination; and the residual on environmental, economic, market, infrastructure, and resource assessments. The West, Southeast, and Great Lakes programs dedicate more than one-third of their regional project dollars to technology development and demonstration, while the Pacific Northwest focuses on technology assessments (primarily entailing fuel characterization and standards development). The Northeast spends a large proportion of its resources on environmental analyses. 
- Across its history, RBEP has emphasized technology development over technology demonatration.

Within the technology development and demonstration category, over $85 \%$ of the regional project resources have been spent on engineering designs, modeling, and laboratory and field testing. Less than $15 \%$ of these funds have supported demonstrations of market-ready technologies; these projects have been conducted in the Southeast and Great Lakes. In contrast, the state projects funded by RBEP have had a stronger focus on demonstrating technologies that could be commercialized immediately.

- Consulting firms and university researchers have been involved as contractors in the great majority of the regional projects conducted with the five RBEPs.

Over the five-year period, from 1987 to 1991, consulting firms have received about three-quarters of project funding in the Northeast region, two-thirds in the Great Lakes, about half from the Southeast, and onethird in the Western region. University researchers received seven of every eight dollars invested in regional projects during this period from the Pacific Northwest, about two-fifths of the funding from the Western region, and nearly one-third of the project funding from the Southeast and Great Lakes regions. Funding of projects with end users implementing techy.ulogy (state government installations, local government, and industry) represents $24 \%$ of project dollars in the Southeast, but significantly less in other regions. State based projects do better; $58 \%$ of PNAB funded state projects and 55\% of SERBEP state projects are associated with end users.

The breadth if the projects in terms of project purposes, information dissemination needs, stages of development, etc., means that little is left over for interactions with industry. Only a small fraction of RBEP's regional project expenditures have involved industry as contractors (6\%); most of this investment has taken place in the Southeast, which has directed $20 \%$ of its project funds to industry participants. Contracting with industry is a more common feature of RBEP-supported State projects. In the Southeast and Pacific Northwest, the funding of State projects with industry participants represents $15 \%$ and $24 \%$, respectively.

- RBEP has a strong track record in addressing the environmental implications of biomass energy.

The RBEP was an early leader in exploring the environmental implications of bioenergy. These issues are especially important for the Northeast region, where environmental tradeoffs determine $t_{\text {. }}$ : constraints and opportunities faced by the program. 
- Market targeting is taking place in all re fions, but could be improved.

Most information dissemination efforts art. targeted at broad audiences.

- Resource assessments have been conducted by all five regional programs, but divergent approaches have been employed.

Over the past decade, resource assecsements and facilities directories have been developed by all five of the regional programs, and provide basic data for almost every state in the nation. These assessments vary in terms of the means by which they were derived, their level of resolution, and the degree to which they identify point sources of available residue. A consistent format for the development of these resource assessments across regions has not been developed. 


\section{RESOURCE LEVERAGING}

Resource leveraging offers managers of government programs the opportunity to increase the efficiency and effectiveness of their activities. This chapter begins by briefly discussing the importance of leveraging and its measurement (Section 5.1).

The RBEP secks to loverage both external and internal resources. External resource leveraging refers to the application of non-RBEP funding and in-kind resources to projects that are supported by RBEP. Cost sharing of this nature is important for many reasons. One, it indicates a commitment or the part of multiple parties to the success of the project. Two, it enlarges the resources available to complete the project. Finally, it enhances the credibility of the project's results. External leveraging (i.e., cost sharing) is discussed in Section 5.2.

Intemal resource leveraging refers to inter-regional collaboration whereby projects and activities are jointly supported by two or more of the RBEP regions. Like external leveraging, internal leveraging is important to the success of RBEP. It reduces the waste associated with duplicative efforts, expands the resources available to individual activities, and promotes consistency across regions thereby enabling the aggregation of information across state and regional boundaries. Internal leveraging (or inter-regional collaboration) is discussed in Section 5.3.

\subsection{LEVERAGING AND ITS MEASUREMENT}

In its broadest sense, "resource leveraging" represents an effort to trigger desired changes through small but critically placed investments of public resources that serve as a catalyst for investment by others. By reducing risk or lowering technical, regulatory, or market barriers for private enterprise, resource, leveraging can trigger critical commitment by other parties and help bring about desired changes. Resource leveraging is frequently the result of "entrepreneurial" behavior that crosses institutional barriers to achieve results.

The measurement and evaluation of resource leveraging is complicated (see Table 5.1). Since the general concept of leveraging has been borrowed from the field of Financial Accounting, most analyses of leveraging in the evaluation of government programs have measured leveraging ratios, or the ratio of outside resources acquired to program dollars invested. This measure functions well in the private sector in analyses of commitment and assumption of risk, but falls short when discussing the ability of government funds to trigger private-sector investment. It can direct attention away from the entrepreneurial and catalytic behavior being promoted. In addition, the current emphasis on leveraging and multiparty participation, if extended across the board, can encourage agencies to engage in interagency activity driven by the criterion of multiparty 
participation rather than the achievement of programmatic goals. These factors suggest that in addition to calculating resource leveraging ratios, it is useful to examine the underlying entrepreneurial and leadership behavior being promoted.

Table 5.1 The Evaluation of Resource Leveraging

\begin{tabular}{|c|c|}
\hline 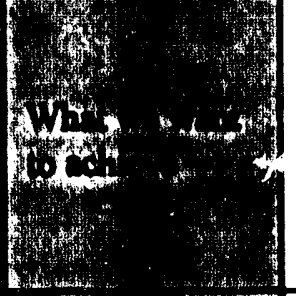 & $\begin{array}{l}\text { - Catalytic involvementinvestment of government } \\
\text { - Critical commitment and participation of partners } \\
\text { - Private sector equity investment } \\
\text { - Entrepreneurial behavior by program managers } \\
\text { - Interdieciplinary and interagency activity that crosses institutional barriers to achieve } \\
\text { results. } \\
\text { - Efficient use of taxpayer resources }\end{array}$ \\
\hline & LeverageRetto $=\frac{\text { sValue Outulde Resources }}{\text { Program FundeInvested }}$ \\
\hline & $\begin{array}{l}\text { Enables tracking of outcomes of government investment } \\
\text { - Identifies equity contributions } \\
\text { Helps identify commitment to public:private partnership } \\
\text { - Helps in identifying investments in which government intervention made a real difference. }\end{array}$ \\
\hline 4 & $\begin{array}{l}\text { - Much important activity is not captured by leveraging ratios } \\
\text { - Several kinds of leveraging relationships exist, some of which are more valuable than } \\
\text { others } \\
\text { - We cen overemphasize leveraging to the point that program managers waste resources in } \\
\text { bean-counting } \\
\text { - Circumstances exist in which high leveraging reflects neither high commitment nor a high } \\
\text { commercialization potential, as do situations in which low financial leveraging masks } \\
\text { significant leveraging of other resources } \\
\text { Leveraging data must reflect long-run equity investment } \\
\text { - Accounting of in-kind investment is inadequate } \\
\text { - The traditional "bell-shaped curve" doesn't fit real world project portfolios; average values } \\
\text { are often misleading }\end{array}$ \\
\hline Why & $\begin{array}{l}\text { - Look behind the quantitutive measures of leveraging to the underlying context and activity; } \\
\text { - find out whether an investment made a difference } \\
\text { - Recognize the non-normality of leveraging behavior, support analyses of central } \\
\text { tendencies with measures other than average values } \\
\text { - Find more and better ways of understanding, validating, and reporting in-kind investment } \\
\text { - When examining interagency leveraging, develop procedures to minimize double counting } \\
\text { - Ask questions such as "In what way were these dollars critical?" and "How can we have } \\
\text { more impact or do the same thing better, faster, cheaper, or more effectively?" }\end{array}$ \\
\hline
\end{tabular}


In onder to doscribe the ability of each region to leverage its resources, information on cost sharing was solicited for all FY 1991 projects. Funding data were collected successfully for all of the FY 1991 projects funded by the Southeast and Pacific Northwest programs, but we were able to collect information only on a subect of the projects funded by the remaining regional programs. In the Great Lakes and Northeast regions, the technical assistance grants given by the regional programs to the states generally are not applied to specific projects. Since finds invested in individual projects cannot be traced back directly to the RBEP grants, project level leveraging ratios for state projects cannot be calculated. In order to develop a more complete picture of funding patterns, an effort was mado to collect funding data on all projects conducted by the Southeast and the Pacific Northwest during the time period of 1987-1991. For these two regions, data is available on both state and regional projects in which RBEP funds were invested. Analyses of funding patterns in these regions is thus more complete than in other regions.

A leveraging ratio was calculated for each project, by dividing the contributions of outside parties by the RBEP costs. Total outside contributions included the financial contributions of co-funders and the value of in-kind contributions of participants. As an example, information was available on 37 Southeast regional projects. Total outside contributions for this set of projects were estimated to be $\$ 4,430,000$; RBEP funding was $\$ 1,512,000$; thus, the leveraging ratio was 2.9 .

The loveraging described in this report must be considered to be preliminary values. While all five regional programs pay attention to resource leveraging, the regions have developed different approaches toward recording leveraging, and different levels of detail in what they track. One region, for instance, includes oil overcharge funds applied to state projects, while the other regions have not done so. The regions also differ in terms of whether they keep track of in-kind commitments and other non-financial contributions to program activity. For the purposes of this report, leveraging values were accepted as reported for those projects in which RBEP funds were invested. This eliminated some cases in which the reported leveraging was never matched with a financial commitment from RBEP. In-kind investments were accepted on a dollar-for-dollar basis as seported. Other than in-kind contributions, there was very little data on non-financial contributions.

\subsection{COST SHARING}

The RBEP is more highly leveraged than most governmental programs. Based on the Program's regional projects, the Southeast region has a leveraging ratio of 2.9, the Great Lakes region 0.8 , the Westem region 1.5, the Northeast region 1.1, and the Pacific Northwest region 0.6. The national program can be characterized by the weighted mean of these individual ratios - 1.9 - indicating that, on average, every RBEP dollar spent on a regional project was matched by $\$ 1.90$ from external sources. 

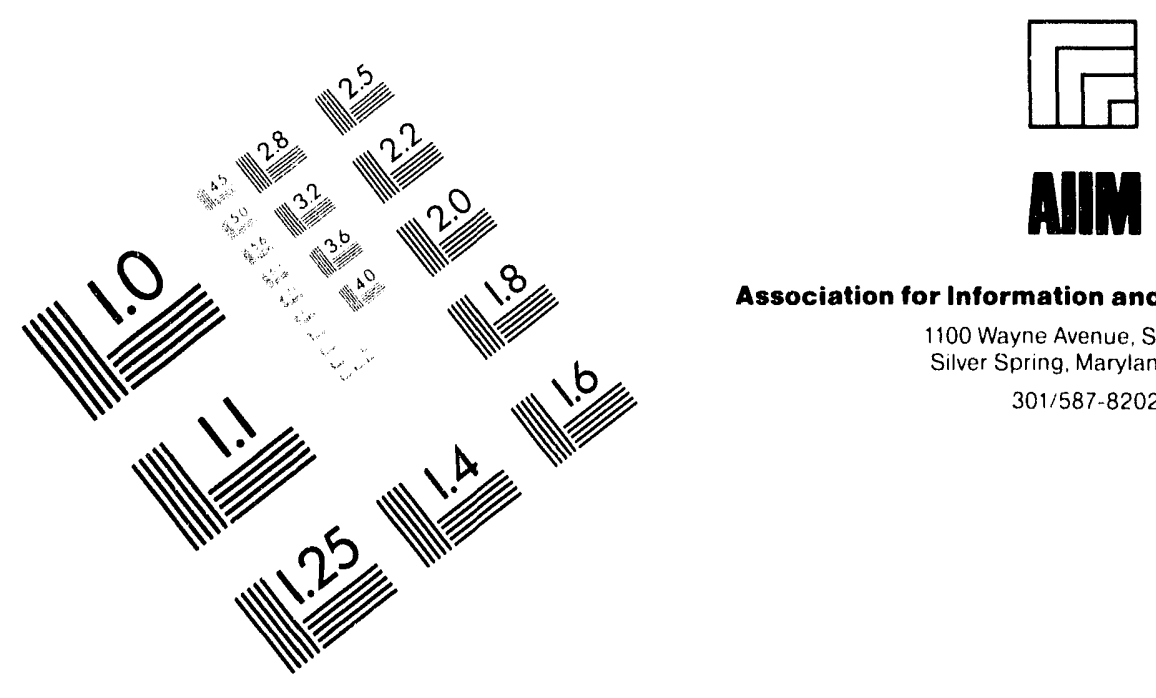

Association for Information and Image Management 1100 Wayne Avenue, Suite 1100 Silver Spring. Maryland 20910 301/587-8202

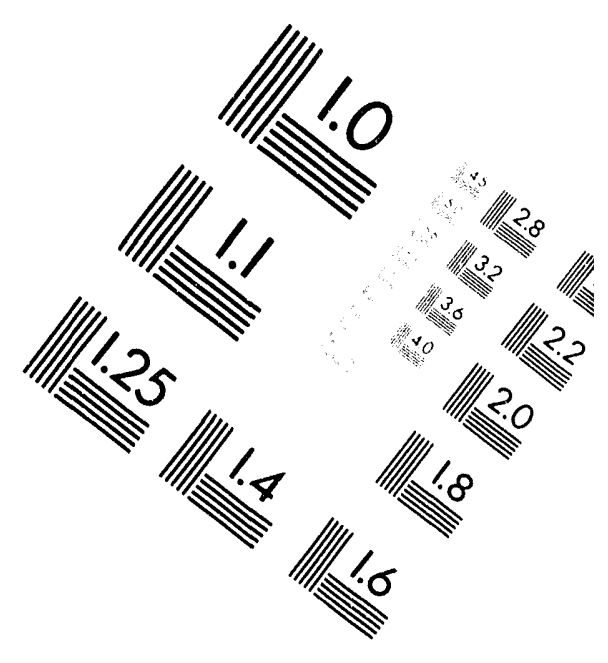

\section{Cenrimeter}

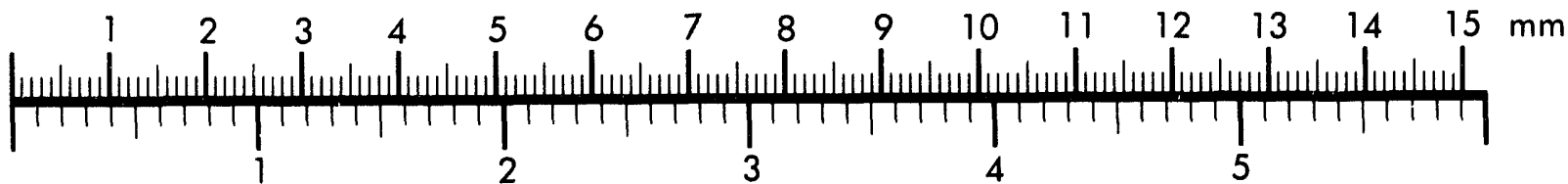
Inches
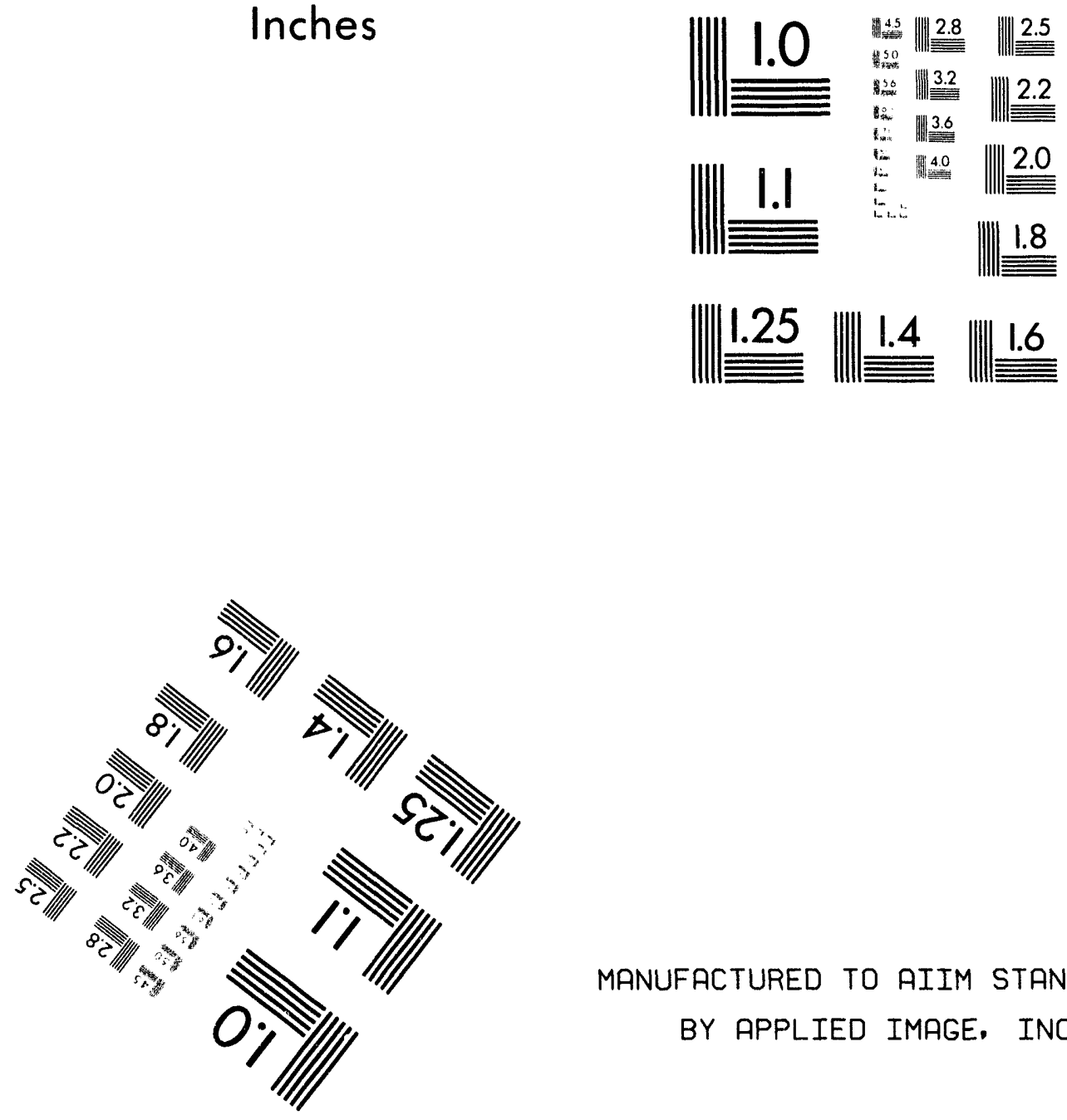

MANUFACTURED TO AIIM STANDARDS BY APPLIED IMAGE. INC.

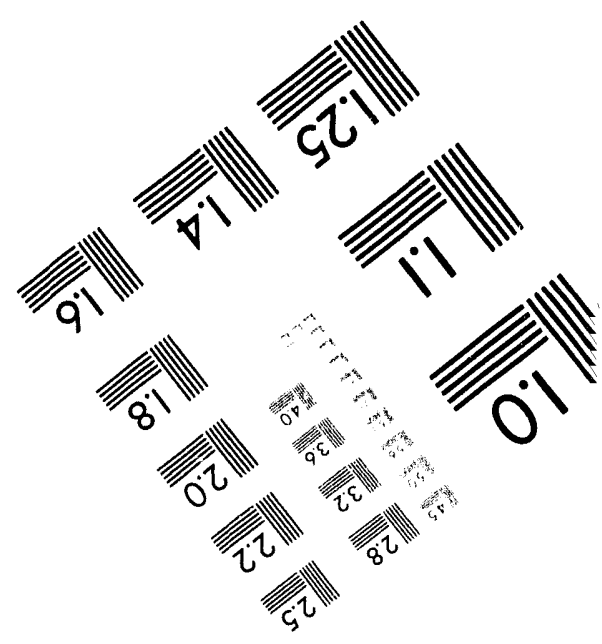



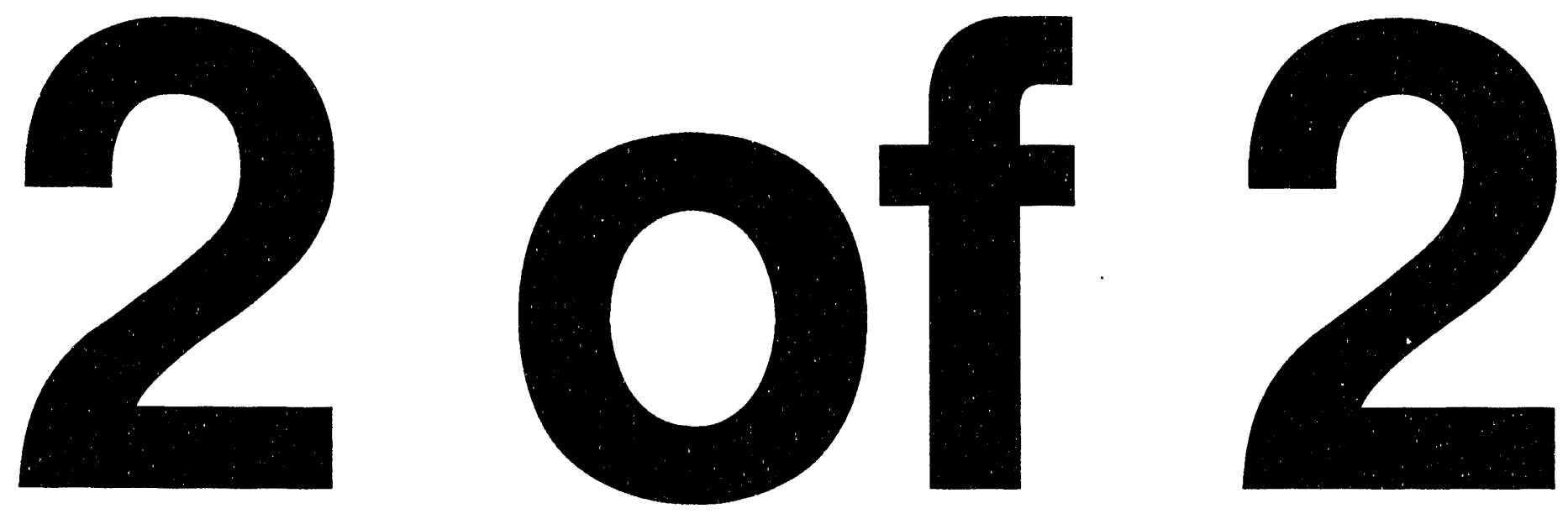
Cost sharing is even greater among RBEP's state projects, based on an analysis of two regions (Table 5.2). State projects in the Pacific Northwest had an average leveraging ratio of 4.5 during the five-year period from 1987 to 1991, in contrast to regional projects which averaged 0.6. Similarly, state projects in the Southeast region had an average leveraging ratio of 5.4 , while the regional projects funded by the Southeast program averaged a leveraging ratio of 2.9 .

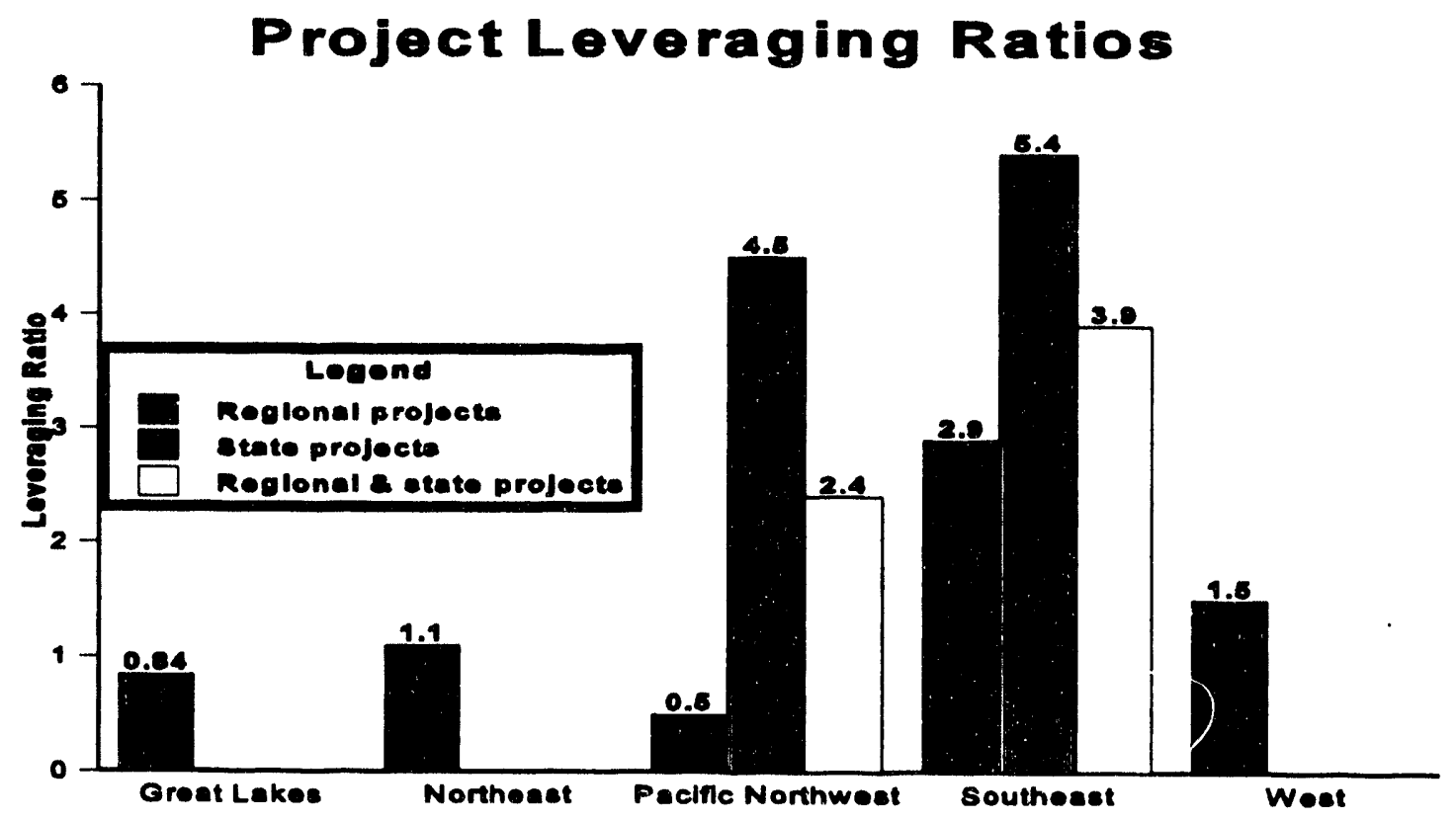

Figure 5.1 Leveraging Ratios for RBEP's Regional Projects

\subsubsection{Cost Sharing and Project Type}

A review of cost sharing patterns by project type and development stage reveals that resource leveraging associated with RBEP projects has been most pronounced in technology demonstration activities. In the Southeast, technology demonstrations sponsored directly by the regional program have brought in almost eight dollars for every RBEP dollar invested. The portfolio of state-based demonstration projects in the Southeast has shown an overall leveraging ratio of 9:1, while the state-based bioenergy demonstrations conducted in the Pacific Northwest have shown a leveraging ratio of almost 7:1. Other types of projects have brought in smaller proportions of funding from other sources. Appendix D includes a breakdown and discussion of leveraging ratios for other types of projects. 


\subsubsection{Cost Sharing and Feedstock Type}

Examination of leveraging by feodstock reveals some of the sectors which are especially motivated to explore energy recovery from biomass. In particular, municipal solid waste projects and projects associated with mill residue have attracted substantial amounts of cost sharing.

Local government agencies attempting to address municipal solid waste issues have been bringing in significant amounts of resource leveraging associated with two projects in the Southeast. Both projects resulted from the region's annual solicitation for bioenergy projects. In the Pacific Northwest, several state-based MSW projects were conducted with RBEP funds that also brought in large amounts of leveraging.

State-based projects associated with mill residue have been designed to help primary and secondary forest product firms install direct combustion systems for energy recovery or cogeneration. Projects of this type in the Pacific Northwest and the Southeast have brought in \$7.40 and \$6.10, respectively, for every $\$ 1.00$ of RBEP funding. Regional projects in the Southeast involving mill residue were heavily cost shared by lumber companies. These projects have included the testing of a sawdust dryer, support for the production of wood pellets, the installation of a turbine and generator set at one lumber company, and a gasification system at another.

\subsubsection{Cost Sharing and Type of Contractor}

Leveraging differs dramatically by type of contractor. Industry participants in state-based projects in the Pacific Northwest, and both regional and state contracts in the Southeast, have contributed over seven dollars of their own funds for every RBEP dollar committed. This represents a significant acceptance of financial risk on the part of these participants.

While local governments represent a small fraction of the total number of RBEP contractors, their level of cost sharing has sometimes been substantial. The Southeast Program's associations with local municipalities have produced projects with leverage ratios in excess of 20:1.

Few foderal agencies have conducted RBEP projects. In the Pacific Northwest, however, there have been some highly leveraged State-based projects in which the U.S. Forest Service has contributed significant resources and in which USFS researchers have served as primary investigators.

Regional projects conducted by consulting firms, state agencies, and university faculty are not generally associated with substantial amounts of leveraging. A wide variety of consulting firms have conducted projects with the RBEPs. Many of these have been consulting engineering firms attempting to design bioenergy systems or to conduct feasibility studies. Consulting engineering firms conducting projects with the Western regional program have on average contributed $2: 1$ cost sharing and have assembled at least $1: 1$ cost sharing on all the 
projects they have conducted with WRBP. In the Southeast, consulting firms have been employed to conduct economic assessment acti ${ }^{*} \cdot{ }^{*}$ es, develop economic impact assessment tools, and conduct consumer surveys. Firms performing these sorts of services for the Southeast were not required to produce cost sharing, although many projects offered cost sharing.

\subsection{STRATEGIES FOR ACHIEVING COST SHARING}

The amount of cost sharing is one of the most important project selection criteria employed by each of the five regional programs. It is particularly important in selecting regional projects. In its $1992 \mathrm{PON}$, for instance, the Western program allocated 20 out of 100 points in its weighting scheme to the degree of cost sharing. This represented an increase over the weight given to cost sharing during its 1988 PON (8 out of 100 points). Similarly, the proposal evaluation criteria outlined in a recent RFP issued by the Great Lakes region allocated 15 out of 100 points to the level of proposed cost-sharing with the private sector.

The emphasis placed on level of cost sharing in the selection of state projects varies dramatically between regions and across time periods. In most cases, each state within a region receives approximately the same level of funding, subject to the availability of matching funds. The regional programs tend to target a particular level of state cost-sharing, and the states generally have obliged. In the Pacific Northwest, the cost sharing requirements on demonstration projects was set at 3:1 for FY 1992 and raised to 4:1 for FY 1993. The Southeast program strives for a dollar-for-dollar match. The Northeast negotiates each state grant and associated cost sharing individually, recognizing that some states have an abundance of potential co-funding, while others operate on a shoestring.

In several of the regions, a steering council or some other advisory group is involved in the selection of state projects. In these instances (e.g., in the Great Lakes and Northwest regions), level of co-funding and participation of private industry, local government, citizens groups, and other organizations, as appropriate, are evaluated favorably.

The Southeast has a two-tiered approach to cost sharing. It requires cost sharing on the technology development and demonstration projects when the primary beneficiary is a specific company. While the minimum cost share threshold is set at $1: 1$, successful proposals have typically had higher leveraging values. State-based projects that receive Southeast funds are also required to have at least a 1:1 match. While cost sharing was not required for projects with more generic benefits, such as resource assessments, region-wide market assessments, or economic impacts studies, it was frequently offered by those proposing projects.

The Northeast has a unique approach to resource leveraging. The region does not in general pursue cost sharing for the analyses it conducts. Instead, it has conducted extensive campaigns to draw in cost sharing 
funds on its major initiatives with a great deal of success. In its multi-year series of studies on wood stoves, the region has invested $\$ 338 \mathrm{~K}$, which has been accompanied by some $\$ 1,500 \mathrm{~K}$ in cost sharing. In 1991, the region was able to draw in $\$ 10$ for every dollar it invested in the development of methods for assessment of boiler emissions and ash. Even if this was the only project (as reported) which was accompanied by cost sharing in 1991, this project would produce an overall leveraging ratio for all projects conducted in 1991 to 1.2 .

Although the circumstances in which a bioenergy program can catalyze interagency activity may be somewhat rare, the likelihood that an agency will identify issues on which it can take an interagency leadership role can be eninanced through systematic gap analysis. This involves the identification of issues which fall within a program's mission and capabilities and in which other agencies are interested, but which are not being addressed adequately by other agencies. The Northeast program has made gap analysis a central component of its planning process. This has helped the region identify at least two programmatic areas around which it has developed a significant amount of consensus and interagency activity -- ongoing studies on residential biomass combustion and efforts to develop urban waste wood as a biomass resource. Use of gap analysis to define the scope of programmatic activity might also be adopted to good effect by other regions.

Internal leveraging, or cooferation between the regional programs, has been an important factor in several of the RBEP's most successful endeavors. This leveraging has come both in the form of financial and nonfinancial support. Some examples are illustrated below:

- Wood stove studies, conducted as parallel streams of research in the Northeast and the Pacific Northwest

- Cofunding of biofuels conferences

- The parallel streams of research on wood stoves conducted by the Northeast and the Pacific Northwest regional programs in the mid-1980's developed

- Cooperation between regions on anaerobic digestion and landfill gas extraction technology

- Support by the Pacific Northwest for the expansion of pellet manufacturing in the Southeast

- Production trials on rapeseed conducted by the Southeast in support of the Pacific Northwest

- Extension of a site specific economic impacts model from the Southeast to the Western region 


\subsection{FACTORS INFLUENCING MULTI-PARTY PARTICIPATION}

In the past, RBEP leveraging with other local, state, and federal governmental agencies has been more or less successful depending upon the urgency of any particular biomass issue at any point in time. For instance, before 1984 in the Pacific Northwest, almost all of the Pacific Northwest projects were associated with interagency agreements involving the assessment of forestry resources on public lands. During this time frame, these other agencies (e.g. EPA, the U.S. Forest Service, and the Bureau of Land Management) provided the majority of funding for PNWA-cofunded resource assessments and emissions tests. During the latter part of the 1980's (when the level of harvesting from national forests in the region decreased dramatically resulting in a reduced supply of sawmill residue and increased competition over feedstocks), government agencies lost interest in the use of logging and mill residues as sources of biomass energy. As a result, co-funding for forestry resource assessments and emissions tests virtually disappeared. More recently, the Northeast program is generating cofunding for municipal solid waste and wood waste projects, because of the urgency of these issues in its densely populated states.

Similarly, co-funding from private-sector sources is most successful when RBEP projects are part either of the industrial partner's current business operations or new business development activities. Because of this, RBEP's demonstration projects have been especially successful at acquiring private-sector contributions. These projects tend to address an immediate need of an industrial or govermmental partner, and therefore are able to attract considerable co-funding.

Multi-party participation is significantly enhanced by entrepreneurially oriented project managers who aggressively pursue cost sharing. Well leveraged projects typically have a project champion who aggressively pursued cost sharing. The Watts Bar whole tree combustion project (in the Southeast) illustrates the positive role of an entrepreneurial manager. The project was spearheaded by a manager at an engineering company (Energy Performance Systems), who solicited TVA, DOE, ORNL, and EPRI support to add to funding from RBEP and his own company. Altogether, RBEP contributed $\$ 40,000$ to this project in 1990 , and the four external sources contributed $\$ 420,000$.

Working out multi-party agreements can be difficult and time consuming. This has resulted in a "hands-on" approach in one region and a "hands-off" approach in another. Headquartered in Washington, D.C., and housed in the Hall of States, the Northeast program has ready access to headquarters staffs from a wide variety of organizations and interest groups. Due to this networking, and a quick and efficient procurement process at CONEG, the Northeast finds itself at the center of many deals. While the process is time consuming, the regional program manager believes it is responsible for much of the region's leveraging. In contrast, the Southeast program manager has concluded that when he aggressively pursues project-specific cost sharing, he 
has to commit valuable time and energy that could be directed towards more region-wide efforts. For this reason, he has decided to manage the program so it provides a healthful climate for the development of cofunded projects. Some of the Southeast program's policies and procedures are discussed below.

External leveraging is particularly difficult when projects are contracted through an RFP system, because those who prepare proposals have little time and a fairly weak bargaining position from which to negotiate for cost sharing from other parties. The Southeast builds in a minimum of three months response time to its RFPs, to allow the proposer time to work out relationships with co-funders. It also provides suggestions and guidance to proposers concerning approaches to cost sharing. Cost sharing improves when the community that is preparing project proposals for submission perceives the rules to be reasonable, and applied fairly and firmly.

Rewarding successful cost sharing may also encourage multi-party participation. The Western region included a provision in a recent Program Opportunity Notice (PON), offering more funding to multi-party participative projects.

\subsection{LESSONS LEARNED}

- The RBEP is unusual amung government programs in the degree to which it has been able to attract outside rescurces. It has shown a variety of approaches to be successful.

Although levels and types of leveraging vary from region to region, all five of the regional programs are highly leveraged. The leveraging ratio for bioenergy projects across the program as a whole is conservatively estimated to be 1.9. RBEP's decade-long track record in orchestrating multi-party participation and the leveraging of resources provides a wealth of experience that should prove useful to DOE as it seeks to maximize the impact of federal investments.

Across the five RBEPs, a range of different approaches is used to draw in this leveraging. The Pacific Northwest and Alaska Bioenergy Program requires cost sharing on both its regional projects and its state-based demonstrations. The Southeast and Western programs require specific amounts of cost sharing on all the technology development and demonstration projects arising from their project solicitations, but they do not make explicit efforts to recruit cost sharing for these projects. The Southeast does not require cost sharing on market analyses or economic assessments, although cost sharing has frequently been associated with these types of projects. The Northeast, by contrast, actively recruits cost sharing for its multi-year activities and major programmatic thrusts. 
- RBEP has a golden opportunity to become a leader within DOE in establishing standards for the acquisition and reporting of leveraging. Guidelines based on its experience could benefit other programs within DOE.

An earty leader in resource leveraging, the RBEPs have a strong interface with industry and extensive experience with multi-party participation. They have a ten-year record of experiences with industry and interagency involvement to draw upon. The breatth of the program also gives them an opportunity to compare different approaches and different means of accounting for leveraging. This experience base could be useful for a broad range of DOE programs.

- The RBEP's diverse experience with leveraging encompasses the complexities of acquiring, computing, and reporting leveraging, and highlights the need for guidelines for the regional programs.

Working with a wide range of state and federal entities as well as private sector parties, the regional programs have developed diverse patterns in the ways they acquire, compute, and report leveraging. The regions vary, for instance, in the way they account for financial versus non-financial leveraging, as well as the way they treat the acquisition of funds from state agencies and oil overcharge funds. Application of similar conventions across the five regional programs would make it easier for RBEP to interpret its cost sharing experiences.

- Internal leveraging, or cooperation between the regional programs, has been associated with some of RBEP's most successful efforts.

Experience shows that the regional programs develop synergy when they come together to work on common projects.

- More industry involvement means more cost sharing.

Most of the Program's leveragea resources have been attracted by technology demonstration and deployment projects. Funding for these project types has come primarily from private sector industrial firms which are in a position to receive immediate financial benefits. Several types of projects are not usually associated with large amounts of cost sharing. Technology development efforts that are not linked to near-tern। market impact generally do not attain large amounts of cost sharing. The same is true for most resource assessment activity. 
Levels of cost sharing differ dramatically by type of contractor. Contracting with industry, in particular, is associated with strong leveraging. Projects conducted by consulting firms, state agencies, and university faculty, on the other hand, tend to attract relatively small amounts of cost sharing.

- There are many types of leveraging, and no simple relationship between leveraging and the value of projects.

Assessing the value of resource leveraging is a complex task because projects with especially high leveraging ratios are often not the projects with the greatest impact, while some important projects cannot be easily leveraged. 


\section{RECOMMENDATIONS}

Several recommendations emerge from this process evaluation that pertain to the planning, operation, and management of the Regional Biomass Energy Program. The lessons learned from the evaluation and the recommendations derived from them are illustrated in Table 6.1 and are discussed in more detail below.

- Continued support for state bioenergy programs. The regional programs have been instrumental in maintaining a bicenergy presence at the state level. Historically, the RBEPs have invested about half of their funds in support of a network of state bioenergy programs. This network represents a unique and valuable asset for the program. This national network of state bioenergy representatives should be maintained, and the program should find additional means to employ it. For instance, this network might be employed more actively in transferring information from the National Laboratories and other DOE research programs.

- Stronger DOE networking support. The DOE RBEP Office should increase its level of brokering activity within DOE. As an organization with a national network of state bioenergy representatives, the regional programs are ideally positioned as a bicenergy demonstration team for DOE. DOE management should promote this demonstration capability within DOE, and develop linkages for the regional programs through which costshared projects can be conducted.

- More active support of the technology demonstration component of DOE bioenergy development efforts. DOE should help broker these relationships. With its network of state representatives and closeness to the market, the RBEPs are positioned to provide support for DOE's other bioenergy development programs through jointly funded demonstration projects. This would help make use of RBEP's state network as well as its information dissemination capability, and would bring in needed funds for demonstration activities.

- Greater focus. The breadth of the RBEP and regional program objectives should be narrowed, especially since budgetary constraints limit the number of objectives that can be achieved. Attention should be focused on the deployment of market-ready technology, including the systematic targeting of likely candidates for bioenergy adoption and increased support for technology demonstrations. Projects involving technology development that do not have near-term market potential should be discouraged.

- Stronger emphasis on market-ready, short term projects is needed. RBEP's distinctiveness among DOE sponsored programs is the degree to which it is linked with industry and immediate or near-term commercial potential. RBEP should strengthen this focus. This could be made more workable if RBEP positions itself as the bioenergy demonstration arm of DOE, and can obtain funds for the support of demonstration projects from other components of DOE.

- Recognition for the program's success in the acquisition of outside resources. The regional programs have been unusual in the degree to which they have leveraged resources from the private sector and other governmental agencies. This achievement should be recognized.

Development of guidelines for reporting of leveraged resources. The diversity of the five RBEP programs and their related state programs provides a breadth of experience with resource leveraging. Because of this diversity, and the importance of leveraging as a performance indicator, the RBEP should develop guidelines for reporting leveraging in the future. Such guidelines could prove useful to other programs within DOE. 
- The use of leveraging ratios to allocate funding to the regions should be minimized until reporting standards are developed and the regions have had time to adapt to them. Experience from within RBEP suggests that there are many types of leveraging, and there is not a direct relationship between leveraging and the value of projects. Many inherently valuable projects cannot be easily leveraged. And projects with especially high leveraging ratios are often not the projects with the greatest impact. The RBEPs should be careful about selecting projects on the basis of the amount of leveraging they can assemble, and the funding formula should not reward "leveraging" until these issues are addressed more fully.

- Expanded industry participation in regional contracting. While industry participation has been active in all regions, industry contracting on regional projects has been limited. On a nationwide basis, industry participants have received only abcut $6 \%$ of all funds used for regional projects. This percentage should be increased, since contracting with industrial partners is an effective means of promoting technology transfer and could help to accelerate the acceptance of biomass technology.

- Stronger involvement of industry in planning. The regional programs have developed strong, participatory planning procedures involving planning committees and technical advisory groups. In each of the five regions, industry has provided significant input into the deliberations of these committees. This industry involvement should be maintained. In addition, industry representation should be extended to the planning committees in all five regions.

- Enhancement of host relationships. Host organizations have had a significant impact on the structure and activities of the regional programs. The DOE should encourage active support on the part of host agencies. The support the Northeast region has received from CONEG illustrates the potential benefits the RBEPs can receive from strong relationships with hosts. Where active involvement in planning and carrying out of RBEP objectives is not forthcoming, DOE should consider alternative hosts.

- Reduced reliance on support services contracting. The Western and Pacific Northwest regions have acquired substantial management assistance from support services contractors. The magnitude of support services contracts in these two regions may create problems of coordination and control. Such problems could be avoided by reducing this reliance on outside contractors and expanding in-house staff responsibilities.

- Quantifiable goals for the regional Programs. Each of the regional programs should examine its goals and objectives to identify opportunities to develop quantifiable targets by which to track progress. Examples of quantifiable measures that might be incorporated into objectives include the MBtu's recovered from bioenergy sources and the number of conversions assisted by program efforts. Similarly, the RBEPs should develop more quantitative goals for the state bioenergy programs that they support.

- Impact evaluation of the RBEP. The national program should develop a set of quantitative goals for the program on a national basis, as well as a system to track program performance. It should identify specific measures of program opportunity, and develop quantifiable targets based on these measures. After these quantitative goals and tracking systems have been established and in operation for some period of time, the national program should undertake an impact evaluation to assess the program's performance. 
Table 6.1 Lessons Learned and the Recommendations Derived from Them

\begin{tabular}{|c|c|}
\hline 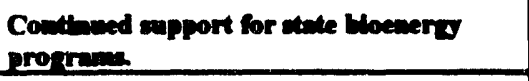 & 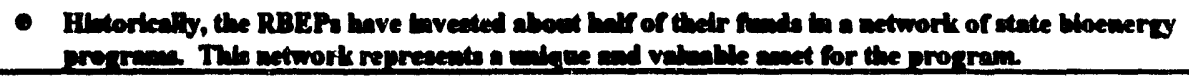 \\
\hline Stromer DOR wetworitang mpport. & 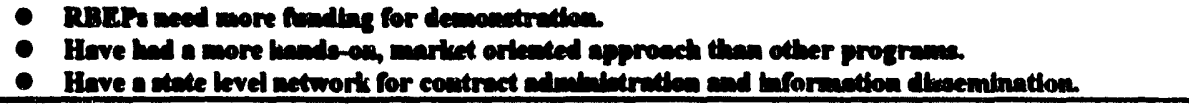 \\
\hline 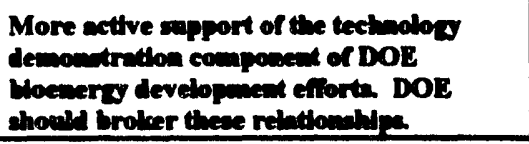 & 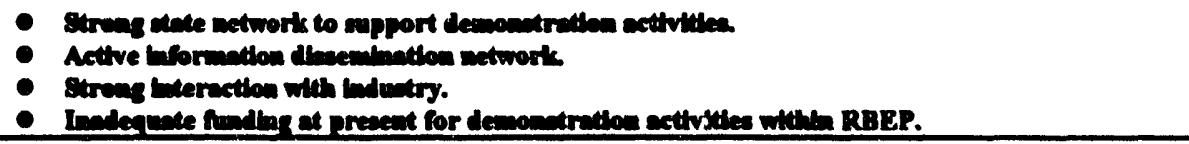 \\
\hline Greater foces. & 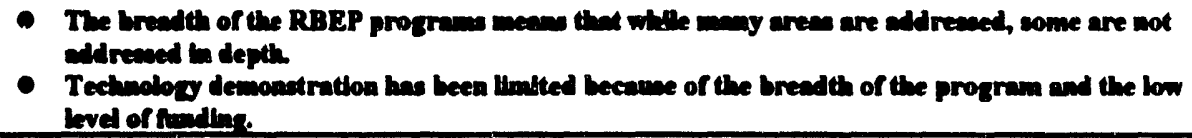 \\
\hline $\begin{array}{l}\text { Stronger emplunde on martet-ready short- } \\
\text { terme projectil. }\end{array}$ & 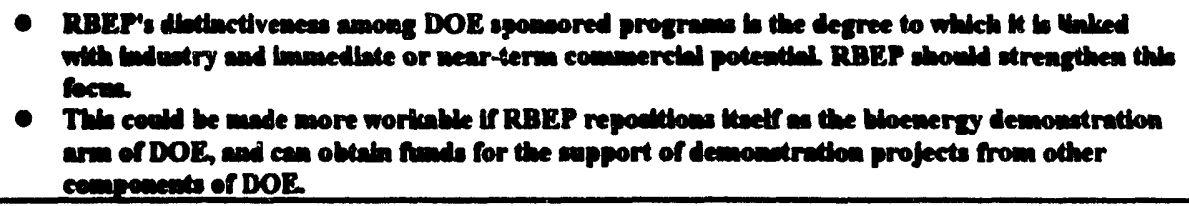 \\
\hline 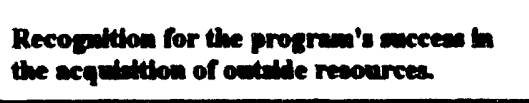 & 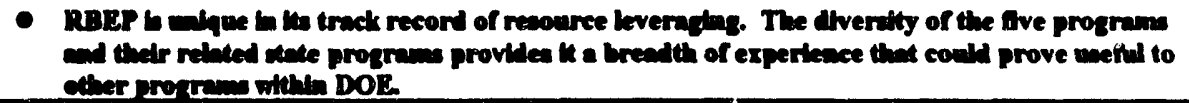 \\
\hline $\begin{array}{l}\text { Development of gudelwes for reporting } \\
\text { newource levern ing. }\end{array}$ & 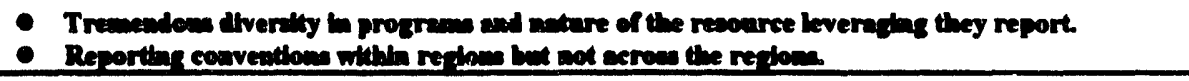 \\
\hline 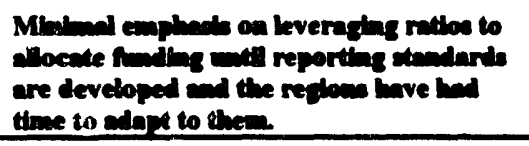 & 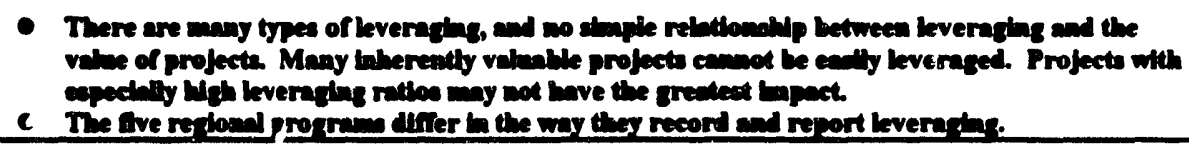 \\
\hline 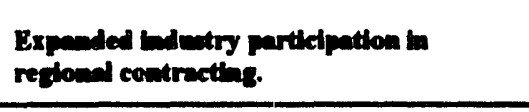 & 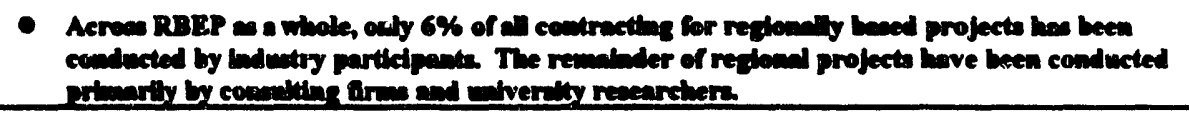 \\
\hline $\begin{array}{l}\text { Stronger buvolveswemt of moleatry in } \\
\text { planning. }\end{array}$ & 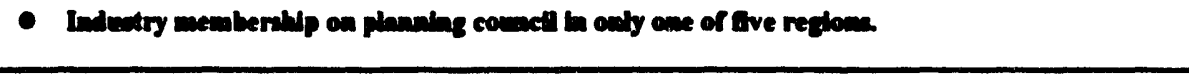 \\
\hline 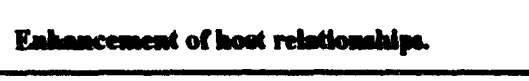 & 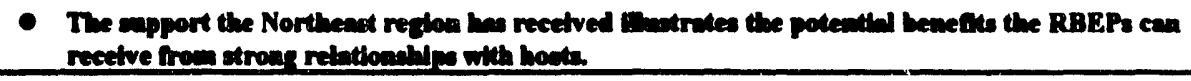 \\
\hline $\begin{array}{l}\text { Reduced rellance on mpport services } \\
\text { condracting. }\end{array}$ & 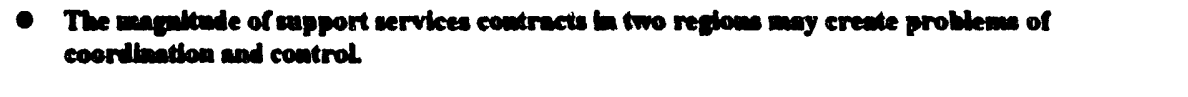 \\
\hline $\begin{array}{l}\text { Quantianble goelb for the regional } \\
\text { programe. }\end{array}$ & 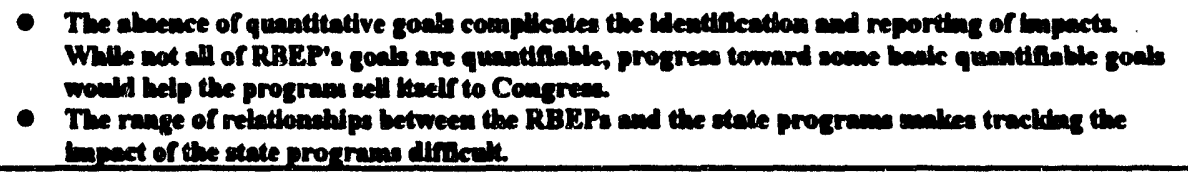 \\
\hline Impact eveluation of the RBEP. & 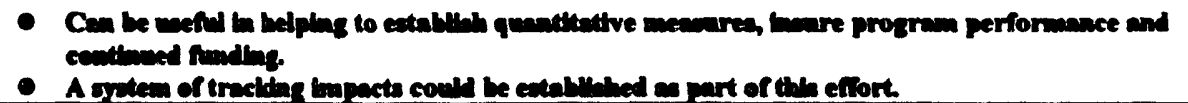 \\
\hline
\end{tabular}


APPENDIX A

CURRENT BIOENERGY USE, FUTURE POTENTIAL, AND BARRIERS TO PRODUCTION AND USE 


\section{CURRENT BIOENERGY USE AND FUTURE POTENTIAL}

Total primary renewable energy consumption in the U.S. is about 6.3 Quads.' Biomass contributes about 2.9 Quads or $46 \%$ of this total, with hydroelectric power contributing about $47 \%$ and geothermal, wind, and solar accounting for $6 \%$ (Fig. A.1). Wood wastes and residues make up $82.1 \%$ of total biomass consumption. Other biomass wastes, such as manufacturing wastes, municipal solid wastes, and methane produced at landfill sites account for about $14.3 \%$ of total biomass. The remaining $3.6 \%$ is ethanol derived from com.

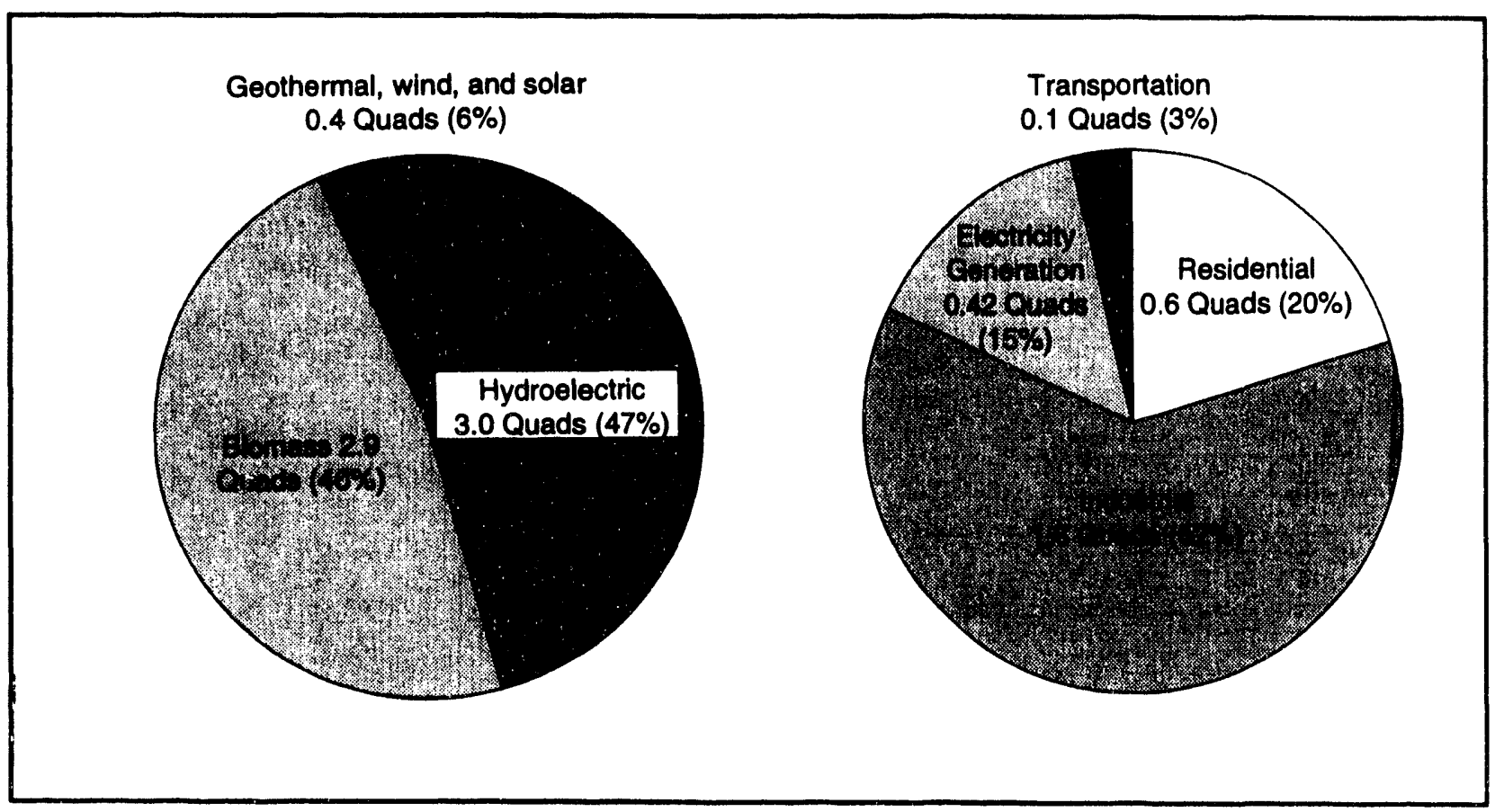

Fig. A.1 Current Bioenergy Use in the United States

Over $80 \%$ of the 2.9 Quads of biomass energy produced each year is used in industrial processes, which accounts for $62.1 \%$ of total biomass energy, or for residential uses, which consumes $20.0 \%$. Electrical generation employs $14.5 \%$ of total biomass energy while the transportation sector commands but $3.4 \%$. Industrial use of biomass is for process heat and cogeneration applications. The primary users are the lumber and pulp and paper industries, which have a ready supply of wood and waste product feedstock. Residential use of biomass (wood)

Estimates of biomass energy consumption in this section are derived from Energy Information Administration, Annual Review of Energy, U.S. Department of Energy, DOE/EIA-0384(91), Washington, June 1992. 
is nearly all for space heating, and is the primary source of heat for about $17 \%$ of the 23 million households that burn wood. The transport sector is a relatively small user of biomass energy.

Independent power producers (IPPs) are the source for over 95\% of the 0.42 Quads of electricity generated from biomass. In 1990, IPPs generated nearly 40 billion kWh from $7.5 \mathrm{GW}$ of installed biomass electric generating capacity. Wood and wood wastes were used to generate about $77 \%$ of this power with MSW accounting for the remaining $23 \%$. During the 1980 s electricity generation was the fastest growing use of biomass.

Table A.l summarizes biomass energy consumption by U.S. census regions for selected years during the 1980s. The data show that wood energy use declined during the 1980 s in the Northeast, Midwest, and South regions. The West was the only region where wood energy use increased. The decline in wood energy use occurred mostly in the residential sector. Although the number of households reported to burn wood increased during the 1980 s (21.6 to 22.9 million), the average amount of wood burned per household declined by about

Table A.1 Biomass Energy Consumption by U.S. Census Region for Years 1981, 1984 and 1990 (trillion Btu)

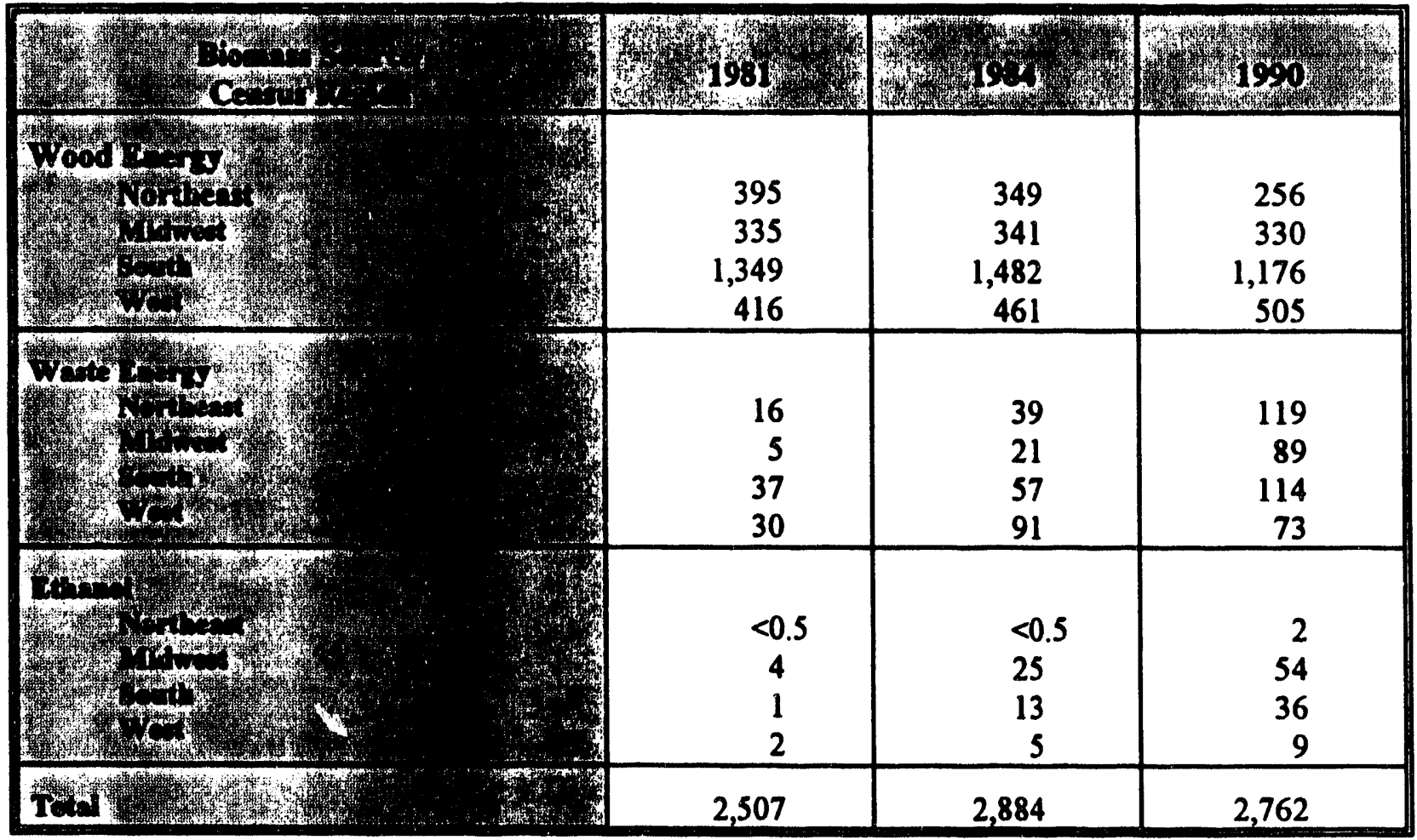

Notes: Census regions are not consistent with DOE RBEP regions.

Source: Energy Information Administration, Annual Review of Energy, U.S. Department of Energy, DOE/ELA-0384(91), Washington, June 1992. 
$35 \%$. Incustrial wood energy use increased slightly and electric utility use increased substantially. Waste energy and ethanol fuel consumption increased in all regions.

The growth in biomass-fired power generation (wood waste and MSW) and ethanol production was due in large part to addod financial incentives, which helped to reduce market barriers. For example, there was over a thirty-fold increase in biomass-fired electric generating capacity. The presence of PURPA legislation with favorable buy-back rates plus the availability of low- or zero cost feedstocks prompted many to invest in biomass capacity. The growth in U.S. ethanol production was the result of favorable financial incentives as well -- a federal excise tax subsidy and, in some cases, state subsidies for ethanol production. Under current federal law, ethanol blenders are allowed a 5.4 cent per gallon exemption from the gasoline excise tax on blends containing at least $10 \%$ ethanol. State subsidies are much less in amount and exist primarily in the Midwest.

Biomass has perhaps the greatest QUAD potential of all the renewable sources of energy. Biomass is also the most versatile -- it can be burned to provide heat and power, it can be gasified through incomplete burning or anserobic digestion to produce a low- or medium-energy content gas and it can be thermochemically or biochemically converted into a variety of liquid fuels (ethanol, methanol, and synthetic hydrocarbon fuels). Biomass technology also has the capacity to provide for disposal of wastes and to offer both local and global environmental benefits. For example, biomass has very little sulfur and if grown renewably adds no carbon dioxide to the atmosphere.

\section{BARRIERS TO PRODUCTION AND USE OF BIOMASS RESOURCES}

The RBEP seeks to increase the production and use of biomass energy. However, efforts to advance greater biomass energy use are constrained by a host of market, institutional, regulatory, public perception, and technical barriers. Surmounting these barriers is a prime objective of the regional programs.

\section{Market Barriers}

- Cost of Conventional Fuels. The low cost of conventional fuels makes it difficult for biomass to compete successfully. Relatively stable oil and gas prices have discouraged residential use of biomass and slowed institutional and industrial conversions. Utility avoided cost calculations have reduced buyback rates to levels that are too low to attract the interest of potential developers. Currently, biomass power generation is viable only in instances where there are low- or negative-value feedstocks.

- Costs of Biomass Energy Systems. Costs of biomass systems are often too high relative to uncertainty of the technology and the unfamiliarity of the technology to potential users. Costs and risks associated with biomass fuel collection, handling, transport, storage, and processing discourage the use of biomass energy. 
- Environmental Externalities. The favorable environmental externalities and resource management benefits associated with biomass energy cannot be internalized by potential developers. Conventional fuels often have hidden subsidies. Few public utility commissions have addressed externalities from the use of conventional fuels. Biomass proponents charge that the playing field needs to be levelized to have fair competition.

- Biomass Resources Infrastructure. There exist uncertainties in the supply of biomass fuels. Potential users are concerned about the infrastructure and logistics for harvesting or collecting woodfuels, recycling wood wast s, supplying end-users with a sufficient degree of assurance, and having a service and supply infrastructure available for biomass combustion facilities. In all regions, the undeveloped nature of biomass energy feedstock markets contributes to the underutilization of biomass energy.

- Financing Issues. There are insufficient financing mechanisms for industry development. Investment tax crodits no longer exist to stimulate investment in biomass equipment. The amount of biomass-fired capacity going into service declined from a high of $1840 \mathrm{MW}$ in 1986 to $200-300 \mathrm{MW}$ in $1990{ }^{2}$ This docline is partly due to the absence of tax credits. Financing for biomass systems, which are sometimes perceived as speculative investments by lenders, is difficult to obtain.

- Lack of information. There is a general lack of information about the technical feasibility and the financial viability of many biomass energy systems. Biomass energy is perceived as risky, unreliable, and old-fashioned.

\section{Institutional and Regulatory Barriers}

- Plant siting requirements. Numerous permitting, siting, and environmental requirements, and regulatory issues must be confronted before a biomass facility can be made operational. Environmental emissions from combustion facilities are of paramount importance in siting decisions. Moreover, siting requirements often vary by state within each $R B E P$ region.

- Environmental Regulations. Regulations on use of wastes as feedstocks, emissions from facility boilers, and disposal of ash are complex and confusing to potential developers. Emissions from biomass facilities are not well understood or communicated by developers, regulators, or environmental groups. Regulations concerning the disposal of ash are not clear. Composition of the biomass feedstock (wood wastes, MSW) being combusted affects emissions. Moreover, the complexity of regulations is exacerbated when there are differences across states.

- Utility integrated resource planning programs. Utility and state IRP programs do not fully recognize biomass as a technically viable power generation option.

- Insuficicient tax credits $(\$ 0.15 / \mathrm{kWh})$ for biomass. The recent passage of the $1.5 \mathrm{cent} / \mathrm{kWh}$ production credit is for use of dedicated biomass feedstocks (i.e., grown exclusively for a biomass facility). It does not include existing resources or wastes. The National Wood Energy Association (NWEA) estimates that extending this credit to all biomass would lower U.S. revenues by $\$ 182$ million, but create substantially more additional revenues from corporate and payroll taxes from biomass facilities. NWEA reports that subsidies to conventional fuels total some $\$ 2.5$ billion.

U.S. Department of Energy, Electricity from Biomass, Office of Solar Energy conversion, April 1992. 
- Need for stronger stakcholder coalitions. Biomass has no strong coalition of stakeholders. There is no adequate system for bringing potential suppliers of feedstocks together with potential users. Various interest groups are often at odds about the benefits of biomass energy. The pulp and paper industry is often an uncooperative partner for not wanting to share the resource. The agriculture sector is uninformed and conservative, and has been reluctant to promote biomass as an alternative crop.

\section{Public Perception Barriers}

- Plant Siting and Environmental Emissions. Biomass energy and in particular waste to energy plants are difficult or almost impossible to site. Not-in-my-backyard (NIMBY) effects and the interests of various local political and environmental groups have effectively prevented the location of many biomass energy facilities. Much of this apprehension is because emissions from biomass facilities and the overall resource management and environmental benefits of biomass are not well-understood by developers, regulators, and environmentalists.

- Information. There is a general lack of information about the technical feasibility, financial viability, and environmental effects of utilizing biomass energy. The recognized benefits of biomass as a means of cost-effective waste disposal, recuced landfill costs, and other local and global environmental benefits are not understood by the public.

\section{Technical Barriers}

- Availability of Biomass Technology. Conversion equipment is needed that is able to offer high efficiency at low capital costs. Biomass power is currently competitive in situations of low to negative value feedstocks. As low-cost biomass feedstocks are used there will be a need to develop dedicated supplies. The extra cost of these feedstocks will need to be partially offset by conversion technology cost reductions (lower capital costs and/or higher conversion efficiencies).

- Lack of Industrial Standardization. One problem with biomass is that there is little industry standardization and little interest from industry in developing standards and in producing technology in the appropriate scale for biomass. Biomass conversion technologies are often relegated to side activities of many of the larger private firms. There is little industry involvement in developing more efficient and cost-effective biomass harvesting systems. Industry has shown a reluctance to develop and refine biomass technology without a clear indication of the potential market (sales revenue).

- Information. Biomass feedstock handling, processing, and conversion technologies are not wellunderstood by potential developers, regulators, environmental groups, and the general public.

- Need for Technology and Feedstock Supply Infrastructure. The supporting infrastructure for biomass is not in place. Fuel supply and its availability is an integral part of a biomass energy system. Potential users without an existing feedstock supply may be unlikely to convert to biomass without some form of supply guarantee.

- Feedatock Properties and Storage Considerations. Biomass feedstocks have different physical and chemical properties that must be taken into consideration. Factors affecting biomass storage (physical space, degradation, logistics of supply, and seasonality of supplies) are complex and not wellunderstood. Conversion technology may not be amenable to mixing of feedstocks. 
- Fuel Standards. There are no fuel standards for biomass. Feedstocks vary considerably with respect to physical and chemical characteristics. Technology choice and performance depend on fuel characteristics. Biomass feedstocks may be contaminated with undesirable components (e.g., treated wood, MSW containing a host of unknown chemicals, etc.), which affects emissions and raises difficult permitting and siting issues.

Overcoming these numerous barriers requires the enlistment of both the public and private sectors. To this end, RBEP has been on the forefront of coalition building. It has supported a wide array of activities aimed at enlisting stakeholder groups to see that technology needs and energy and environmental policy issues are being addressed. Issues associated with how RBEP plans, selects projects, and interacts with its public and private sector partners to promote biomass energy are discussed in the main body of this report. 
APPENDIX B

RBEP GOALS AND OBJECTIVES 


\section{RBEP GOALS AND OBJECTIVES}

\section{Great Lakes Region}

The goal of the Great Lakes RBEP is to increase the production and utilization of biomass fuels in the Great Lakes states. Its objectives include:

- to improve the capabilities and effectiveness of biomass energy programs in state energy offices;

- to assess the availability of biomass resources for energy in light of other competing needs and uses;

- to encourage private and public sector investments in biomass energy technologies;

- to transfer the results of govemment-sponsored biomass research and development to the private sector;

- to eliminate or reduce barriers to private sector use of biomass fuels and technology; and

- to prevent or substantially mitigate adverse environmental impacts of biomass use.

\section{Northeast Region}

The goal of the Northeast RBEP is to increase acceptance and application of biomass energy technologies by the private sector and local governments. Its objectives include:

- identify and remove barriers to biomass energy development;

- establish the availability of biomass resources in the Northeast.;

- encourage private investment in biomass fuels harvesting and processing;

- promote investment in biomass and waste-to-energy facilities;

- contribute to solid waste management solutions and biomass energy utilization goals;

- contribute to understanding and mitigating environmental impacts of biomass harvesting and use; and improve the coordination among, and capabilities of, state agencies with biomass-related responsibilities.

\section{Northwest Region}

The goal of the Northweat RBEP is to expand the use of biomass energy within the region, emphasizing cost-effective, environmentally sound options. Its objectives include:

- to strengthen and expand the region's efforts to encourage acceptance and use of biomass fuels through technology transfer and educational activities; 
- to continue developmental activities leading to cost effective resource recovery and energy conversion options that abate or mitigate environmental concerns resulting from energy conversion activities and waste disposal;

- to continue technical assistance and commercialization activities that will match local biomass resources with energy requirements; and

- to foster cooperation between industry and energy agencies through cost-shared projects that will build private sector confidence in the adoption of biomass energy technologies.

\section{Southeast Region}

The goal of the Southeast RBEP is to encourage the production of biomass feedstocks and their conversion to fuels by the private sector through support of regionally specific biomass energy projects. Its objectives include:

- to establish the availability of biomass resources within defined regions through resource assessment studies;

- to enable industry to match local resources with conversion technologies that will permit private sector investments in biomass energy technologies.

- to transfer results of research and development to the private sector; and

- to establish a partnership with industry through cost-shared projects that will build private sector confidence in adopting biomass energy technologies.

\section{Western Region}

The goal of the Western RBEP is to stimulate the use of biomass resources which are regionally important, technically and coconomically sound, and which address the energy needs of the Western States. Its objectives include:

- to conduct assessments of the biomass feedstocks available in the Western region in order to compile current and ongoing information about the composition, quantity, and location of regionally important resources;

- to establish and continue systematic reviews of technologies to identify those most suitable for use with the biomass resources available and which have practical application to the energy and economic development needs of the Western region; and

- to strengthen the links between parties which have biomass feedstocks, knowledge of conversion technologies, and are potential end users in order to establish working relationships, initiate cost-shared projects, and build private-sector confidence in the use of biomass energy. 
APPENDIX C

PROGRAM PLANNING, BY REGIONS 


\section{PROGRAM PLANNING, BY REGIONS}

\section{Planning Committees and Technical Advisory Groups}

Great Lakes. A 40-member Technical Advisory Committee (TAC) establishes priorities for the biomass needs of the Great Lakes region and recommends programs to address those needs. TAC members are appointed annually and are biomass professionals from federal agencies, state agencies, universities, industry, not-for-profit organizations, and trade associations located throughout the seven-state region. Each state has five TAC members and there are five members from regional federal agencies. The responsibilities of the TAC are to: attend an annual program meeting, review technical materials and proposals, provide recommendations on all technical issues, and assist in the drafting and reviewing of requests for proposals.

The TAC is currently organized into three working groups -- forestry, municipal solid waste, and agriculture. The TAC meets as working groups. Each working group will discuss and develop project proposals that are sent to the Great Lakes Regional Biomass Program Steering Council (SC) for approval.

The SC is a seven-member committee that provides guidance to the Great Lakes program Project Director on overall project management. This body is composed of one representative appointed from each of the seven states by their respective governor. The role of the SC is to act on the recommendations of the TAC, advise the Project Director on specific program activities, and set basic program guidelines. In general, the SC tends to follow the recommendations of the TAC. However, the SC will often make changes in projects by reducing the scope of activities, combining projects, and otherwise exercising judgment. The SC also approves annual operating plans and provides guidance regarding short- and long-term policy directions. The SC has the major role in developing projects and in preparing the formal request for proposals. Steering Council membership is fairly stable with little annual turnover.

Long-range planning through its SC or TAC has not been a key priority with the Great Lakes program. The Great Lakes program has had a primary mission to fund cost-shared state programs. The limited availability of funding beyond that required for state programs has also limited planning for regional projects.

Northeast. The Northeast Regional Biomass Program has a Steering Committee (SC) that consists of state appointed members and non-voting consultants. The operation and function of the SC is similar to other regions in that it provides general programmatic guidance, defines technical projects, and places requests for proposals. The criteria the SC uses for selecting projects include agreement with Northeast program objectives, regional significance, opportunities for cost-sharing, contributions no other organization is making, useful technology transfer tools, and consistency with available resources. 
The SC is also largely responsible for assembling technical advisory groups. The technical advisory groups are used to provide oversight for the subcontracts and grants that have been identified by the SC as important to the region. The SC makes an effort to ensure that advisory groups represent a range of state and private sector interests. The Northeast program tries to get additions to their advisory groups through talks with state representatives and agencies and with industry.

To guide their planning efforts, the SC organized a long-range planning exercise that spanned six months during 1984. The 1984 Long Range Planning Task Force was organized into three committees: (1) supply -focused on feedstock issues and competition for the resource; (2) demand -- examined both constraints and opportunities; and (3) conversion technologies -- addressed direct combustion, gasification, cogeneration, and other conversion processes. Membership on these committees was composed of representatives from state and federal governments, industry, academia, national umbrella organizations, and small businesses. The recommendations generated by the Planning Task Force in 1984 were generally adopted by the Northeast program.

During the 1980 s the Northeast program became involved in several areas identified by the long range planning task force as important for the region: MSW, commercial and industrial wood conversions, domestic wood stoves, and forestry concerns. This Long Range Plan was updated in 1989 based on interviews with individuals and a review of pertinent research and reports. To support the planning process, five different meetings, convened in various locations throughout the region, took place between June 1988 and August 1989. Representatives at the meetings discussed current conditions and future priorities in four areas of concern. Environmental impacts, economic impacts, and fossil fuel displacement (national security implications) were discussed for each issue area. New project ideas have resulted from this planning exercise.

Northwest. The Pacific Northwest program has a Task Force Committee, composed of one or two members from each state, who are appointed by their respective governors. The members are usually from federal and state energy, resource management, and environmental agencies. In general, the Task Force provides guidance to the regional manager in the development of program direction and plans. Each task force member is involved in biomass energy at the state level and maintains a network of contacts with industry representatives. Members stay informed by exchanging information with each other and by participating in task force meetings. During these meetings, presentations are made by individuals from universities, industry, testing laboratories, trade associations, and consulting and engineering firms

Activity area working groups, which are primarily composed of Task Force members, were established to develop a strategic plan for each of four activity areas: 
- Technology Transfer, Information, and Education. The focus of this working group is on identifying subject matter and communication methods, and integrating its activities with those of other regional programs and national laboratories.

- Municipal Solid Waste. This group identifies subject areas to foster the development of MSW as an energy alternative.

- Biomass Derived Liquid Fuels. This group attempts to identify resource development activities that are necessary to move ethanol and other liquids (e.g., diesel substitutes) as viable fuel options.

- Biomass Fuel Combustion. This group identifies target areas that can further the development of residential wood consumption and mitigate environmental emissions.

For each programmatic area, the working groups develop project recommendations that encompass: purpose, scope, level of effort; approaches and tasks; schedules and milestones; funding; performance criteria; and measurable program objectives.

Southeast. The Planning Committee (PC) for the Southeast program gives general guidance to the Southeast program manager and plays a key role in the selection of projects to be funded. Its 17 members have three-year terms, and represent private industry, universities, government agencies, and the two DOE support offices within the region. Other stakeholder groups are also represented and currently include the Audubon Society, the Southem States Energy Board, and the National Food \& Energy Council. In contrast with the Northeastern, Great Lakes, and Northwestern regions, non-govermmental representatives predominate, and only two state governments (GA and AL) are represented on the Planning Council. The Southeast program, which is not tightly linked to a regional organization of governors, has chosen this balance to insure its responsiveness to industry viewpoints and address the interests of stakeholder groups.

Peer review groups are used to review solicited proposals. These groups are composed of experts in a particular field, are usually from widely dispersed geographic backgrounds, and are changed every year. Proposals are mailed to the review groups for review and then the groups meet after $\mathbf{3 0}$ days for one-half day to finalize funding recommendations. The group leader is usually from TVA - the host organization.

A review of the annual planning meeting illustrates how the state contacts and the planning committee have worked together since 1990. On the afternoon of the first day of the meeting, peer review groups meet for review of proposals. The next morning the planning committee and the state bioenergy staffers meet together to hear task force reports and develop a consensus for the following year. On the third day of the meeting, the Peer Review teams report to the planning committee on the proposals received. The chairs of each review team present the top three proposals emerging from the peer review team. These are put on flip charts, discussed, and voted on by the planning committce. 
Western. For the Western program, an Ad Hoc Committee provides guidance on program direction, implementation, and development. Members of the Ad-hoc Committee are appointed by the respective governors of each state. A key responsibility for the members is to provide visibility within their respective states. They are the primary point-of-contact for biomass energy. They also promote Western program biomass energy project solicitations and encourage submission of proposals by individuals with biomass interests in their State.

A Resource Group provides advice on specific biomass resources and identifies technologies that will stimulate the use of such resources for energy conversion. The focus of the resource group is on agriculture -the predominant source of biomass within the region. The Resource Group also identifies and recommends projects, promotes solicitations, and encourages submission of proposals by their constituent groups.

The Western program also makes use of Technical Review Teams to provide technical review on proposals submitted in response to competitive solicitations for biomass energy projects. Members of the Technical Review Team are recognized experts in biomass resources and/or the energy technology being pursued. Members are selected informally and come from numerous organizations -- national laboratories (NREL), inhouse staff, and from recommendations from DOE.

\section{The Role of Host Organizations}

Great Lakes. The Great Lakes program is physically housed within the confines of the Council of Great Lakes Governors. This provides for frequent high-level contact with state officials and also facilitates contacts with the private sector (e.g., ethanol industry). There are no formal reporting requirements by the Great Lakes program to their host organization. However, copies of weekly reports and financial records are made available. The staff of the Council is about six in number and this explains why much of the day-to-day contact with the Great Lakes Regional Biomass Program is rather informal. The lack of sufficient Great Lakes program support staff also explains the informality of contact with the host organization.

The Council provides considerable support to the Great Lakes program. This support is in the form of photocopying, general office support, computer facilities, and office space. The percentage of the Great Lakes program budget consumed by the host organization is small (2-3\%), and is primarily used for building overhead.

Northeast. CONEG (Coalition of Northeastern Governors) is actively involved with the Northeast program. In the early years of the Northeast program, CONEG was instrumental in providing continuity when DOE support was minimal. CONEG often is involved in Northeast program projects. For example, CONEG has a solid waste task force that is working with industry to reduce packaging. This effort complements MSW efforts. CONEG also helps the Northeast program develop integrated approaches to biomass energy issues. It can get state solid waste managers involved through linkages with governors. 
CONEG's relationship with state govemors has given the Northeast program visibility within the region. Relationship is similar to that of Council of Great Lakes Governors and Great Lakes Region. State projects require a supportive letter from the governor, and CONEG helps corral that support. Several governors have mentioned biomass as an important issue. CONEG also provides linkages with national organizations by having headquarters located in Washington. CONEG has also provided direct funding to projects undertaken by the Northeast program. This funding is particularly useful for projects that extend over multiple years.

CONEG requires biweekly updates and status reports and quarterly progress reports. The Northeast program is also subject to monthly budget and financial reviews. Six percent of total Northeast program grant funding is used to pay CONEG overhead and eighty percent of the cost of the direct labor CONEG provides for the Northeast program is charged to the program. CONEG requires some standardized boiler plate in the contracts, quarterly project reports, and retains signature authority. Support services from CONEG includes some secretarial support, computer facilities, office equipment, and document warehousing.

Northwest. Since the latter part of the 1980s, the BPA has allowed the PNA Bioenergy Program to follow its own course. This is consistent with the BPA's approach to decentralization of decision making that frees line managers to make certain program decisions without requiring explicit approval from higher management. Following this general principle, BPA managers rarely participate in program planning and do not vigorously monitor the activities of the program.

BPA provides all procurement support as delineated in the Bonneville Acquisition Guide. All acquisitions (inter-agency agreements, grants, contracts, purchase orders, etc.) are processed through BPA's procurement office. The BPA procurement office also issues announcements, RFPs, collects all technical proposals, makes awards, tracks contract progress, and issues close-out documents.

In addition to handling all contracting issues, BPA provides secretarial support, photocopying, printing, computers, and general office support. Travel assistance is also provided through the BPA travel office. About 5 to $10 \%$ of the bioenergy program budget is consumed by the host organization.

The Pacific Northwest program provides all procurement information, annual budgets, and technical reports to BPA. Periodic briefings are also made to BPA management.

Southeast. The Southeast program is housed within the TVA's National Fertilizer and Environmental Research Center in Muscle Shoals, Alabama. TVA management has little contact with the program at present, but at the inception of the regional program, they encouraged emphasis on market ready technology and alcohol fuels. TVA is able to provide several types of in-house support for the Southeast program, including an in-house printer, contracting support, and office equipment. The Southeast regional program manager has made use of the technical staff at TVA by seeking TVA employees as technical monitors for Southeast program projects. In most 
cases, these positions have been filled by staff members from the Muscle Shoals facility where the Southeast program is housed. TVA has also provided library resources and interlibrary loan access.

TVA Central Accounting performs primary accounting and billing for the regional program. TVA has also provided some support in the development of contracts, although relative to the other four regional biomass programs, this has been counterbalanced by the red tape involved in the contracting process. TVA overhead is $35 \%$ of all funding used in-house; this equates to roughly $10 \%$ of the overall Southeast program budget.

Western. The Westem program has an arrangement with their host orgzizization similar to that of the Northwest program. The host organization prepares all contracts, purchase orders, cooperative agreements, cost analysis, legal review, and contracting officer review. The host organization's financial management system is also used, which provides monthly reports, commitments, and obligations. For support services, WAPA provides secretarial support, photocopying, computers, office space, and general office support. The host organization also provides a technical writer to facilitate the preparation of publications, briefs, and presentations. The Western program provides weekly reports to WAPA. Less than $10 \%$ of the regional budget is consumed by the host organization. 
APPENDIX D

PROJECT PORTFOLIOS, BY REGION 


\section{OVERVIEW OF PROJECT PORTFOLIOS, BY REGION}

Great Lakes. Historically, the Great Lakes Regional Biomass Program has been divided into two main initiatives - state grants and regional projects. The state grants are intended to provide funding (with a 50 percent matching requirement) to each state energy office, to encourage joint biomass energy activities between the state energy office and other state agencies, and to address state specific biomass energy issues. In contrast, the regional projects are intended to address biomass energy issues that are important to the entire Great Lakes region.

State grants have been the priority activity for use of Great Lakes program funding. Regional projects have been funded subject to overall budget levels and supporting state energy offices. During the last three years (1991, 1990, and 1989) there were five, four, and two regional projects supported, respectively. The lack of funding in 1988 meant that no regional projects were supported. In 1987, four regional projects received support.

The grants awarded to each state over the past five years have supported a variety of activities and projects. The state projects have largely been aimed at information development and dissemination. The regional projects or the subcontracted activities have focused on a few themes. Initial regional projects focused on the use of agricultural residues, direct combustion conversion processes for residues and wood, and the compilation of a directory of biomass facilities. More recently, the program has focused on ethanol fuel production. The region produces about three-fourths of the U.S. ethanol. The greater emphasis being placed on reducing U.S. dependency on imported oil, the recent passage of the Clean Air Amendments calling for greater use of oxygenated fuels, and the fact that RBEP funds are limited means that a focus on ethanol for the Great Lakes region makes sense. However, the program still supports work on biomass combustion and related activities .MSW, pelleting, emissions and ash testing.

Northeast. The Northeast program also has a state grant program and a regional project program. The state grants are dispersed to states with a 50 percent matching requirement. These grants are for strengthening and facilitating interagency (e.g., forestry, energy, air quality, etc.) cooperation on state-specific biomass energy issues. Among the issues addressed by the state grants are: industrial energy conversion, resource availability and use assessments, technical information development and dissemination, and conversion of state facilities to biomass energy.

Regional projects have centered on a few important issues -- MSW and the associated problems of resource recovery and landfills, wood energy conversions, residential wood stoves, and environmental issues (including emissions from combustion processes, ash testing, and biomass and global warming). 
Northweat. The Northwest has five major programmatic areas -- state activities, technology transfer, biomass fuel combustion, biomass derived liquid fuels, and MSW. State activities within the region are broad. States are required to provide help in the development of information related to state regulatory requirements, environmental impacts, biomass energy planning, private sector involvement in biomass energy, and technology transfer and information dissemination. In addition, each state is supposed to serve as an information center in a specific subject area. The Northwest program also makes available to each state grants for biomass demonstration projects.

Biomass fuel combustion projects have centered on the environmental problems associated with the use of woodstoves. The regional program has sponsored research aimed at reducing emissions -- emission testing and certification, pellet stoves, pellet fuel combustion testing, and efficiency improvements. Liquid fuels from biomass projects have examined the use of deriving ethanol from MSW and demonstrating the use of vegetable oils as diesel fuel substitutes. MSW projects have focused on energy recovery, information dissemination, and recycling.

Southeast. The Southeast has four major programmatic thrusts. These include the assessment and development of regional biomass resources, development and application of biomass technologies, information development and transfer, and development of state biomass projects. The programmatic activities have focused on the utilization of woody biomass, agricultural wastes and residues, animal wastes, industrial wastes, MSW, and sewage wastes. These resources are greatly underutilized within the region. The Southeast program has recently completed region-wide assessments of all of these biomass resources.

Regional projects undertaken by the Southeast have a definite focus on demonstration, feasibility studies, and applied research. The program has few projects that can be classified as purely informational in scope. The state supported projects also reflect an emphasis on demonstration, feasibility, and applied research. The state projects focused on the utilization of wood, agricultural, and animal wastes.

Western. The Western program has focused on the development and funding of regional projects rather than specific state grant allocations. To be sure, the Western program has a goal to demonstrate a project in each of the thirteen states that either converts biomass to energy, wastes to energy, or produces a product that reduces energy consumption.

The initial projects funded during the first two years of the Westem program centered on state resource assessments. Regional projects that resulted from the first Project Opportunity Notice (PON-I) process have focused on increasing the use of biomass wastes (agricultural residues, dairy and feedlot wastes, and MSW). These projects could be categorized as technology development and testing. 


\title{
APPENDIX E
}

\section{INFORMATION DEVELOPMENT AND}

\section{DISSEMINATION ACTIVITIES,}

\author{
BY REGION
}




\section{INFORMATION DEVELOPMENT AND DISSEMINATION ACTIVITIES, BY REGION}

Information development and dissemination activities are discussed in two separate sections below, the first dealing with the development of biomass energy information and the second with the dissemination of biomass energy information.

\section{The Development of Biomass Energy Information}

Great Lakes. As noted earlier, the Great Lakes program dedicates a substantial portion of its budget to the compilation and assessment of biomass information, by relying heavily upon state agencies to disseminate information. Recent information development activities have included: (1) guidelines and case studies of biomass pelleting; (2) a secondary wood manufacturers directory; (3) case studies of air emissions and ash disposal rogulations of wood buming facilities; (4) a casebook describing 14 operating waste-to-energy facilities; and (7) a directory of biomass energy facilities. The Ohio Biomass Boiler Conversion Program is a State-level program that illustrates the strength of the State agency efforts supported by the Great Lakes program. It is a comprehensive program of information compilation, assessment, dissemination, and market impact.

- Ohio Biomass Boiler Conversion Program. This program recognizes the significant potential market in Ohio for converting existing coal-fired boilers to wood-fired boilers. Many of Ohio's coal-fired boilers were put in place 30 to 40 years ago. With an average age of about 37 years, many of these boilers need to be overhauled or replaced, making them ideal candidates for conversion. The program stresses off-the-shelf equipment. No technology development is required. There are no major market barriers other than the availability of feedstocks at competitive costs.

The program began in 1989 with a survey of all licensed boilers in the State of Ohio. This resulted in the identification of approximately 1000 boilers as candidates for biomass conversion. These candidate boilers were then matched with timber concentrations and transportation infrastructure, utilizing a satellite-based geographic information system. The result was a ranking of candidate boilers based on an estimate of their payback potential for conversion.

With this assessment complete, an aggressive outreach program was launched. The high-potential candidates were invited to attend a one-day seminar. Seminar speakers addressed the types and costs of wood combustion equipment, tax incentives, financial options to purchase equipment, and environmental effects of burning wood. Lists of consulting engineers, equipment manufacturers, and whole tree chippers were also provided. Finally, each boiler conversion candidate was given information on the amount of wood resources 
within a 70-mile radius, and an eatimate of the cost of transporting the wood to their boiles. Follow-up surveying suggests that the program can take some credit for subsequent conversions.

Northeast. The Northeast program has commissioned a series of ascossments that address barriers to the production and utilization of biomas resources in the Northeast. An example of this is described below.

- A Comparative Riak Analysis of Landfill and Resource Recovery Facilities. The purpose of this project was to inform docision makers and the public about the relative risks of two waste disposal options and to suggest how such information can be used in formulating local and regional MSW management strategies. The two options are: (1) a state-of-the-art resource recovery facility, including an ashfill for handling residual materials after burning; and (2) a landfill designed to meet all existing state and federal regulations. Health, safety, and environmental risks were considered. Guidelines for communicating comparative risk also were developed.

Other recent information activities include: (1) the creation of a database of emissions tests of wood products in field boilers; (2) development of recommendations for cconomic and other equity adjustments associated with the citing of resource recovery facilities; (3) a wood ash disposal and recycling sourcebook; and (4) a case stuxdy of New Hampshire's wood-fired electric power plants, which produce almost $10 \%$ of that State's supply of electricity.

Northweat. The following project illustrates the types of technical asseasments undertaken by the Pacific Northwest regional program.

- Biomass Enerry Project Development Guidebook. In 1989, the regional program completed a guidebook to assist individuals and firms considering biomass energy projects. The guidebook contains information on fuel contracting; biomass fuel recovery, collection, and processing; biomass combustion; and agricultural residues. It provides industry-specific information associated with the planning of biomass energy projects, such as the geographical distribution of feedstocks. The guidebook has been in high demand; altogether approximately 1,000 copies have been distributed.

Some information assessment activities are targeted at particular biomass tochnologies. In 1991, for instance, the Washington State Energy Office lead an effort to identify gaps in information dissemination on energy aspects of solid waste management and to assess where the regional program could fill these gaps.

Other recent information activities of the Pacific Northwest program include: (1) development of a handbook for small-scale pellet manufacturers containing a pellet fuel industry assessment; directories of fuel, equipment, and stove manufacturers; and a case study documenting the operation of a small-scale pellet fuel manufacturing business; and (2) a biomass residue assessment, bringing together the best data available on the 
wood biomass resource of the 7-State region that may have potential for supplying current or future energy conversion facilities, as input to energy and other wood products industries and decision-makers.

Southeast. The Southeast program has a well-developed program of information dovelopment. The following two projects are characteristic of the Southeast program-supported technical asseasments:

- Methods for Asseasing the Economic Impacts of Biomass Energy Facilities. the project will produce a handbook and computer progrum describing a method for asseasing the cconomic impects of biomass energy facilities. The audience for this work includes the dovelopers and manages of biomnes enery systems and covernment officials. The availability of a simple and relatively inexpensive method for evaluating the direct and indirect economic impacts of biomas energy projects should permit developers, citizens, and public officials to evaluate the comomic effects of projects in a more objective manner. This should facilitate the process of biomas energy facility permitting.

- Case Studies of Sewace Treatment with Methane Recovery. The objectives of this project are to obtain and accurately document the technical, financial, and operating data of 10-12 sewage treatment plents that recover methane and use the methane to generate electricity to operate the plants. The case studies will portray a variety of methane recovery technologies ueed in typical large and amall opernions in the Southeast. The engineering and equipment used in these cases are to be recorded and displayed for reference by ochers interested in replicating any of the systems. The publication will promote this technolosy by conveying the success and opportamities of these projects to other potential users. The result will be a reduction of climatic impact from carbon dioxide and methane and a reduction in use of nonrenewable fuels such as oil.

Other recent technical ascesment activities of the Southeast program include: (1) an assessment of the cconomic impact of firewood use in the Southeast and (2) a database documenting current biomass energy-using industrial, commercial, and institutional facilities in the Southeast.

Western. The Western program has establiahed two publications that compile and assess information for its audiences.

Biomass Literature Search. Begun in March 1990, this monthly publication provides a summary of citations on various biomass related topics.

Biomass Digest. Published periodically, each issue contains in-depth information on a different biomass technology, addressing the technology or conversion process, environmental concerns, regulatory and legislative issues, and case studies.

The Western program has developed a database that provides information on individuals and organizations with biomass interests. For each entry the following data are provided: name/position/title, 
organization, address, phone, affiliation, biomass interest, and miscellaneous information. In addition, the database indexces literature on biomass feedstocks, technologies, and end products. The database is divided into four categories-agriculture, aquaculture, municipal solid wastes, and wood. The Western program has developed an extensive library of biomass-related documents. The library is available to those interested in researching biomass topics. Among other subjects, the Western program's library includes information on biomass feedatocks, tochnologies, and end products. These databases and the Westem program's library are available to all interested parties.

Periodically, the Weatem program will fund a faculty fellowship in order to strengthen the Western program links with parties which have biomass feedstocks and/or knowledge of conversion technologies. The Western program also sponsors and co-sponsor conferences and workshops. Finally, the Western program periodically conducts tours to demonstrate to verious groups the advantages of building private-sector confidence in the use of biomass energy.

\section{Biomass Energy Information Dissemination}

Great Lakes. The Great Lakes program is located in a region where state agencies have effective information dissemination networks. By utilizing this existing infrastructure, the regional program can reach its various audiences in a cost-effoctive and officient manner. As a result, the Great Lakes program dedicates more of its resources to technology development ectivities and the compilation and assessment of technical information, than 10 information dissemination activities.

The State of Illinois' various ethanol demonstration projects are illustrative of the information discemination activities that the Grea Lakes program is currently emphasizing. Technology demonstrations can be a powerful and often eseential maketing step for new technologies.' They are a method of providing tangible evidence of technical and cconomic acceptability, and are therefore a type of information dissemination activity.

- Ethanol Fiee Demonatration. The numerous sponsors supporting the State of Illinois' ethanol fleet demonstration reflects the region's broad commitment and enthusiasm for this transportation energy option. The E-87 Ethanol Demonstration Project involves a fleet of 12 Chevrolet Luminas, the first vehicles especially built for U.S. testing of ethanol. The cars are designated "E-87" because they use a blend of $87 \%$ denatured 200-proof ethanol and $17 \%$ natural gasoline. The State is operating the fleet of E-87 vehicles to evaluate ethanol as a potential substitute for gesoline. Most of the cars are being used in the state motor pool--being put through their paces in urban and rural settings and in hot and cold weather conditions. The

3 See Brown, Livesay, Lux, and Wilson (1992) for a discussion of the role of demonstrations in the deployment of new technologies. 
cars are being extensively tested for performance, reliability, cost of operation, and emissions. In addition, each driver is asked to evaluate the car's driveability and operation.

Northeast. Information dissemination is a major focus and a notable strength of the Northeast program. One key to its success is the program's reliance on state agencies to reach its audiences. As an example, Northeast program publishes only $200-300$ copies of project final reports. These are shared with state agencies, which in turn reproduce and distribute them and are a point of contact for inquiries. Brochures prepared by Northeast program are also distributed by state agencies, typically with the state agency's return address and logo printed on them. An example of this is provided by the Wood Stove Communication Program.

- Wood Stove Communication Program. This \$143,000 project involved the development of 20-minute Public Service Amouncement for television as well as a series of radio talk shows. "Lessons Leamed" describes for the viewer the extent to which stove emissions are dependent upon the way a person uses a wood stove. The project also produced a brochure entitled "Burn It Clean, Burn It Right," which was distributed to the public by state agencies in the Northeast.

Another key to success has been the execution of targeted and customized dissemination campaigns. For example, the results of a wood waste study were targeted to very specific population areas and audiences, using a database of 20,000 entries maintained by a consultant for Northeast program. To ensure that Northeast program research results are made available to industry, Northeast program contractors are required to prepare an article for the trade press, customizing and summarizing the material in their project reports.

Stakeholder coalition building is another approach used by the Northeast program to ensuring that research results are put to effective use. Since the carly 1980's, the Northeast program has sponsored a program of research on wood stove technology and environmental impacts. The results of this research program have influenced public policy and wood stove design, in large part as the result of effective coalition building, as described below. ${ }^{4}$

- Wood Stove Coalition Building. Between 1987 and 1987, the Northeast program conducted the Cooperative Wood Stove Study. This study was the first to indicate that there were problems in the field with catalytic technology, particularly with regard to equipment degradation. The study also indicated that catalytic add-ons and retrofits were not performing as well in the field as they had in the laboratory. Finally, the study indicated that low emission non-catalytic technology had the potential to perform well in the field.

While these results were emarging, the EPA was involved in setting up a "regulatory/negotiation" process to seek input and comments from a wide range of parties on proposed regulations to limit particulate emissions

Citizens Conservation Corporation. 1992. The Impact of Regional Biomass Program-Sponsored Wood Stove Research on Public Policy and Technology. (Citizens Conservation Corporation, Boston, MA), July. 
within the wood stove industry by setting certification standards for new equipment. At the same time, the Northeast program was instrumental in bringing together a coalition of regional representatives and manufacturers to share research findings. The result was an unprecedented level of participation and dialog between manufacturers, researchers, regulators, and the public. The wood stove research program also involved two RBEP regions: the Northeast and the Pacific Northwest.

The impacts of this participatory process were numerous. It awakened the wood stove industry to the probability that testing had something to offer the design of better stoves. It heightened industry awareness of the clean air problem and interest in manufacturing quality control. Finally, it impacted EPA regulations. The Cooperative Wood Stove Study prompted the EPA to agree to the separate and more lenient emissions standards for non-catalytic equipment. The study also helped convince EPA to incorporate weighted burn rate averages into its testing protocol. Finally, the study influenced EPA to set strong manufacturing quality control requirements and to broaden its in-factory inspection protocol.

Northwest. This region's information dissemination activities have historically relied heavily upon the State Technical Assistance Programs, which are funded by the program. The state bioenergy offices have maintained contact databases and have managed the distribution of reports to interested parties within the states, State programs within the Pacific Northwest and Alaska Bicenergy Program have also published their own bioenergy newsletters. The activity of the state bicenergy offices has been supplemented by a variety of other information outreach activities.

The strategic planning process initiated in 1990 resulted in the establishment of a "Technology Transfer, Information and Education" Working Group. This working group recommended several activities aimed at improving the Pacific Northwest program's outreach, including: (1) an inventory of the information and technical services provided by the program and recommendations for marketing them; (2) establishment of a uniform information structure within the region to improve access to the regional program's documents; (3) development of a systematic approach toward improving contacts with biomass industries, regulatory agencies, and environmental organizations; (4) improvement of working relations and information exchange with the other regional programs and with ORNL and NREL; and (7) development of a modia support plan.

Public education has been an important element of the residential wood use activities of the Pacific Northwest regional program. The following project is illustrative.

- Residential Wood Energy Use Education. This series of educational activities aimed to reduce residential wood smoke emissions. It was initiated in Klamath Falls, Oregon, under the leadership of the Oregon Department of Energy. During this initial phase, the Klamath County Health Department provided wood energy users with lessons on proper seasoning, free moisture content analysis, and public information The program also operated a roadwide advisory 
project, creating signs to instruct local residents of daily burning levels. This public education effort was supplemented by baseline surveys on a neighborhood-by-neighborhood basis to identify and communicate with the "worst offenders"--those neighborhoods with a high concentration of sole source wood stove households.

In 1991, the project was expanded to cover additional cities, focusing again on their "worst offending" neighborhoods. Due to budget limitations, the project was not continued in the 1992 program.

Southeast. The Southeast program has a well-developed program of information dissemination. In addition to relying on state biomass coordinators to reach its various audiences, the program has its own newsletter (with a circulation of 2,000 concentrated in the Southeast, but also extending nationwide) and a database of contacts that is used for the targeted distribution of reports and other Southeast program products. One useful requiremeni of each project manager, is a public presentation of project results, which typically takes place at a conference or industry trade show. In addition, Southeast program staff are often "on the road," trying to develop stakeholder coalitions and to link biomass resource suppliers with potential users. Similarly, the prograr i pays for educators and state agency staff to travel to make key bioenergy contacts.

Perhaps more than any of the RBEP regional programs, the Southeastern program has invested a considerable amount of program resources into the development of educational curriculum materials. The program's activities span the range from secondary schools to universities. For instance, targeting elementary and middle school teachers, a generic biomass mini-workshop was developed to introduce the concepts of biomass resources, conservation, and recycling. At the university level, materials were developed to acquaint mochanical engineers with direct combustion of biomass and its potential to compete with fossilized hydrocarbons fuels. The pilot oducation module includes videotaped lectures, notes, and laboratory exercises, geared to senior level undergraduate engineering courses and focusing on direct conversion of biomass residue into thermal energy.

Western. The Western program has established a series of publications to support its information outreach goals.

Biomass News. Published on an as-needed basis, this publication summarizes various Westem program activities and announcements.

Biomass Bulletin. Published on a semi-annual basis, this bulletin updates readers on news from states in the Westem program's area, the other reg nal programs, and information on Western program activities and projects. Attendance and participation at conferences and meetings serve to inform and share information about biomass resources and technologies and to make the biomass community aware of the Western program. In 
addition, the Westem program periodically hosts and sponsors presentations on biomass energy projects. Recent presentations include: anaerobic digestion of manure, benefits of utilizing agricultural residues for biomass energy production, ethanol and methanol production, and municipal solid waste-to-energy.

Periodically, the Westem program funds a faculty fellowship in order to strengthen the Western program links with parties which have biomass feedstocks and/or knowledge of conversion technologies. The Western program also sponsors and co-sponsors conferences and workshops. Finally, the Western program periodically conducts tours to build private-sector confidence in the use of biomass energ 


\section{APPENDIX F}

COST SHARING, BY PROJECT TYPE,

FEEDSTOCK, AND CONTRACTOR 


\section{COST SHARING, BY PROJECT TYPE, FEEDSTOCK, AND CONTRACTOR}

\section{Cost Sharing by Project Type and Stage of Development}

The Southeast region has achieved a 10.7 leveraging ratio on projects associated with prototype testing and field studies. The lion's share of this leveraging was provided by a single project associated with the installation of municipal waste to energy equipment. With this project excluded, average leveraging for prototype testing and field studies is still respectable, but becomes a more mundane 1.2.

Other types of projects have brought in smaller proportions of funding from other sources. Studies associated with emissions and environmental impacts have brought in significant proportions of resources from outside sources in the Northeast, which has established some of its environmentally related projects as major programmatic thrusts and has then actively pursued multi-party leveraging on these projects. While the Pacific Northwest was very active in the pursuit of data on environmental issues in the mid-1980's, it has scaled back its activity in the time frame of 1987-1991. Regional and state projects addressing environmental issues had leveraging ratios of 0.7 and 0.5 , respectively.

Relatively few projects associated with technology assessment, fuel standards, or the development of testing methods were conducted by the regional programs. The two projects conducted in the Pacific Northwest brought in about \$1.2 for every RBEP dollar invested. The two Pacific Northwest projects in this category consisted of studies of the combustion characteristics of biomass fuels and MSW. In the Northeast there was a single project in this category; because the region perceived this project as a major programmatic thrust and widely sought outside funding, \$11 of outside funds were brought in for every RBEP dollar spent.

There is little data available concerning cost sharing for resource assessment activities. Resource assessment activity was well underway in most of the nation before the time frame of 1987-1991; in recent years, much of the assessment activity has been conducted by the states without direct investment of RBEP funds. The Westem region, which initiated a series of state-by-state resource assessments in 1989, has averaged about \$1.20 in matching funds from its member states. Several States in the Southeast have also updated their state-wide assessments during this period, and they too have contributed about $\$ 1.20$ in cost sharing.

Analyses of economic, market, or infrastructure issues made up a significant proportion of the Southeast program's project portfolio during this period. These were projects on which the Southeast program did not seek cost sharing. Southeastern states also conducted a small amount of analyses of this type, and met their cost sharing criteria with $\$ 1.20$ in matching funds.

Information dissemination activities at the State level in which RBEP funds were invested were matched with \$1.90/dollar in the Pacific Northwest and \$1.80 in the Southeast. Regional activities of this type brought 
in \$0.50/dollar in the Northwest and $\$ 0.20$ in the Southeast. These projects in general were projects that could not be expected to attract large amounts of cost sharing. In the Southeast, for instance, the development of education curricula for engineering students and the development of a design manual for small turbines are projects that are targeted toward general program goals but for which a deep-pocketed constituency is unlikely to be found.

Table F.1 Cost Sharing by Project Type and Stage of Development

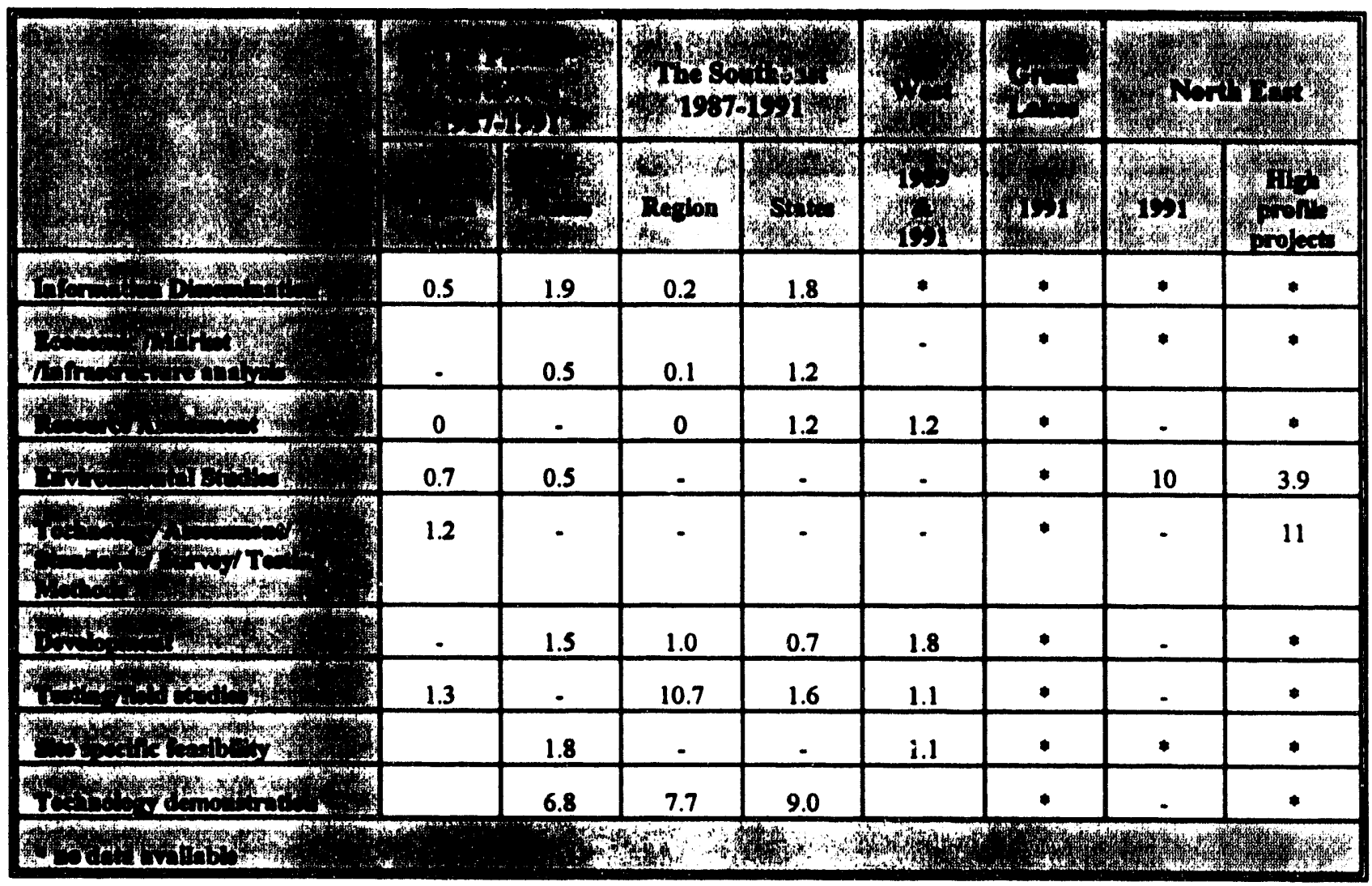

\section{Cost Sharing and Feedstock Type}

Projects associated with animal waste during this period were conducted primarily in the Southeast and West. The Southeast program has taken a leadership position in the development and dissemination of anaerobic lagoon systems for processing wastes from feedlots. In these projects, both regional and state-based projects have brought in about two dollars in cost sharing for every dollar contributed by the Southeast program. In the Western region, the two projects from PON-I that employed animal waste as a feedstock were associated with \$1.20/RBEP dollar invested. Although not included in this sample frame, a state-based project in Oregon has recently pulled in some very significant outside funding for a methane digester in the Tillamook valley. 
Agricultural residues were addressed by over half of the projects funded in the Western region's PON-I. While all of these projects provided at least a 1:1 cost share, two projects -- development of a gasifier/turbine system and development of a cotton stalk harvesting system -- contributed significantly greater proportions.

Table F.2 Cost Sharing - by Feedstock

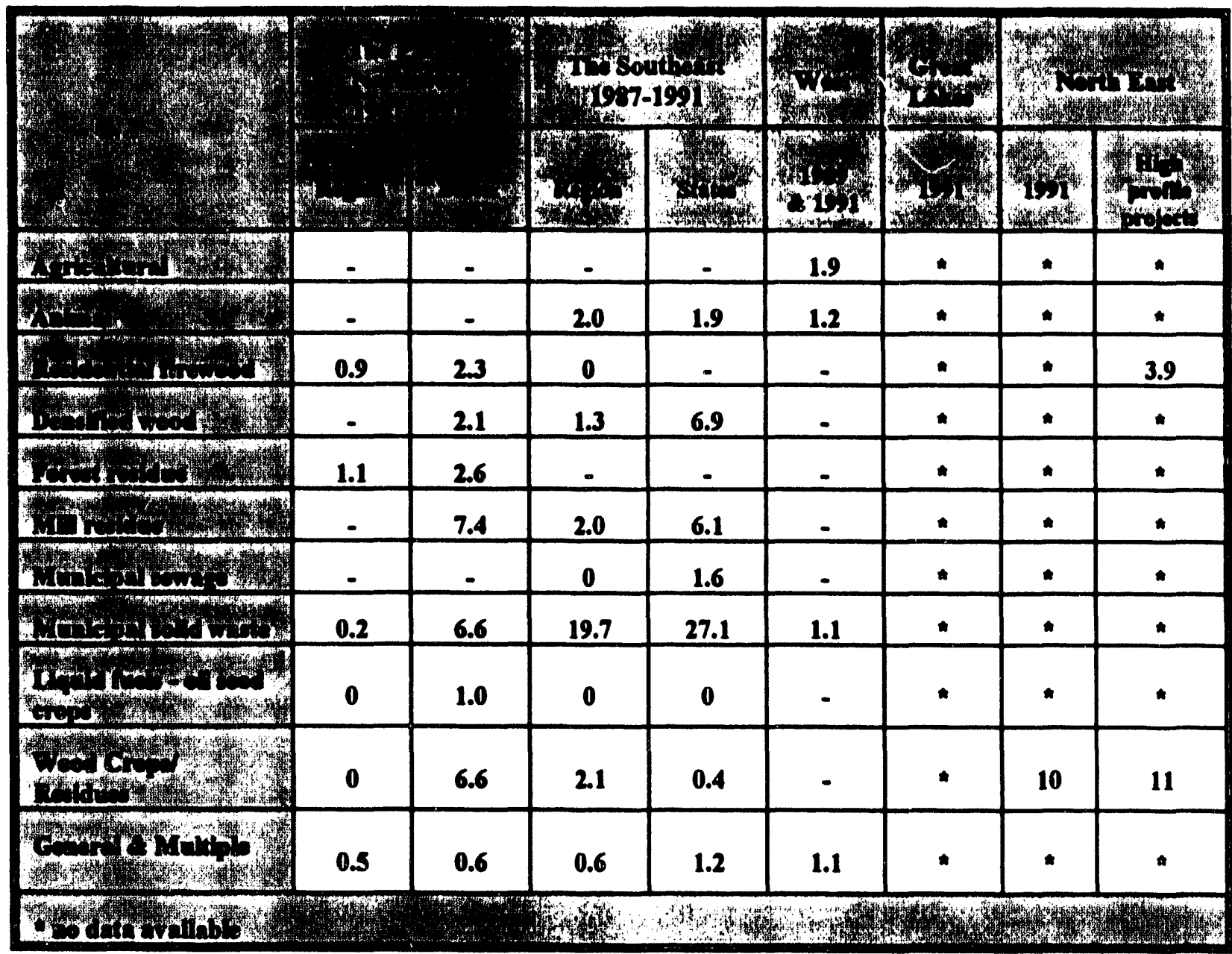




\section{Cost Sharing and Type of Contractor}

Table F.3 Cost Sharing - by Contractor Type

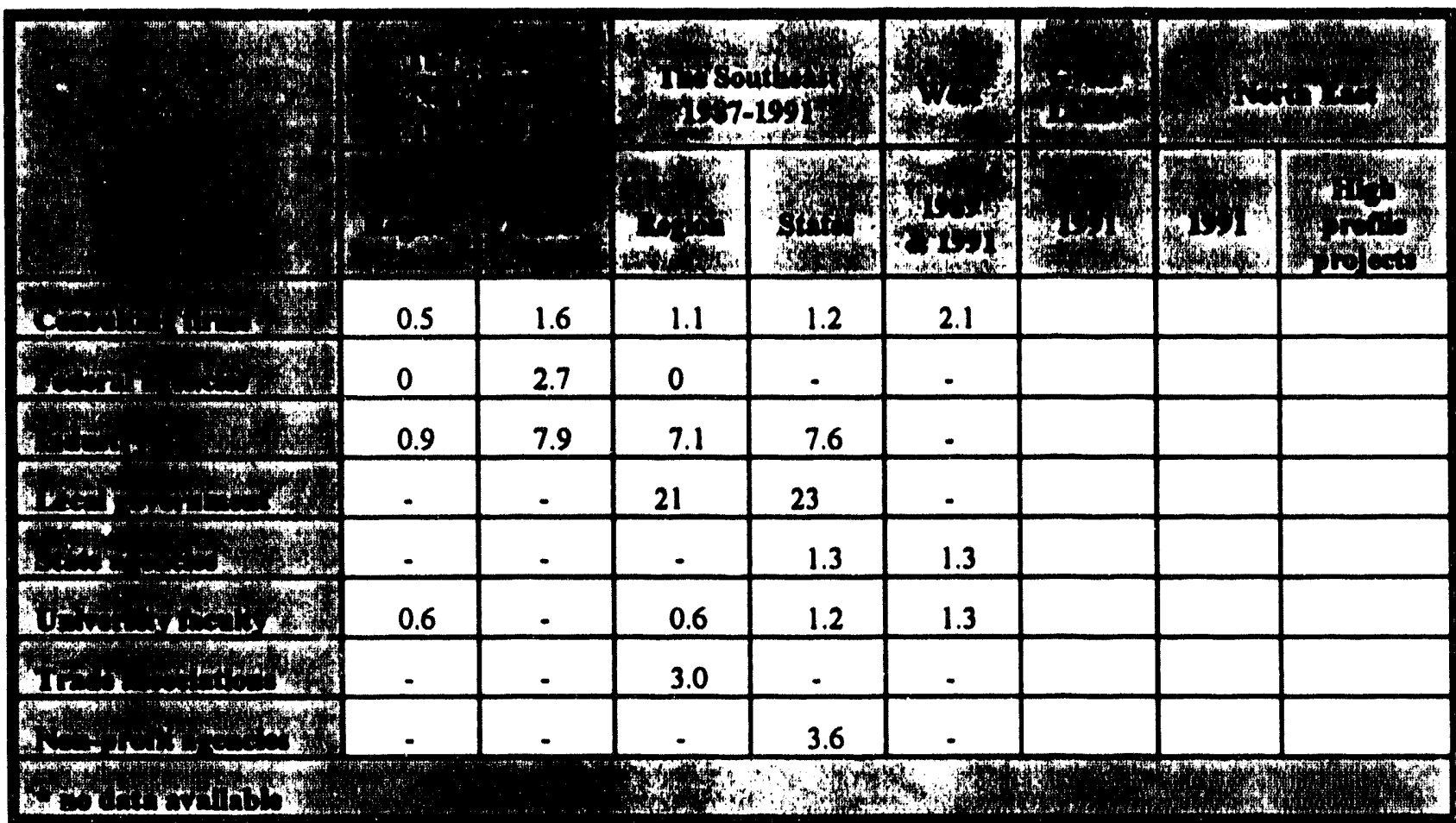


APPENDIX G

\section{COMMERCIALIZATION POSSIBILITIES}

AND OUTCOMES 


\section{COMMERCIALIZATION POSSIBILITIES AND OUTCOMES}

This appendix highlights RBEP activities that have led to general commercialization outcomes or are likely to have a commercialization outcome in the near future.

\section{Residential Wood and Pellet Stove Development}

Wood stove technology is where the RBEPs have had the most direct impact on commercialization. RBEPs have been instrumental in emissions characterizations and alternative wood stove testing. The RBEPs have warked in cooperation with state agencies, the EPA, and the private sector. The changes in the way industry tests stoves and the type of stoves that are found in the marketplace are in-part the result of RBEP activities.

The RBEPs have also been on the forefront of promoting the use of pellet stoves. Pellet stoves offer a number of advantages over conventional "cond" woodstoves. Pellet stoves are cleaner burning and more efficient. The pellets are denser and therefore are easier to store and transport. Moreover, the use of pellets would open-up new biomass resources (c.8., mill residues, saw dust, agricultural residues) that have not previously been used in the residential sector.

Northeast. The Northeast progrnm has had some notable successes in resideritial wood stoves. Concerns about wood stove efficiency, emissions, health and safety (carbon monoxide, creosote accumulation) prompted a series of activities. From their project on the performance monitoring of advanced wood stoves it was found that catalytic and advanced technology stoves per formed no better than conventional air-tight stoves. The Northeast program projects resulted in changes in the way stoves are certified so that laboratory tests more closely approximate in-house use. Northeast program projects also identified areas in stove construction (gaskets, baffles, sloppy assembly, etc.) that could result in increased emissions. Improved stove designs incorporating better and stronger materials with higher manufacturing quality and fewer emissions have resulted.

Northwest. The Northwest program has had commercialization outcomes similar to those of the Northeast. The Northwest's multiyear activities have led to the quantification of emissions, the development of more appropriate stove testing procedures, and in changes in manufacturing procedures including the marketing of more reliable and lower emitting stoves. As in Northeast region, new and improved stoves are now on the market.

The Northwest program has also initiated a number of projects involving pellet stoves. For example, the performance of pellet stoves were monitored in Medford, Oregon. Results indicate that emissions from pellet stoves were much lower than those from conventional woodstoves. Moreover, the stoves ran at fairly high thermal efficiencies. Although this project did not have any direct commercialization outcome, the project demonstrated that these stoves performed to near "lab" certified values. Projects of this type can directly impact 
sales by demonstrating that the stoves perform as indicated and are durable under actual use conditions. For example, the pellet stove teats are being used as marketing tools by stove manufacturers.

Southeast. The Southeast program has funded a few pellet stove and pellet fuel projects. There are no specific commercialization outcomes to date, but the prospects for significant market impects remain. One project involves the we of com as a pellat fivel. As originally envisioned, famers would grow their own com (1-1.7 acres for 2 tons of fuel) for conversion into pellets. This project has the potential for widespread adoption as their is excess cropland and these fuels could be an inexpensive source of home heat. In addition, the Southeast program is funding other pellet fuel projects that are using a combination of feedstocks (wood wastes, MSW, coal fines) and a extruded log project that uses wood wastes as a feedstock. For all of these projects, it is premature to discuss commercialization outcomes. However, there exists considerable potential for greater use of these fuels.

Weatern. The Westem program has fundod a project to use surplus agricultural residues to produce a densified fiel log for sale to residential wood fuel markets. The project would use existing technology. If successful the project would lead to the commencialization of a now biomass product and have considerable local benefits where the fuel $\log$ is produced. The project is currently in progress. Commercialization success is dependent on a varicty of factors, including product cost relative to locally gathered firewood, and development of a supporting infrastricture.

\section{MSW Disposal and Alternatives}

Although each of the RBEPs is addreasing the problem MSW disposal, it is difficult to point to particular tochnology commercialization outcomes. MSW disposal is an extremely contentious issue fraught with a myriad regulatory and siting issues (NIMBY concerns). Increasing difficulties in finding adequate landfill space and in siting incinerator facilities has not made it easier for the RBEPs to promote alternatives. Nonetheless, the RBEPs have been key players in confronting some of these issues and barriers. Projects involving waste separation and characterization, derivation of fuels from waste streams, characterization of emissions and ash from MSW combustion boilers, and application of cogeneration technology could lead to greater utilization of MSW resources and in determining alternatives to landfills.

\section{Industrial and Municipal Biomass Energy Conversions}

A priority for many of the RBEPs has been biomass energy conversions. This technology area includes the conversion of existing industrial, municipal, and utility boilers to biomass energy. These projects have been 
varied with respect to fuels used and end-use application. The potential commercialization outcomes for this technolosy are discussed below.

Great Lakes. In the Great Lakes region, one of the most comprehensive biomass energy conversion programs is being undertaken by the State of Ohio with financial support from the Great Lakes program. In 1989, over 70,000 survey forms were mailed to boiler and operators. About 8000 of the surveys were returned and the responses entered into a database. This data was then matched with information on wood resources and costs. To date the program has identified over 1200 boilers that are likely candidates for conversion to wood. The prospects that some of these will be converted are promising as many of the boilers are near the end of their useful life (40 years) and stricter air quality standards may limit the continued use of coal.

Northeast. Northeast program activities in this area have focused primarily on information dissemination. However, the Northeast program has providod tochnical assistance to many commencial eatablishments and intitutions. This assistence had led to the conversion of several facilities to biomass energy. For example, $t / r e$ public schools in Vermont were converted to wood-fired heating systems. In addition to space !stating applications, there are now over 60 wood-fired power plants in the region that are either already existing or planned and proposed.

Southeast. The Southeast progrem finded Energy Peformance Systems to determine the technical and economic feasibility of converting a 60 MW coal-fired unit at TVA's Watts Bar Power Station to bum whole tree wood. The results indicate that power could be produced inexpensively and be competitive with alternative baseload generation. Moreover, the project would offer numerous environmental and regional economic benefits to the area as well. Although decisions to $g 0$ ahead with this project have been placed on hold, this project has the potential to demonstrate a new generation of steam-turbine technology.

The Southeast region has also had considerable success with industrial wood energy conversions. The most recent data sugest that there are well over 1000 commercial and industrial facilities that use wood energy (wood waste and wastes from pulp and paper industry) in the region. The direct and indirect economic impacts are extimate $\mathrm{d}$ at over $\$ 1$ billion in income and over 71,000 jobs. One example project that is producing spinoffs is the cogeneration facility installed at Sutton Lumber in Tennessec.

Westem. The Westem program has a number of projects underway that could lead to some commercialization outcomes involving the use of biomass wastes for industrial, commercial, and municipal applications. While these projects are not expected to reach the market within the next 2 to 7 years, they may provide valuable information. Among the projects that have high potential are: Development of an Integrated Gasifier/Gas 
Turbine Biomass Power Plent; Commencialization of a Small-System Biomass Gasifier; and Biomass Firing for Cotton Drying at an Oklahoma Cotton Gin Plant. All of these projects have potential for replication throughout the Westem region.

\section{Blomass Derived Liquid Fuels}

A 1 psi RVP waiver from the Clean Air Act's requirements for gasoline was recently granted for gasolines blended with ethanol. This waiver has the potential to double U.S. sales of ethanol. In addition to the RVP waiver, efforts are underway to change the current ethanol tax exemption. Under current law ethanol blenders are allowed a 7.4 cent per gallon exemption from the gasoline excise tax on blends containing at least 10\% cthenol. The $10 \%$ blend makes for a fivel containing $3.7 \%$ oxygen. The proposed changes to the law would allow the equivalent excise tax exemption at less than $10 \%$ blends, namely $7.7 \%$ and $7.7 \%$ percent ethanol. These changes would conform to oxygen requirements of $2.7 \%$ and $2.0 \%$, as mandated by Clean Air Act for nonattainment areas. The net effect of these changes would make gasoline-ethanol blends more competitive with reformulated gasolines. The Great Lakes program has had the lead in ethanol technology. Other programs have focused more on the development of liquids from non-corn foedstocks for niche markets.

Great Lakes. The Great Lakes program has pleced a greater emphasis on ethanol production in recent years. A project with potential commercialization success involves the development of a membrane technology that could serve to increase process conversion efficiency and lower overall ethanol production costs. The Great Lakes program has also sponsored an ethanol fleet demonstration and the development ethanol-fueled heavy engines. Both of these projects could lead to greater use of ethanol fuel in the future.

Northweat. The Pacific Northwest program has had a number of activities in biomass derived liquid fuels. These projects have included the conversion of MSW to ethanol and the use of vegetable oils as diesel fuel substitutes. There have been no commercialization outcomes from these projects. These projects have demonatrated technical feasibility, but these fuels, at present, are not competitive with conventional fossil-based liquids.

Weatern. The Western program has funded a number of projects to derive liquid fuels from biomass, primarily agricultural wastes. As with all Weatern program projects, these activities are in the process of completion and there are no direct commercialization outcomes at this stage. However, the potential for commercialization success exists in the five year time frame. Among the projects that could lead to greater use of biomass derived liquid fuels are the Conversion of Rice Hulls to Dieacl Fuel and the Bioconversion of Cellulosic MSW to Ethanol. 


\section{Anaerobic Digestion Technolocy Development}

Anacrobic digestion technology development has not been a key programmatic area for all RBEPs. The Southeast has had activities in this area and the most commercialization outcomes. The Great Lakes and Northeast do not have a significant program in digestion technology.

Southeast. The Southeast program has numerous anaerobic digestion technology projects. An estimated 34 trillion Btu's of harvestable energy in the form of biogas (methane and carbon dioxide) is annually lost to the atmoephere from anserobic lagoons used to treat liveatock wastes in the Southeast Region of the US. Livestock production facilities could use a large portion of this energy to become nearly energy self- sufficient which would have a major positive coconomic impact to the Southeast Region. It has been demonstrated that it is quite feasible to harvest and utilize the biogas produced from lagoons. The development of anaerobic digestion systems has been a multiyear activity for the Southeast program. There are currently operating digestion systems in at least six states (Arkansas, Florida, Louisiana, North Carolina, south Carolina, and Virginia) in the southeast region. The results of these demonstrations have resulted in the installation of digestion systems outside of the region (California and Texas). The Southeast program is attempting to develop information that can assist others wanting to know more about anaerobic digestion systems. Commercialization efforts to date are minor relative to the potential resource contribution. 


\section{DNTMRNAL DISTRIBUTION}

1 T.D. Anderson, 4500N, MS 6189

2 D.C. Bauer, 4500 N, MS 6206

3 L.G. Berry, 4500N, MS 6206

4 M.A. Brown, 4500N, MS 6206

5 R.S. Carlsmith, 4500 N, MS 6188

8 J.W. Cooke, 4500 N, MS 6269

9 J.B. Cannon, 4500 N, MS 6189

10 T.R. Curlec, 4500N, MS 6205

11 J.H. Cushman, 1503, MS 6352

12 M.E. Downing, 1503, MS 6205

13 W. Fulkerson, 4500N, MS 6247

14 S.W. Hadley, 4500N, MS 6206

15 L.J. Hill, 4500N, MS 6205

16 E.A. Hirst, 4500N, MS 6206

17 P.J. Hughes, 3147, MS 6070

18 M.A. Kuliasha, 4500N, MS 6189
19 R.D. Perlack, 4500 N, MS 6205

20 D.E. Reichle, 4500 N, MS 6253

21 A.C. Schafthauser, 4500 N, MS 6186

22 R.B. Shelton, 4500N, MS 6187

23 M.E. Walsh, 4500N, MS 6205

24 D.L. White, 4500N, MS 6206

25 T.J. Wilbanks, $4500 \mathrm{~N}$, MS 6184

26 C.R. Wilson, 4500N, MS 6206

27 L.L. Wright, 1503, MS 6352

28 ORNL Patent Office

29 Central Research Library

30 Document Reference Section

31 Laboratory Records (3)

32 Laboratory Records - RC

32-332 4500N, Room HII-D

\section{EXTERNAL DISTRIBUTION}

333 D.R. Bohi, Director, Energy and Natural Resources Division, Resources for the Future, 1616 P Street, N.W., Washington, DC 20036

334 T.E. Drabek, Professor, Department of Sociology, University of Denver, Denver, Colorado 80208-0209

335 P. Badger, Program Manager, Southeastem Regional Biomass Energy Program, Tennessee Valley Authority, Chemical Engineering Building IC, Reservation Rd, Muscle Shoals, AL 35661

336 C. Chase, Biomass Energy Systems \& Energy Resource Management, 4532 133rd Avenue S.E., Bellevue, WA 98006 
337 P. Fox, Program Manager,Pacific Northwest and Alaska Bioenergy Program, Bonneville Power Adminstration, 905 NE 11th,Portland, OR 97232

338 R. Handley, Program Manager, Northeast Regional Biomass Energy Program, Coalition of Northeastern Governors, 400 North Capitol St., N.W., Suite 382, Washington, D.C. 20001

339 F. Kuzel, Program Manager, Great Lakes Regional Biomass Energy Program, Council of Great Lakes Governors, 35 East Wacker Drive, Suite 1850, Chicago, IL 60601

340 H. Lane, Director, Office of National Programs, U.S. Dept of Energy, 1000 Independence Ave., S.W., Washington, DC 20585

341 C.D. MacCracken, President, Calmac Manufacturing Corporation, 101 West Sheffield Ave., P.O. Box 710, Englewood, NJ 07631

342 S. Morgan, Citizen's Conservation Corporation, 530 Atlantic Avenue, Boston, MA, 02210

343 Office of Assistart Manager for Energy Research and Development, DOE Oak Ridge Field Office, P.O. Box 2008, Oak Ridge, TN 37831-6269

344-345 OSTI, U.S. Department of Energy, P.O. Box 62, Oak Ridge, TN 37831

346 J.B. Shrago, Director, Office of Technology Transfer, Vanderbilt University, 405 Kirkland Hall, Nashville, TN 37240

347 G.F. Sowers, P.E., Senior Vice President, Law Companies Group, Inc., 114 Townpark Drive, Suite 250, Kennesaw, Georgia 30144-5599

348 D. Swanson, Program Manager, Westem Regional Biomass Energy Program, Western Area Power Administration - A7100, 1627 Cole Blvd, P.O. Box 3402, Golden, Colorado 804013398

349 D. Stevenson, Assistant Program Manager, Southeastern Regional Biomass Energy Program, Tennessee Valley Authority, Chemical Engineering Building 1C, Reservation Rd, Muscle Shoals, AL. 35661

350 M. Voorhies, Manager, Regional Biomass Energy Program, Office of National Programs, U.S. Dept of Energy, 1000 Independence Ave., S.W., Washington, DC 20585 

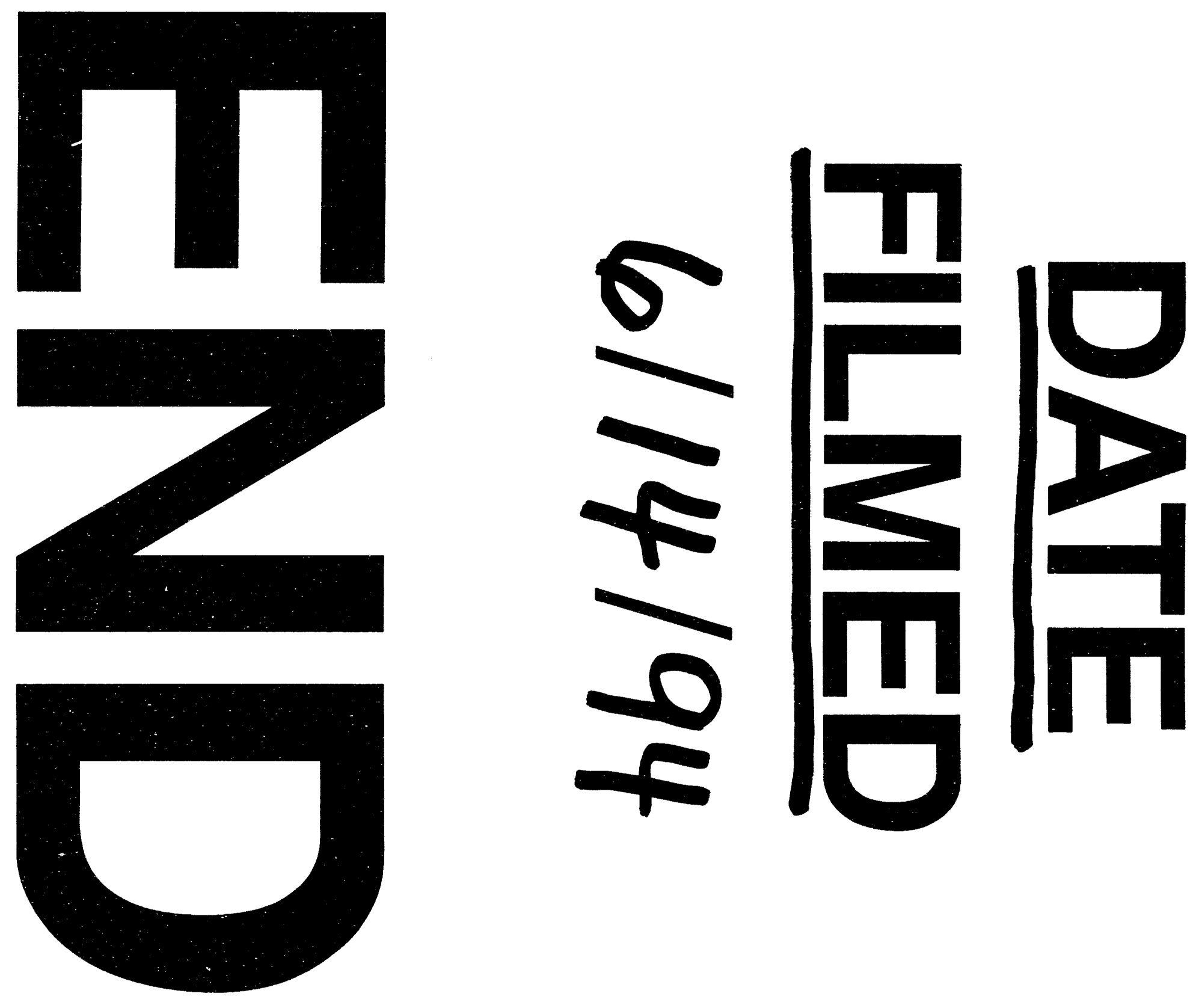
